University of San Diego

Digital USD

2012-05-01

\title{
Inpatient Glycemic Management: Glucose Control Relationship with Hospital Variables, Discharge Planning and Education
}

Crisamar Javellana-Anunciado PhD, FNP-BC, RN

University of San Diego

Follow this and additional works at: https://digital.sandiego.edu/dissertations

Part of the Nursing Commons

\section{Digital USD Citation}

Javellana-Anunciado, Crisamar PhD, FNP-BC, RN, "Inpatient Glycemic Management: Glucose Control Relationship with Hospital Variables, Discharge Planning and Education" (2012). Dissertations. 421.

https://digital.sandiego.edu/dissertations/421

This Dissertation: Open Access is brought to you for free and open access by the Theses and Dissertations at Digital USD. It has been accepted for inclusion in Dissertations by an authorized administrator of Digital USD. For more information, please contact digital@sandiego.edu. 


\section{UNIVERSITY OF SAN DIEGO}

Hahn School of Nursing and Health Science

Inpatient Glycemic Management: Glucose Control Relationship with Hospital Variables,

Discharge Planning and Education

\section{By}

Crisamar Javellana-Anunciado, PhD, RN, FNP-BC

A dissertation presented to the

FACULTY OF THE HAHN SCHOOL OF NURSING AND HEALTH SCIENCE

UNIVERSITY OF SAN DIEGO

In partial fulfillment of the requirements for the degree

DOCTOR OF PHILOSOPHY IN NURSING

May 2012

Dissertation Committee

Cynthia D. Connelly, PhD, RN, FAAN, Chairperson

Kathy S. James, DNSc, APRN

Pablo Velez, PhD, RN 


\begin{abstract}
This dissertation study examined the relationship of glucose control with clinical outcomes, costs, discharge planning and education. Extant studies showed that hyperglycemia, in the presence or absence of a diabetes diagnosis, is prevalent in hospitalized patients. Hyperglycemia is found in one-third of all hospital admissions and is linked to poor clinical outcomes and increased healthcare costs. Furthermore, clinical evidence suggests that lack of discharge coordination associated with medical errors and readmission. This entire body of work contains three distinct sections: Two manuscripts and a grant proposal. The two manuscripts in this study were based on more current retrospective data at the time of the study. The first manuscript "Inpatient glycemic management: relationship among glucose control, clinical outcomes and costs" discussed the results on glucose control, clinical outcomes and costs by provider groups. The second manuscript "Inpatient glycemic management: team approach in diabetes education and discharge planning" discussed the outcomes of improved discharge planning and coordination with the intervention of the glycemic management team. The grant proposal "Inpatient glycemic management: clinical and economic impact of changing from sliding scale insulin to basal-bolus" was awarded $\$ 105,000$ funding by a private pharmaceutical company. The study associated with the grant funding was a completely separate study done in collaboration with the grantor.
\end{abstract}




\section{Dedication}

This work is dedicated to my patients and many of my family members who battle with diabetes management everyday. Their daily struggles, including momentary lapses or dedicated resolve in diabetes care, minor or catastrophic health failures, and every small or transformational accomplishments inspire and motivate me in my work to strive for the best diabetes care possible for each and every one of them. Diabetes is a disease of the most human and humbling kind. Its complications are devastating to the people and their loved ones affected by the disease. Despite its grim outcomes, hope exists when individuals decide to take steps in healthy lifestyle changes and when we as healthcare providers deliver the right guidance and care. With continued collaboration of patients and healthcare providers, we can overcome the negative effects of this disease and improve our patients' chances in living longer, healthier, and more fulfilled lives. 


\section{Acknowledgements}

I would like to acknowledge Dr. Cynthia Connelly for her invaluable support through this dissertation process; Dr. Pablo Velez for his guidance and dedication in seeing this project through; Dr. Georges M. Argoud for his clinical insights throughout the research process and for being my endocrinology mentor; Dr. Patricia Roth, Dr. Mary Jo Clark, Dr. Jane Georges, Dr. Kathy James and Dr. Karen Wikoff who have been my inspiration and mentors for many years; Dr. Dale Glaser, this study's statistician, who spent countless hours on this project; my family, whose support and love has been unconditional; and my husband, Doug, who has been by my side through it all.

Special thanks to the Sharp Healthcare team who have been instrumental in this project: Jacqui Thompson, Brett Maclaren, Josh Fluty, Josie Nonog, Melinda Nylund, Marc Reyes, Sue Ressmeyer, Kara Yu and the Medical Records team, Angela Norton, and David Gehlken. 


\section{Table of Contents}

$\begin{array}{lll}\text { Chapter 1: PROBLEM } & \text { Page }\end{array}$

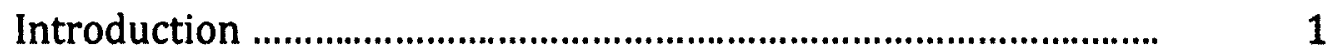

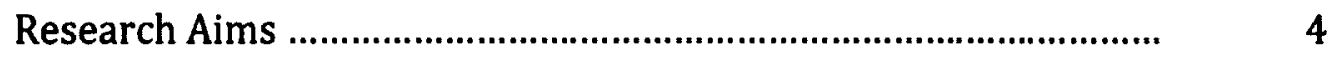

Conceptual Framework............................................................ $\quad 5$

\section{Chapter 2: REVIEW OF LITERATURE}

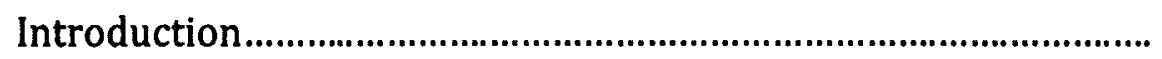

Critical Care Setting.

Surgical Care Setting...

General Hospital Ward Setting

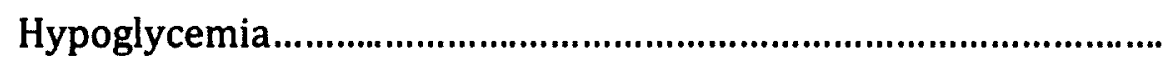

Glycohemoglobin A1C

Discharge Plan

Role of the Advanced Practice Nurse

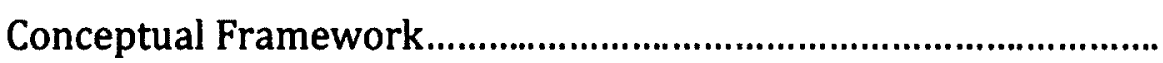




\section{Chapter 3: METHODOLOGY}

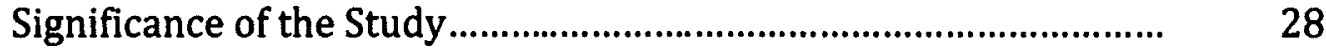

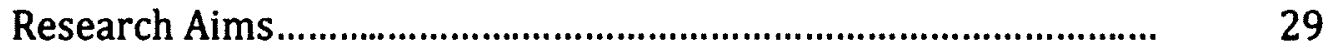

Research Design ...................................................................... 30

Sample and Sampling................................................................... $\quad 30$

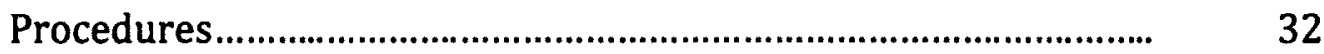

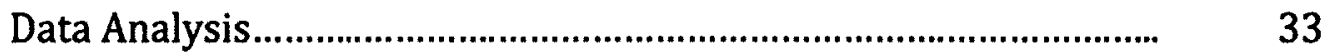

Protection of Human Rights Subjects................................................

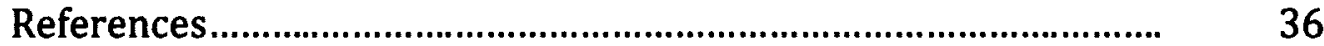

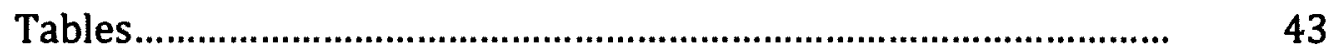

\section{Chapter 4: MANUSCRIPTS}

Manuscript 1:

Inpatient glycemic management: relationship among glucose control, clinical outcomes and costs.

Manuscript 1: Abstract...............................................................

Manuscript 1: Background............................................................

Manuscript 1: Research Design and Methods.................................. 57 
Manuscript 1: Measures................................................................ 58

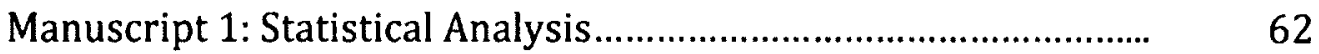

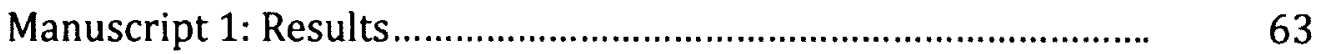

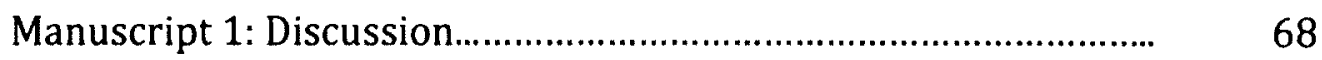

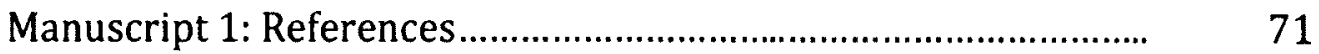

Manuscript 2:

Inpatient glycemic management: team approach in improved diabetes education and discharge planning

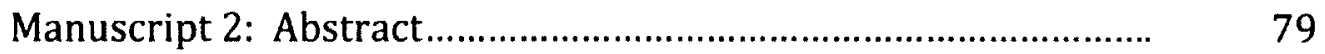

Manuscript 2: Background ........................................................... 81

Manuscript 2: Research Design and Methods.................................. $\quad 84$

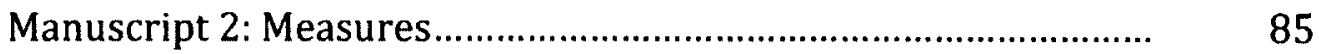

Manuscript 2: Statistical Analysis ................................................... 86

Manuscript 2: Results..................................................................

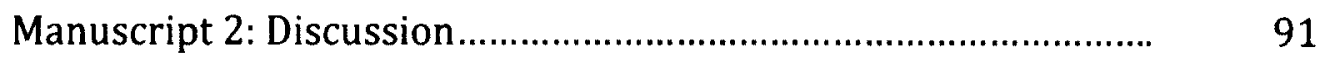

Manuscript 2: References........................................................... 
Manuscript 3: Grant Proposal

Inpatient glycemic management: clinical and economic impact of changing from sliding scale insulin to basal-bolus

Manuscript 3: Introduction

Manuscript 3: Research Aims.

Manuscript 3: Research Questions.

102

Manuscript 3: Research Design and Methods

103

Manuscript 3: Limitations

106

Manuscript 3: Risks to Patients.

109

Manuscript 3: Deliverables

Manuscript 3: Capability and Competency Description

Manuscript 3: Proposed Budget.

Manuscript 3: Payment Schedule

Manuscript 3: References.

Manuscript 3: Email Notification of Award.

Manuscript 3: Appendices. 


\title{
CHAPTER 1: PROBLEM
}

\author{
Introduction
}

Diabetes is not just a U.S. national health crisis but also a worldwide epidemic. In 2010, there were 285 million people worldwide affected by diabetes. The North American Continent (NAC) has 37 million people with diabetes. This is roughly $10 \%$ of the population of NAC with a death toll of $16 \%$. Diabetes is the leading cause of neuropathy, nephropathy, retinopathy, and coronary artery diseases (IDF, 2009, 2010). Diabetes puts a heavy toll on the American people. In the U.S. alone, there are 25.8 million people with diabetes. This is $8.3 \%$ of the total U.S. population and the $6^{\text {th }}$ leading cause of death $(C D C, 2011)$. The overall annual cost for care is a staggering $\$ 174$ billion. Hospital costs of care accounts for $\$ 87$ billion or half of the annual cost. Hospital admissions for people with diabetes is prevalent, accounting for 7.7 million hospital admissions or one out of every five hospital admissions. Patients with diabetes also trigger more emergency department visits, have longer lengths of stay, and higher cost of care than patients without diabetes (ADA, 2008).

Poor glycemic control in the hospital setting can lead to deleterious clinical outcomes and increased economic costs. That is why glycemic control is widely recognized as an integral part of inpatient care. Glycemic management of hospitalized patients, however, is complex and requires considerable hospital resources. Wide glucose variability, persistent hyperglycemia, recurrent, and severe hypoglycemia are implicated in poor outcomes (Krinsley, 2003, 2008; Krinsley \& Grover, 2007). Evidence suggests that hyperglycemia during acute illness is a marker of poor clinical outcomes that lead to increased morbidity, mortality, and length of stay (Krinsley, 2004; Umpierrez et al., 2002). 
When blood glucose (BG) is intensively controlled to near normal BG levels of approximately less than $140 \mathrm{mg} / \mathrm{dl}$, it reduces the risks of multi-organ failure, sepsis, morbidity, mortality, and length of stay (Krinsley \& Grissler, 2005; Van den Berghe et al., 2001).

Patients with diabetes occupy approximately $12 \%$ to $25 \%$ of all hospital beds (Cook, et al., 2009; Moghissi, 2004). This rate will continue to rise as the incidence of diabetes increases nationwide. Hospital organizations and healthcare agencies recognize that optimum glycemic control not only improves patient outcomes, it also reduces hospital costs. In an effort to improve outcomes, hospital institutions nationwide implemented programs to improve inpatient glycemic control. Glycemic targets for critical care units are mean BG levels of $140-180 \mathrm{mg} / \mathrm{dl}$ and less than $140 \mathrm{mg} / \mathrm{dl}$ for acute care. The American Diabetes Association (ADA) and the American College of Clinical Endocrinologists (AACE) recommended these targets with a caveat - achieve euglycemia, control hyperglycemia but limit the possible deleterious consequences of severe hypoglycemia (ADA, 2010; Moghissi, et al., 2009).

Inpatient glycemic management is complicated because there are many factors that affect blood glucose control (Smith et al., 2005). Hospital organizations nationwide were quick to adopt various forms of insulin protocols with mixed successes and failures. The increased use of insulin in the hospital setting brought new challenges for clinicians and healthcare providers regarding patient safety issues. Insulin is the number one drug implicated in medication errors causing harm, according to the MEDMARX ${ }^{\circledR}$ data report (a national reporting program for medication errors and adverse drug reactions submitted by 
participating hospital facilities) published by the United States Pharmacopoeia (Hicks, Becker, \& Cousins, 2008). The AACE and ADA recognized that hospital systems might require administrative support and inpatient glycemic expert providers to successfully monitor patient safety and manage care (Moghissi, 2004; Moghissi, et al., 2009). Some studies demonstrated that a diabetes team approach to hospital glycemic management and transition to ambulatory care were effective in controlling inpatient blood glucose, improving post discharge A1C levels, and decreasing length of stay (Flanagan et al., 2008; Jakoby et al., 2008).

Additionally, hospital organizations recognize that in the current healthcare environment, physicians do not have the time or the perceived expertise to manage the intricate daily issues related to glycemic care (Smith et al., 2005). Many hospitals turned to specialized glycemic management teams (GMT) to address inpatient glucose management. Many of these GMTs are staffed with a team of healthcare professionals, which include, but are not limited to, any or all of these team members: physicians, advanced practice nurses, diabetes nurse educators, pharmacists, and/or dietitians (Jakoby et al., 2008; Flanagan, et al., 2008).

The current national economic situation and lack of access to physicians in rural areas are some of the reasons for the increased presence of nurse practitioners (NPs) in various outpatient and inpatient settings. Although there are some practice differences between physicians and NPs, in a study conducted by Mundinger and associates (2000), NPs performing at the same authority and responsibility as physicians, had comparable patient outcomes. 
In the last decade, various approaches to achieving glycemic control have been established at several institutions in the U.S. and abroad. Despite these efforts, glycemic control remains suboptimal (Boord et al., 2009). While there is empirical support for the benefits of intensive inpatient glucose management, there is limited research on its economic costs or savings in relation to clinical outcomes. Moreover, there is less scientific evidence on the impact of GMTs in the care of patients with BG abnormalities who have complex and extensive healthcare needs.

\section{Research Aims}

Hospitals have allocated considerable resources for inpatient glycemic management with the use of a dedicated GMT. This retrospective research study is designed to determine if there are significant differences in the characteristics of a sample of patients receiving traditional care under a physician alone versus GMT (Also see Table 7). Study aims include:

1. Characterize the study population (i.e., age, gender, ethnicity, admission diagnosis, admission BG, A1C level, BMI, co-morbid conditions) by type of care delivery.

2. Examine the differences in glycemic control: mean BG, good glucose control (BG 71 $-180 \mathrm{mg} / \mathrm{dl}$ ), incidences of mild to moderate hyperglycemia (BG 181-299 mg/dl), severe hyperglycemia $B G \geq 300 \mathrm{mg} / \mathrm{dl}$ ), mild to moderate hypoglycemia (BG $41-<60$ $\mathrm{mg} / \mathrm{dl})$, and severe hypoglycemia $(\leq 40 \mathrm{mg} / \mathrm{dl})$, by type of care delivery.

3. Examine which glycemic control variables predict rates of clinical outcomes (hospital complications, LOS, inpatient mortality, and 30-day readmission). 
4. Assess the relationship of glycemic control variables with economic costs (overall hospital costs and direct costs).

5. Examine the differences in inpatient diabetes services provided by type of care delivery.

\section{Conceptual Framework}

The conceptual framework for this study is based upon concepts derived from the literature. See figure 1. Inpatient glycemic management has been traditionally the attending physician's responsibility. Healthcare practices changed over the last few decades resulting in more complex inpatient management and increased healthcare provider responsibility. The mounting evidence of the benefits of improved glycemic control added another layer of responsibility to an already demanding physician schedule. Hence, GMT was implemented to provide assistance to physicians in improving glycemic control for hospitalized patients with diabetes or hyperglycemia.

The main assumption of this study is that the GMT-managed patients, despite having more co-morbid conditions, will have improved glycemic control, decreased in-hospital complications, and decreased costs compared to patients managed alone by the physician. Hence, this study will focus on the differences in the clinical outcomes and economic costs between the two provider groups, as well as determine if there is a relationship between the ranges of glucose control predictor variables with various clinical and economic outcomes (See Figure 1). 
Figure 1. Conceptual Model

\section{Hospital Glycemic Management Conceptual Framework}

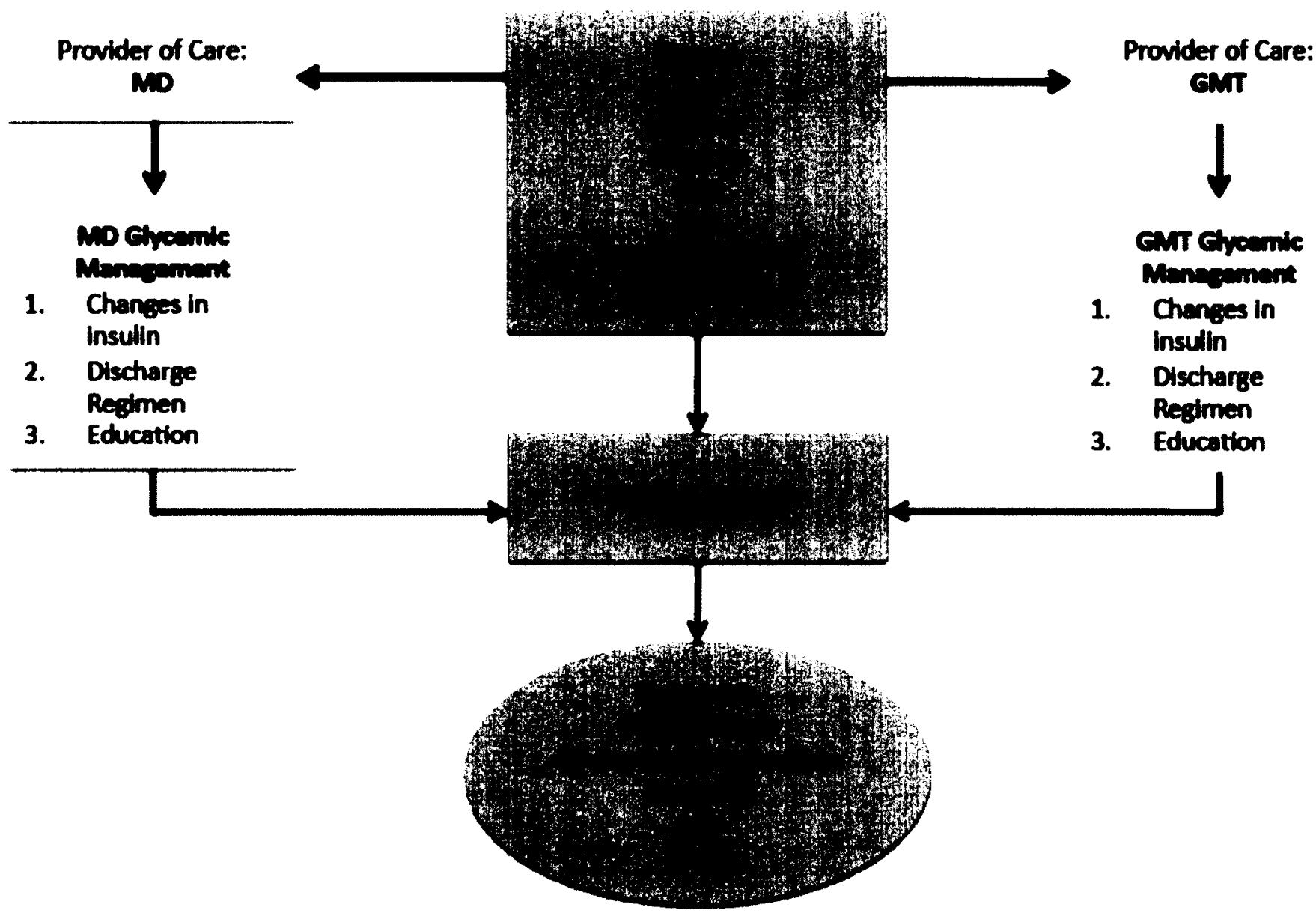




\section{CHAPTER 2: REVIEW OF LITERATURE}

There are countless research studies in inpatient hyperglycemia, hypoglycemia, and glucose management, especially in the first decade of the $21^{\text {st }}$ century. Scientific research interest in inpatient glycemic control has been escalating across the globe. Since the general topic of hospital glycemic control is extensive, a methodical effort was made to present only a synopsis of the most pertinent diabetes care research studies in relation to this research study. The contents of this chapter are organized into ten sections.

1. Introduction: provides a brief overview and statistical facts about inpatient diabetes.

2. Critical care setting: reviews landmark studies that may have broadened research in inpatient hyperglycemia and its management.

3. Surgical care setting: discusses the role of hyperglycemia in surgical patients.

4. General hospital ward setting: elaborates on hyperglycemia and patient outcomes in this population.

5. Hypoglycemia: discusses its role in inpatient clinical outcomes.

6. A1C: states the role and clinical utility of obtaining the laboratory diagnostic measure in the hospital setting.

7. Discharge plan: reviews the outcomes of effective discharge planning for patients with chronic care needs. 
8. Role of the advanced practice nurse: discusses the important role of the nurse practitioner in various settings, especially in chronic care management of the hospitalized patient with diabetes.

9. Conceptual framework: depicts the relationship of the provider BG management on the patient outcomes

10. Summary: recaps the all the important points in this chapter leading to the methods and statistics chapter.

\section{Introduction}

Diabetes is the most common co-morbid condition for patients admitted in the hospital setting. In over a period of 18 years, there was a remarkable increase in hospital stays of patient with diabetes from 2.8 million in 1990 to 7.7 million in 2008 (Fraze, Jiang, \& Burgess, 2010). Prior to the turn of the $21^{\text {st }}$ century, inpatient hyperglycemia was poorly managed or ignored. The use of sliding scale insulin (SSI) was prevalent despite severe criticisms by diabetologists against its use. There is insufficient evidence on its benefits of SSI therapy in the inpatient setting (Queale, Seidler, \& Bracanti, 1997). There were only a small number of studies focusing on inpatient glycemic management prior to the release of the Leuven I study in 2001 (Van Den Berghe et al., 2001). This landmark study changed the course of inpatient glycemic management heading into the 21 st century. 


\section{Critical Care Setting}

The Leuven I was a prospective, randomized, controlled study conducted in Belgium. The investigators examined 1,548 cardiovascular post-operative patients in the surgical intensive care setting. The patients were given insulin therapy to manage their BGs. A total of 783 patients were assigned to conventional therapy with a mean BG goal of $180 \mathrm{mg} / \mathrm{dl}$ to $200 \mathrm{mg} / \mathrm{dl}$. The other group of 765 patients was intensively controlled to a mean BG goal of $80 \mathrm{mg} / \mathrm{dl}$ to $110 \mathrm{mg} / \mathrm{dl}$. Results were favorable in the intensively treated group with decreased intensive care unit (ICU) mortality by $34 \%$, sepsis by $46 \%$, dialysis by $41 \%$, blood transfusion by $50 \%$, and polyneuropathy by $44 \%$ (Van Den Berghe et al., 2001).

Following the tremendous success of the Leuven I study, Van den Berghe and colleagues (2006) conducted the Leuven II study. This prospective, randomized, controlled study of 1,200 medical intensive care (MICU) patients investigated the reduction of morbidity and mortality with intensive insulin therapy. The findings suggested that there was no overall decrease in mortality in the intensively treated group versus the control group. Mortality rate slightly increased in patients who received intensive insulin therapy who stayed in the ICU less than 3 days. However, for those intensively treated patients who stayed in the ICU greater than 3 days, the mortality rate decreased. Morbidity was reduced in the intensively treated group. Furthermore, intensive glucose control prevented new kidney injury, reduced the duration of mechanical ventilation, and shortened ICU stay (Van den Berghe et al., 2006).

Two years after the publication of the Leuven I study, Krinsley (2003) examined glucose control outcomes in a mixed medical and surgical ICU in Stamford Hospital, 
Stamford, Connecticut. Retrospective data was collected from 1,826 consecutive patients between October 1999 and April 2002. Patients with mean BG values between $80 \mathrm{mg} / \mathrm{dl}$ and $99 \mathrm{mg} / \mathrm{dl}$ had the lowest ICU mortality of $9.6 \%$. Mortality rate progressively worsened with the increase in mean $B G$ values reaching $42.5 \%$ on patients with mean $B G$ values greater than $300 \mathrm{mg} / \mathrm{dl}$ (Krinsley, 2003).

Following his 2003 publication, Krinsley (2004) assessed the effects of intensive glucose management using a protocol in the same heterogeneous ICU setting. A total of 800 well-matched participants were enrolled in the study. The use of the protocol significantly improved mean BG levels from pre-intervention baseline to post-intervention (baseline group $=152.3 \mathrm{mg} / \mathrm{dl}$ to $130.7 \mathrm{mg} / \mathrm{dl}$ vs. treatment $=130.7 \mathrm{mg} / \mathrm{dl}$ to $119 \mathrm{mg} / \mathrm{dl}$ ) without significantly increasing the risk for severe hypoglycemia less than $40 \mathrm{mg} / \mathrm{dl}(0.35 \%$ to $0.34 \%)$. The number of patients with new kidney dysfunction and the need for blood transfusion decreased after protocol implementation. The number of hospital-acquired infections did not significantly change. Mortality rate decreased from $29.3 \%$ to $20.9 \%$, and mean length of stay (LOS) decreased from a baseline 3.58 days to 3.19 days with treatment (Krinsley, 2004).

In 2008, Krinsley presented his results on the role of glycemic variability (GV) in hospital mortality. This study was a retrospective review of 3,250 prospectively evaluated patients from October 1999 to October 2007. BG ranges were grouped into four standard deviation (SD) quartiles with quartile 1 having the lowest SD and quartile 4 with the highest SD. The study showed that GV is a strong independent predictor of mortality. The 
lower SD quartile was associated with a lower mortality rate. As the SD quartile increased, mortality rate also correspondingly increased (Krinsley, 2008).

The most current study to date was a large international multicenter study conducted by the NICE SUGAR study investigators in 2009. A sample size of 6,104 noneating patients with hyperglycemia (with or without history of diabetes) was examined. This is a parallel group, randomized, controlled study looking at MICU and SICU patients in 42 hospitals ( 38 academic and 4 community hospitals) in the United States, Australia, and New Zealand. The intensively controlled (IC) group of 3,054 patients had a mean BG goal of $81-108 \mathrm{mg} / \mathrm{dl}$ while the control group (CG) of 3,050 patients had a mean BG goal of less than or equal to $180 \mathrm{mg} / \mathrm{dl}$. The primary endpoint was death within 90 days of study enrollment. The secondary endpoints were survival after 90 days, cause of death, duration of mechanical ventilation, renal failure, ICU stay, and hospital stay. Tertiary endpoints are death from any cause within 28 days, place of death (ICU or another level of care), incidence of new organ failure, positive blood cultures, and need for blood transfusions. The results were significant for intensively controlled group versus the control group as follows: mean BG of $107 \mathrm{mg} / \mathrm{dl}$ vs. $142 \mathrm{mg} / \mathrm{dl}$, increased insulin use with $97.2 \%$ vs. $69 \%$, increased mortality with $27.5 \%$ vs. $24.9 \%$, ICU mortality of $62.9 \%$ vs. $66.3 \%$, and increased risk of severe hypoglycemia $<40 \mathrm{mg} / \mathrm{dl}$ with $6.8 \%$ vs. $0.5 \%$, respectively. It is important to note that a major limitation of this study is that a substantial portion of the intensively treated patients in the study did not achieve target BG goal (NICE SUGAR Investigators, 2009). 


\section{Surgical Care Setting}

In Portland, Oregon, Furnary and his colleagues (2003) evaluated 3,554 post coronary artery bypass surgery (CABG) patients from 1987 to 2001. Patients where placed on subcutaneous insulin and patients from 1992 to 2001 were on continuous insulin infusion (CII) for aggressive hyperglycemia management. The results from this observational study indicated that mortality rate was lower for insulin infusion (2.5\%) compared to subcutaneous insulin (5.3\%). Furthermore, perioperative glycemic control using continuous insulin infusion on the day of surgery through post-operative day two showed an absolute mortality rate of $57 \%$ in the diabetes population.

Furnary and Wu (2006) released findings on coronary artery bypass graft (CABG) patients - an ongoing prospective, nonrandomized, interventional study of 5,534 patients with diabetes who were placed on CII for 3 days (on the day of surgery through postoperative day two]. Associations of various outcomes to levels of hyperglycemia were found including: (1) inpatient mortality rate increased corresponding to increases in BG levels with a marked increase at BGs $>250 \mathrm{mg} / \mathrm{dl}$; (2) deep sternal wound infection (DSWI) rates sharply increased at BG levels $>175 \mathrm{mg} / \mathrm{dl}$; (3) length of stay (LOS) gradually increased corresponding to incremental increases in BG levels: and, (4) inpatient complications, i.e., blood transfusions, new onset atrial fibrillation, any type of infection, low cardiac output syndrome, prolonged ventilation, pneumonia, and cerebrovascular accidents correlated to increases in BG levels. Tight glycemic control for the first 3 days post-surgery effectively reduced BGs to near normal levels, reduced mortality rate by $65 \%$, DSWI by $63 \%$, and LOS by 2 days. Based on the results of this study, Furnary and his 
associates advocated tightening $\mathrm{BG}$ control on the first 3 days post-CABG, also known as 3BG (Furnary \& Wu, 2006).

Some studies were also conducted on noncardiac surgical patients to evaluate glucose control outcomes for this population. Umpierrez and his colleagues (2011) examined 211 patients who were randomly assigned to two treatment groups: basal-bolus insulin regimen ( $n=104)$, and sliding scale regimen $(n=107)$. The purpose of the study was to evaluate optimal treatment of hyperglycemia for this population to prevent poor outcomes. Since these patients did not require an ICU stay, subcutaneous insulin regimen was the treatment of choice. The study showed that the patients who were placed on basalbolus insulin regimen had improved glycemic control and reduced complications compared to the patients on sliding scale insulin regimen.

Frisch and colleagues (2010) conducted a retrospective study at Emory University Hospital in Atlanta, GA on 3,184 patient medical records. The patients in the sample had any of the following surgeries: general, neurosurgery, oncology, orthopedic, vascular, thoracic, urology, otolaryngology, and gynecology. The objective of the study was to determine the impact of perioperative hyperglycemia on clinical outcomes such as, LOS, complications, and mortality. Overall 30 -day mortality was $2.3 \%$ significantly higher in patients with higher BG levels before and after surgery, than patients with lower BG levels. Perioperative hyperglycemia was associated with longer hospital and ICU LOS, with higher incidences of postoperative pneumonia, systemic blood infections, urinary tract infections, and acute myocardial infections. In a multivariate analysis adjusted for age, gender, 
ethnicity, and severity of surgery, mortality risk increased in proportion to perioperative BG levels in patients with no prior history of diabetes.

\section{General Hospital Ward Setting}

Hyperglycemia is not unique in the ICU setting yet majority of the earlier studies conducted since Leuven I in 2001 and other studies through 2004 were primarily on critical care patients. In 2002, Umpierrez and his associates published their retrospective study on hyperglycemia as a marker for inpatient mortality in the general inpatient (ICU and non-ICU) population. They evaluated 2,030 consecutive adult patients with hyperglycemia (with or without prior history of diabetes) in Georgia Baptist Medical Center in Atlanta, Georgia. The study period was from July 1, 1998 to October 20, 1998. The primary endpoint was death. The secondary endpoints were treatment of hyperglycemia, LOS, and disposition at discharge. Hyperglycemia was defined as a fasting $B G>126 \mathrm{mg} / \mathrm{dl}$ or a random $B G>200 \mathrm{mg} / \mathrm{dl}$ twice during the hospital stay. Results showed that hyperglycemia was present in $38 \%$ of the total hospital population $(26 \%$ with history of diabetes and $12 \%$ with no prior history of diabetes). New hyperglycemia was associated with increase in mortality rate of $16 \%$ vs. $3 \%$ on patients with history of diabetes. New hyperglycemia was also associated with increased LOS and admission to the ICU. Furthermore, hyperglycemia was also associated with decreased likelihood of patients being discharged to home and increased transfer to transitional care units or long-term care facilities.

Umpierrez and associates (2002) showed that new hyperglycemia caused poor outcomes in the acute care population. The effects of admission hyperglycemia in the acute 
care setting on patients with type 2 diabetes who were admitted into the hospital for the first time with pneumonia was investigated by a group of researches in Denmark in 2007. They retrospectively examined whether patients with type 2 diabetes had increased mortality and complications after pneumonia. They also wanted to know if there was any value of admission hyperglycemia in this cohort. 29,900 patients were admitted for the first time into the hospital for pneumonia between 1997 and 2004 in North Jutland and Aarhus counties. A total of 2,931 pneumonia patients with type 2 diabetes met study criteria. A regression model was applied to assess for relative risk of pneumonia, bacteremia, and mortality rates. The results showed that there were increased mortality rates among the patients with diabetes than patients with no diabetes, $19.9 \%$ vs. $15.1 \%$ after 30 days, and $27 \%$ vs. $21.6 \%$ after 90 days. The presence of type 2 diabetes was not predictive of pulmonary complications and bacteremia. This study showed that type 2 diabetes and admission hyperglycemia are associated with pneumonia-related deaths.

\section{Hypoglycemia}

Hypoglycemia is not an uncommon problem in hospitals nationwide. The first national and emergency department-based epidemiological study reported approximately 5 million emergency department (ED) visits over 12 years (1993-2005) that was related to hypoglycemia. $25 \%$ of these visits resulted in a hospital admission. This is approximately 34 per 1000 patients who have diabetes. The rate of hypoglycemia-related visits in the ED did not increase over time despite increase emphasis on tight glucose control (TGC) (Ginde et al., 2008). 
Tightening control of BGs can increase the risk of acute hypoglycemia. Many of the inpatient studies related to TGC reported incidences acute hypoglycemia. Whether acute hypoglycemia is a marker of poor prognosis or an independent cause of mortality is still inconclusive. Nevertheless, hypoglycemia management requires increased hospital resources; it is an unpleasant and dangerous adverse reaction from severe illness or insulin therapy; and, both acute and chronic hypoglycemia has been associated with increased mortality.

Most notable randomized controlled trials (RCTs) and other observational studies reported incidences of severe hypoglycemia with BGs $<40 \mathrm{mg} / \mathrm{dl}$. The RCTs that reported acute hypoglycemia are the Leuven I, Leuven II, and VISEP studies. Observational studies targeting the ICU population were reported in the Krinsley (Stamford, CT) and Vriesendorp (Belgium) studies. Turchin and colleagues also published a study on hypoglycemia in hospitalized patients with diabetes in the general acute care setting.

In the Leuven I study with 1,548 patients in the surgical intensive care unit, severe hypoglycemia with BG $<40 \mathrm{mg} / \mathrm{dl}$ occurred in $5.1 \%(39 / 765)$ of the intensively treated group versus $0.8 \%(6 / 783)$ of the controlled group (Van den Berghe et al., 2001). In the Leuven II study with 1,200 patients in the medical intensive care unit, $18.7 \%(111 / 595)$ patients in the intensively treated group had severe hypoglycemia compared to $3.1 \%$ $(19 / 605)$ of the control group (Van den Berghe et al., 2006). When the data for the Leuven I and II were pooled together, severe hypoglycemia occurred in $11.3 \%(154 / 1360)$ of patients in the intensively treated group and $1.8 \%(25 / 1388)$ of patients in the control group (Van den Berghe et al., 2001; 2006). 
The Efficacy of Volume Substitution and Insulin Therapy in Severe Sepsis study (VISEP) was study conducted in Germany with 537 severe sepsis patients. It was widely publicized because the study was abruptly terminated due to the high incidence of hypoglycemia $17 \%(42 / 247)$ in the intensively treated group compared to $4.1 \%(12 / 290)$ in the control group (Brunkhorst et al., 2008).

In the study done by Krinsley (2005) with 1600 patients ( 800 patient pre- and 800 post glucose management protocol institution), the incidences of hypoglycemia with BG $<40 \mathrm{mg} / \mathrm{dl}$ were $0.35 \%$ and $0.34 \%$ respectively. The findings were not significant between the two groups. In a subsequent retrospective study by Krinsley and Grover (2007) with 5365 patients ( 2666 pre and 2699 post implementation of TGC), the incidences of severe hypoglycemia were $1.5 \%$ and $1.3 \%$, respectively.

Vriesendorp and colleagues (2006) examined the short-term consequences of hypoglycemia (coma, seizures and death) in the ICU. They examined 245 occurrences of BGs $<45 \mathrm{mg} / \mathrm{dl}$ with 156 patients over a period of 2 years. The researchers found that seizures and coma occurred infrequently with their study population. Furthermore, they found no relationship between incidental hypoglycemia and mortality. However, with a small data set and lack of randomization, they could not fully exclude hypoglycemia having a causative role in mortality in patients admitted to the ICU.

Turchin and colleagues (2009) published a retrospective study on the relationship of hypoglycemia with $\mathrm{BG}<50 \mathrm{mg} / \mathrm{dl}$ and clinical outcomes on patients with diabetes admitted to the general ward. They studied a cohort 4,368 admissions of 2,582 patients between January 2003 and August 2004. Hypoglycemia was observed in 7.7\% of the 
admissions. The results showed that hypoglycemia was associated with increased mortality during the hospital stay and 1-year from discharge. Each additional day of hypoglycemia was associated with an increase of $85.3 \%$ odds of death and three-fold increase odds of death for every $10 \mathrm{mg} / \mathrm{dl}$ decrease in the lowest BG during hospitalization. LOS also increased by 2.5 days for each additional day with hypoglycemia. This means that inpatient mortality and LOS increased gradually as the number of hypoglycemic events rose.

Glycosylated Hemoglobin A1C

$\mathrm{A}_{1} \mathrm{C}$ assays are traditionally used in the outpatient setting to measure average blood glucose during the previous two to three months. $\mathrm{A}_{1} \mathrm{C}$ assays are expressed as the percentage of hemoglobin that is glycated. $\mathrm{A}_{1} \mathrm{C}$ assays are becoming a routine part of laboratory testing for patients with diabetes (Nathan, et al. 2008). Normal $A_{1} C$ level is 4-6\%. An $A_{1} C$ of $>6.5 \%$ is predictive of diabetes. Good glucose control is an $A_{1} C$ of $<7 \%$ (ADA, 2011). Both patients and practitioners generally have to find a conversion chart to find the average glucose corresponding to the $\mathrm{A}_{1} \mathrm{C}$. Nathan and his associates (2008) examined 507 participants with type 1 diabetes $(n=268)$, type 2 diabetes $(n=159)$, and patients with no diabetes $(n=80)$ to determine if $A_{1} C$ can be accurately expressed as an average glucose $(e A G)$. The linear regression equations did not differ significantly across the study sample. In 2009, the Internal Expert Committee on the role of the $A_{1} C$ assay in the diagnosis of diabetes recommended the routine use of $\mathrm{A}_{1} \mathrm{C}$ in the diagnosis of diabetes (The International Expert Committee, 2009).

The use of $\mathrm{A}_{1} \mathrm{C}$ assay was uncommon in the inpatient setting until the last decade of the $20^{\text {th }}$ century. $\mathrm{A}_{1} \mathrm{C}$ assays are increasingly being utilized in the inpatient setting due to 
the increasing prevalence of hospitalized patients with diabetes and hyperglycemia with no prior history of diabetes. Wexler and associates (2008) examined the prevalence of unrecognized diabetes in 695 hospitalized adults with no history of diabetes using $\mathrm{A}_{1} \mathrm{C}$ assays. The study results showed that $18 \%$, or 1 in every 5 patients admitted to the hospital with no history of diabetes, had an elevated $A_{1} C>6.1 \%$ (Wexler et al. 2008).

There is ample evidence that $A_{1} C$ has great clinical utility in the hospital setting, especially in the day-to-day management of glucose control and subsequent diabetes discharge planning.

\section{Discharge Plan}

Inpatient to outpatient transfer of care is an important part of good glycemic care. Patients enrolled in established and well-structured outpatient diabetes care follow-up have better outcomes. Although the outpatient outcomes of diabetes follow-up are well recognized, there is little known about the transfer of care from inpatient to outpatient. When managing inpatients with complex diabetes care needs, it is important to link these patients back to outpatient care.

Wheeler and associates (2004) reported a retrospective study of 658 inpatients of a municipal hospital in the heart of downtown Atlanta. A hospital-based certified diabetes nurse educator (CDE) saw most of the patients as an inpatient. The follow-up care was stratified into outpatient follow-up (69\%), acute care follow-up (15\%), and no follow-up $(16 \%)$. The odds for coming to the Diabetes Clinic increased if patients were discharged with insulin, had new onset diabetes, or had a direct referral from the CDE. 
Four years after the publication of Wheeler and associates' (2004) study, Cook and colleagues (2009) released a review article on Endocrine Practice about effective planning for inpatient to outpatient transfer of diabetes care. Their web search for studies related to diabetes discharge planning (between 1998 and 2007) yielded very few and inadequate results. This means there were limited studies available on diabetes discharge planning before Wheeler's study and thereafter.

Discharge planning has become a national patient safety goal and priority addressed by the National Patient Safety Goals and the Centers for Medicare and Medicaid Services (Cook et al., 2009). The Joint Commission made it a national priority by setting guidelines and offering hospitals an option to become certified in inpatient diabetes (Joint Commission, 2011). Cook and associates (2009) defines effective diabetes discharge as one where the patient received necessary skill training while in the hospital, and provided a clear and understandable post-discharge plan.

Discharge planning with diabetes nurse follow-up has been shown to improve patient adherence to treatment regimen and improve $A_{1} C$. Wong and associates (2005) did a randomized prospective study in the medical department of a regional hospital in Hong Kong. A total of 101 patients were included in the study, 49 in the control group and 52 in the study group. The outcome measures were $A_{1} C$, self-care adherence, health care utilization, and patient satisfaction. The results showed that patients in the study group had better $A_{1} C$, higher blood glucose monitoring, higher exercise adherence, lower LOS, and lower overall cost. There was no difference in patient satisfaction. 
Since inpatient glycemic management is multidimensional, a thorough glycemic management should include addressing both inpatient glucose control and effectively planning diabetes self-management for discharge.

\section{Advanced Nursing Practice Role in Diabetes Management}

The increased demands on both the physicians and nurses leave little time to address the patients' insulin requirements based on glucose variability and rapidly changing needs. Some of the challenges to effective inpatient glycemic management and discharge planning were identified from a physician's perspective and the nursing perspective (Cook, et al., 2009).

From the physician's perspective, patients with preexisting diabetes may be difficult to manage because: (1) majority of the focus of care is on the co-morbid conditions that triggered the hospital admission; (2) fear of hypoglycemia causing deleterious effects; (3) insulin administration is only initiated at BG levels of greater than $180 \mathrm{mg} / \mathrm{dl}$ to $200 \mathrm{mg} / \mathrm{dl}$; (4) inadequate adjustment of diabetes medications due to alteration in nutritional support and medical illness, (5) unpredictability of hospital-related procedures; and (6) medications can affect glucose metabolism (Cook et al., 2009; Lansang \& Umpierrez, 2008). The nurses also face challenges similar to those faced by physicians. This includes finding little to no time for comprehensive diabetes education and discharge planning, in addition to juggling an ever increasing patient care tasks (Cook et al., 2009).

The physician or a nurse individually, or both, may be inadequately equipped to handle the challenges of a comprehensive inpatient glycemic management. It requires a multidisciplinary team to sufficiently tackle complex disease management. Disease 
management is a patient care service that is coordinated and comprehensive, addressing care across the health care delivery continuum. A review of 102 research studies showed that disease management programs were associated with improved outcomes such as patient satisfaction, patient adherence, disease control, patient knowledge, morbidity, and mortality (Ofman et al., 2004). Many of these disease management programs are staffed with registered nurses (RNs), advanced practice nurses (APNs), and other healthcare professionals who have specialized training or expertise in their particular field of disease management. It is not uncommon to find nurses in disease management teams because nurses have a unique insight in the patient's care needs.

Although nursing has been around for centuries, advanced nursing practice first emerged in the later part of the $20^{\text {th }}$ century. Despite being only half a century old, the nurse practitioner (NP) practice has undergone many professional, academic, and role changes over the last five decades. The NP role is now an integral part of the mainstream health care delivery system. NPs traditionally practiced in the outpatient care setting but the emerging demands of complex disease management and the increasing role of disease management teams have shifted the NPs' practice towards the inpatient setting.

NP practice has been extensively researched in terms of the quality of care and patient outcomes compared to physicians. Mundinger and colleagues (2000) conducted a randomized controlled trial to compare the outcomes of patients assigned to NPs or physicians for a primary care follow-up and ongoing care after an emergency room visit. A total of 1316 patients were enrolled in the study; 806 randomized to NPs and 510 randomized to physicians. No significant differences were found in patient's health status 
at six months between the two groups. Physiologic tests results for both diabetes and asthma were also not different. Patients with hypertension showed lower diastolic value for the NP group versus the physician group. No difference was found in healthy services utilization and patient satisfaction at initial visit. Interestingly, physicians had higher patient satisfaction scores at six months. Where the NP practice is held at the same authority, responsibilities, productivity and administrative requirements, and have the same patient population as the primary care physicians, patient outcomes appear equal in all but one domain (Mundinger et al., 2000).

Another study comparing patient care delivery between NPs and physicians was conducted in a large teaching hospital in Iowa (Pioro et al, 2001). They randomly assigned 318 patients admitted to a general medical ward to either NPs or housestaff. The NP group had 193 patients and the housestaff group had 188 patients. Patient demographics were similar for both groups. Outcomes at discharge and six weeks thereafter were similar in both groups including LOS, charges, costs, consultations, complications, transfers to ICU, 30-day mortality, patient assessments of care, changes in activities of daily living, SF-36 scores, and symptom severity. However, 90 of the 193 patients under the NP group were transferred to the care of the housestaff by NP or housestaff request. Despite the change in sample population distribution, the care between the two groups was similar.

NPs have also expanded their role in diabetes case management. Mullen and Kelly (2006) reviewed 57 patient cases that were followed by NPs who performed the diabetes case manager roles. The study evaluated $A_{1} C$, total cholesterol (TC), and low-density lipoprotein (LDL), six months after discharge. Significant reductions in $A_{1} C$ and $T C$ were 
observed but no reduction in LDL was noted. This study showed that for this patient population, patients followed by APNs as diabetes nurse case managers had improved outcomes.

NPs who are providers and case managers of diabetes care are often part of multidisciplinary teams. Jakoby and colleagues (2008) conducted a prospective, ninemonth study on 308 admissions, to determine the impact of a glycemic management team's intervention on both hospital and outpatient glycemic control. The team consisted of an endocrinologist, a nurse practitioner, diabetes nurse educators, and registered dietitian. As a team, they provided a coordinated glycemic management during the patient's hospital stay. BG levels improved significantly with the team's intervention $(195 \pm 72 \mathrm{mg} / \mathrm{dl}$ to 162 $\pm 41 \mathrm{mg} / \mathrm{dl}$ ). $\mathrm{A}_{1} \mathrm{C}$ measures also improved with $8.2 \% \pm 2.1 \%$ prior to admission versus three months after discharge with $7.3 \% \pm 1.6 \%$. Approximately $80 \%$ of patients agreed to basal-bolus therapy after discharge compared to $56.8 \%$ prior to admission. Approximately $82.6 \%$ of patients discharged on basal-bolus insulin regimen were still on the regimen three months after discharge. The study supports that a team approach to patient care improves diabetes self-management and improve both inpatient and outpatient glycemic control (Jakoby et al., 2008).

Other than NPs, clinical nurse specialists (CNS) have also taken a role in inpatient glycemic management teams. In an article that appeared in Clinical Nurse Specialist, Custer (2010) described the role of a CNS in improving glucose management in an ICU setting. The study evaluated glucose control of 124 patients. $64.5 \%(80 / 124)$ did not receive any treatment. $22.6 \%$ received sliding scale insulin injections other than the standardized 
orders. $12.9 \%$ received either the standardized basal-bolus subcutaneous insulin orders $(4 \%$ or $5 / 124)$ or insulin infusion $(8.9 \%$ or $11 / 124)$. When the standardized orders were used correctly, the mean BG level was $175 \mathrm{mg} / \mathrm{dl}$ with a median of $149 \mathrm{mg} / \mathrm{dl}$. When the standardized orders were not used correctly, the mean BG level was $206 \mathrm{mg} / \mathrm{dl}$ with a median of $190 \mathrm{mg} / \mathrm{dl}$. The CNS encountered many challenges in implementing the program including provider's persistence with using sliding scale insulin, lack of basal insulin use, and inconsistent use of standardized orders. The author also noted that the CNS role was limited due to the lack of prescribing privileges to initiate glycemic management orders.

\section{Conceptual Framework}

Inpatient glycemic management has been traditionally the responsibility of the attending physician caring for the patient. Healthcare practices changed over the last few decades resulting in more complex inpatient management and increased healthcare provider responsibility. The mounting evidence of the benefits of improved glycemic control added another layer of responsibility to an already demanding physician schedule. Hence, GMT was implemented to provide assistance to physicians in improving glycemic control for hospitalized patients with diabetes or hyperglycemia.

The main assumption of this study is that the GMT-managed patients, despite having more co-morbid conditions, will have improved glycemic control, decreased in-hospital complications, and decreased costs compared to patients managed alone by the physician. Hence, this study will focus on the differences in the clinical outcomes and economic costs between the two provider groups, as well as determine if there is a relationship between 
the a ranges of glucose control predictor variables with various clinical and economic outcomes (See Figure 1).

Figure 1. Conceptual Model

\section{Hospital Glycemic Management Conceptual Framework}

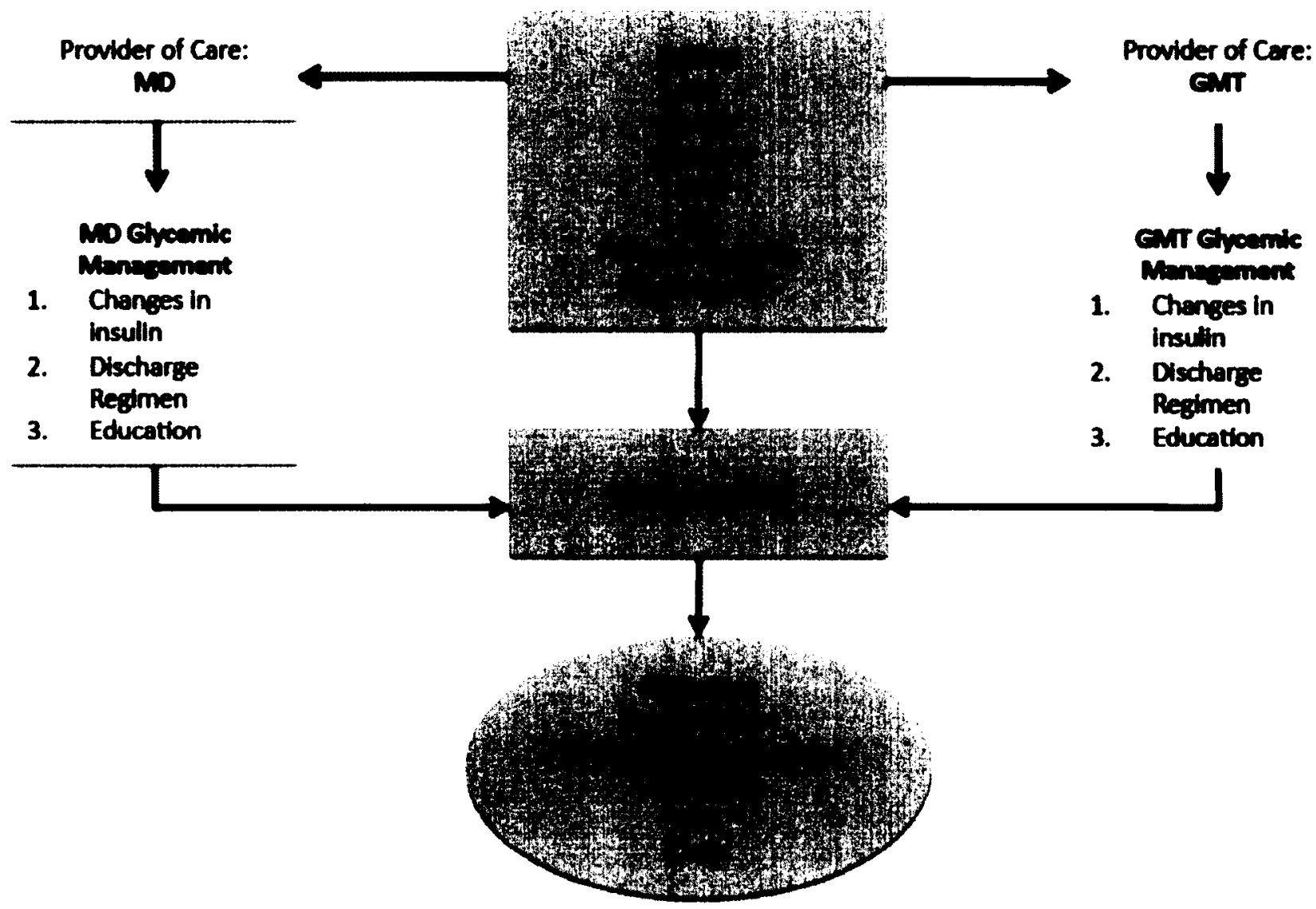




\section{Summary}

Successful implementation of a glycemic control program in the hospital setting may depend on effectively addressing the barriers or obstacles to success. These obstacles are

(1) physicians are inadequately equipped to deliver diabetes care alone; (2) tightening glucose control to improve patient outcomes while minimizing or avoiding severe hypoglycemia; and, (3) providing clear discharge plan and instructions.

The institution of GMTs in the hospital setting hopes to address these challenges. The GMT provides additional resources for physicians and staff in managing patients' glycemic control. (2) As the resident glycemic control experts, control patients' BGs to glycemic targets while minimizing or avoiding severe hypoglycemia. (3) Address the patients' discharge needs by providing a comprehensive discharge plan.

The GMT in this study consists of NPs and diabetes nurse educators (CDE) who are under the supervision of the diabetes medical director. Together, and in collaboration with attending physicians, pharmacists, dietitians, and nurses, they provide care for patients referred to the GMT. Once the patient is referred to the GMT, the NPs will assume responsibility in managing the patient's glucose control and diabetes discharge treatment modification during the hospital stay. The NPs keep similar hours as the attending physicians, providing coverage 24 -hours a day. The diabetes nurse educators function as diabetes case managers along with the NPs. The diabetes nurse educators are available Monday through Friday to provide patients with diabetes survival skills, education, supplies, resources and referral to outpatient diabetes education or case management. 


\section{CHAPTER 3: METHODOLOGY}

\section{Significance of the Study}

In the last decade, a plethora of the research studies showed that improved blood glucose control resulted in better clinical outcomes. Economic cost savings have not been as thoroughly investigated, but have been largely assumed. The ADA, AACE, and other medical organizations recommended the use of a chronic disease management team like the GMT; however, its use has not been thoroughly evaluated in relation to clinical outcomes and economic costs.

In this era of economic downturn and increased healthcare costs amidst the new healthcare reform environment, limiting costs while improving outcomes are a priority. The results of this study can inform and guide healthcare agencies, policy makers, clinicians, researchers, educators, and healthcare consumers about the effects of glycemic control on clinical outcomes and economic costs.

Despite the increased use of NPs in the outpatient setting, NP practice is still relatively uncommon in the inpatient setting. Outcomes related to inpatient glucose management by the GMT, where NPs primarily manage glucose control, can promote advanced practice nursing, direct nursing education, and stimulate further research in nursing science.

The purpose of this study is to examine the key clinical outcomes and economic cost differences between two service delivery groups, the GMT versus traditional solo physician management. The main assumption of this study is that the GMT-managed patients, despite 
having more co-morbid conditions, will have improved glycemic control, decreased inhospital complications, and decreased costs compared to patients managed alone by the physician.

This chapter presents a review of the study aims and questions, and a description of the research methodology including study aims, study design, sample and sampling, instrumentation, data collection procedures, data analysis, and the protection of human subjects.

\section{Research Aims}

Aim 1. Characterize the study population (i.e., age, gender, ethnicity, admission diagnosis, admission BG, A1C level, BMI, co-morbid conditions) by type of care delivery.

Aim 2. Examine the differences in glycemic control: mean BG, good glucose control (BG $71-180 \mathrm{mg} / \mathrm{dl}$ ), incidences of mild to moderate hyperglycemia (BG 180 $-299 \mathrm{mg} / \mathrm{dl}$ ), severe hyperglycemia $B G \geq 300 \mathrm{mg} / \mathrm{dl}$ ), mild to moderate hypoglycemia (BG $41-<60 \mathrm{mg} / \mathrm{dl}$ ), and sever hypoglycemia $(\leq 40 \mathrm{mg} / \mathrm{dl})$, by type of care delivery.

Aim 3. Examine which glycemic control variables predict rates of clinical outcomes (hospital complications, LOS, inpatient mortality, and 30-day readmission).

Aim 4. Assess the relationship of glycemic control variables with economic costs (overall hospital costs and direct costs). 
Aim 5. Examine the differences in inpatient diabetes services provided by type of care delivery.

\section{Research Design}

This is a cross-sectional, retrospective, quasi-experimental research study that will be conducted in a 343-bed, nonprofit, urban community hospital in Southern California.

\section{Sample and Sampling}

The hospital admitted 3,961 and 3,953 patients with diabetes in 2008 and 2009, respectively. This does not include patients with hyperglycemia diagnosed during the hospital stay. 1,000 patient cases per year (2,000 cases for the two years) between January 1, 2008 and December 31,2009, will be selected randomly from the electronic database for manual paper chart review. A final sample size of 800 patient cases that meet all study criteria (see Table 1) will be reviewed. The sample will be equally distributed between the two groups: 400 for the GMT group and 400 for the physician group.

Inclusion Criteria

- Diabetes/Hyperglycemia Diagnosis: A diagnosis of diabetes or hyperglycemia as a secondary diagnosis will be obtained based on descriptions by diagnosis related group (DRG).

- Age: All pediatric patients, once stabilized in the emergency department (ED), are sent to the closest children's hospital. The hospital does not offer inpatient pediatric services. Hence, the sample population for this study will include adult patients who are 18 year old and older. 
- Complete patient characteristics and baseline information: all patient cases should have complete information on age, gender, ethnicity, admission diagnosis, admission $B G$, glycosylated hemoglobin $A_{1} C$ (or just called, $A_{1} C$ ), body mass index (BMI), and type of practitioner managing the BG (see Table 2 for listing).

- Length of Stay (LOS): LOS has a specific definition and parameters in terms of billing. Admit day starts as soon as the physician writes the order and it is entered into the IDX hospital system software. If the patient is admitted as an inpatient through the ED, admission Day 1 begins regardless of when the patient is transferred to the ward/unit. Cut off is at midnight for discharge. Discharge day is not counted as part of the admission day. For example, if the patient was admitted in the ED on 01.01.11 and discharged on 01.05.11, that would be a four-day LOS. For the purpose of this study, patient cases with LOS of three days or more are included. LOS less than three days will not provide adequate blood glucose values for analysis of the primary endpoints; hence, they are excluded from the data.

- BG Values: Two or more glucose values per patient day from point-of-care (POC) blood glucose fingerstick and laboratory serum glucose are included to ensure that there is an adequate number of BGs included in the analysis. 


\section{Exclusion Criteria}

- LOS > 14 days: Preliminary analysis of patients with diabetes and hyperglycemia showed that a cut-off of 14 days includes $85 \%$ of the total patients. The team determined that LOS $>14$ days may skew the data negatively. Patients with LOS >14 days stay for several reasons: they could have placement issues, hence they stayed in the hospital longer; they have no insurance, hence they stay so their treatment can be completed before discharge; or, they are sicker or terminally ill but their level of care requires hospitalization.

- DKA/HHS Patients: Patients admitted for the primary diagnosis of diabetes ketoacidosis (DKA) or hyperosmolar hyperglycemic state (HHS) are excluded from the study. These patients' BGs are intentionally kept outside of the hospital glycemic targets and at high levels for the first 24-48 hours to allow for BGs to return to normal or near normal levels gradually.

- Location: only patients admitted to all units in the acute care setting and critical care setting are included in the study. Patients who are in the longterm care facilities attached to the main hospital are excluded from the study.

\section{Procedures}

Patient cases will be randomly sampled from the pool of patients with the use of the hospital patient database for the periods described. Patient cases will be selected through electronic query based on this study's inclusion criteria i.e., a diagnosis of either diabetes or hyperglycemia ( $\mathrm{BG}>180 \mathrm{mg} / \mathrm{dL}$ during the hospital stay), 18 years of age or older, stayed 
in the hospital for 3 or more days, have available demographic \& baseline data (see Table 2), and recorded BG values of two or more in a 24-hour period. Patient cases that do not meet all the inclusion criteria or if admitted in diabetes crises will be eliminated from the analysis (see Table 1).

Data will be obtained through electronic medical records (EMR), electronic financial records (EFR), and paper chart reviews (PCR). Although the hospital system uses EMR for some of it's patient information, documentation of clinical information is still largely entered on paper charts. The basal-bolus order set was implemented on February 14, 2010, along with the implementation of the GMT to assist in the daily management of BG control. The GMT only intervened with patients referred by the physician for GMT consult. The physicians continued to see majority of the patients with diabetes or hyperglycemia without the assistance of the GMT. It is therefore appropriate to evaluate the impact of GMT on clinical outcomes and economic costs compared to physicians on measures described on Table 2.

\section{Data Analysis}

Data will be analyzed using the SPSS 18.0.2 and Stata 11.0 programs. Descriptive and multivariable statistics will be used for data analysis. Descriptive statistics will be reported on all dependent and independent variables.

Question 1. Is there a difference in patient characteristics between provider groups (GMT versus physician)? Comparison of patient characteristics (i.e., age, gender, ethnicity, admission diagnosis, admission BG, A1C level, BMI, co-morbid conditions) by practitioner types will be 
analyzed. One-way ANOVA will be used for continuous variables to determine whether group means differ from each other. Categorical variables will be analyzed using chi-square to test for fit.

Question 2. Is there a difference in the range of glucose control between the two provider groups? A Mann-Whitney U will be used to analyze glycemic control ordinal data between the two provider groups. Glycemic control predictor variables include mean BG, good glucose control (BG $71-180 \mathrm{mg} / \mathrm{dl}$ ), incidences of mild to moderate hyperglycemia (BG $180-299 \mathrm{mg} / \mathrm{dl}$ ), severe hyperglycemia $B G \geq 300 \mathrm{mg} / \mathrm{dl}$ ), mild to moderate hypoglycemia (BG 41-<60 mg/dl), and severe hypoglycemia $(\leq 40 \mathrm{mg} / \mathrm{dl})$.

Question 3. Does level of glucose control predict rates of hospital complications, LOS, inpatient mortality, and 30-day readmission? Logistic regression will be used to determine odds ratio and describe the relationship between glycemic control predictor variables and rates of clinical outcomes (hospital complications, LOS, inpatient mortality, and 30day readmission). However, noting that the dependent variables are count data and the event occurs in a particular event or time frame, i.e., during the hospitalization, Poisson logistic regression or log-linear regression modeling may be used.

Question 4. Which predictors account for the variance in cost of hospitalization? Multiple regression analysis will be employed to determine the 
relationship of glycemic control variables with economic costs of overall hospital costs and direct costs.

Question 5. Is there a difference in inpatient diabetic services (glucose management, diabetes education, and changes in diabetes regimen upon discharge by type of care delivery? These categorical variables will be analyzed using chi-square to test for the difference between the two provider groups in inpatient diabetes services provided such as glucose management, diabetes education and changes in diabetes regimen upon discharge.

Table 6 summarizes the research aims, study questions and types of statistics corresponding to each research inquiry.

\section{Protection of Human Subjects}

Institutional Review Board approval will be obtained from the University of San Diego and associated health care facility. Since the data will be collected retrospectively, there will be no actual patient contact involving any risk. Precautions will be taken to protect patient privacy in accordance with the Health Insurance Portability and Accountability Act (HIPAA). Access to patient identifiers will be limited to data collectors (including the primary investigator, data analysts, accounting department personnel, and research assistants). Data will be de-identified prior to transferring the information to the statistician for analysis. 
References

American Diabetes Association (ADA) (2008). Economic Costs of Diabetes in the U.S. in 2007. Diabetes Care, 311(3), 596-615. doi: $10.2337 / \mathrm{dc08}-9017$

American Diabetes Association (ADA) (2010). Position Statement: Standards of Medical Care in Diabetes - 2010. Diabetes Care, 33(S1), S11-S61. doi: 10.2337/dc10-S011

American Diabetes Association (ADA) (2011). Standards of medical care in diabetes. Diabetes Care, 34(S1), S11-S61. doi: 10.2337/dc11-S011

Boord, J. B., Greevey, R.A., Braithwaite, S., Arnold, P.C., Selig, P.M., Brake, H., Cuny, J., \& Baldwin, D. (2009). Evaluation of Hospital Glycemic Control at US Academic Medical Centers. Society of Hospital Medicine, 4(1), 35-44. doi: 10.1002/jhm.390

Brunkhorst, F. M., Engel, C., Bloos, F., Meier-Hellmann, A., Ragaller, M., Weiler, N., et al. (2008). Intensive insulin therapy and pentastarch resuscitation in severe sepsis. New England Journal of Medicine, 358(2), 125-139. doi: 358/2/125 [pii] 10.1056/NEJMoa070716

Center for Disease Control and Prevention (CDC) (2011). National diabetes fact sheet: national estimates and general information on diabetes and prediabetes in the United States, 2011 (pp. 12). Atlanta, GA: Center for Disease Control and Prevention.

Cook, C. B., Seifert, K. M., Hull, B. P., Hovan, M. J., Charles, J. C., Miller-Cage, V., et al. (2009). Inpatient to outpatient transfer of diabetes care: Planning for an effective hospital discharge. Endocrine Practice, 15(3), 263-269. 
Custer, M. L. (2010). Outcomes of clinical nurse specialist-initiated system-level standardized glucose management. Clinical Nurse Specialist, 24(3), 132-139. doi: 10.1097/NUR.0b013e3181d82a31 00002800-201005000-00006 [pii]

Ehrlich, S. F., Quesenberry, C. P., Jr., Van Den Eeden, S. K., Shan, J., \& Ferrara, A. (2010). Patients diagnosed with diabetes are at increased risk for asthma, chronic obstructive pulmonary disease, pulmonary fibrosis, and pneumonia but not lung cancer. Diabetes Care, 33(1), 55-60. doi: 10.2337/dc09-0880

Flanagan, D., Moore, E., Baker, S., Wright, D., and Linch, P. (2008). Diabetes care in the hospital-the impact of a dedicated inpatient care team. Diabetic Medicine, 25, 147151. Doi:10.1111/j.1464-5491.2007.02326

Frisch, A., Chandra, P., Smiley, D., Peng, L., Rizzo, M., Gatcliffe, C., et al. (2010). Prevalence and clinical outcome of hyperglycemia in the perioperative period in noncardiac surgery. Diabetes Care, 33(8), 1783-1788. Doi: dc10-0304 [pii] 10.2337/dc10-0304

Ginde, A. A., Espinola, J. A., \& Camargo, C. A., Jr. (2008). Trends and disparities in U.S. emergency department visits for hypoglycemia, 1993-2005. Diabetes Care, 31(3), 511-513. doi: dc07-1790 [pii] 10.2337/dc07-1790

International Diabetes Foundation (IDF) (2009). The world at a glance. Retrieved from at a glance website: http://www.diabetesatlas.org/sites/default/files/At\%20a\%20Glance_ 
International Diabetes Foundation (IDF) (2010). Morbidity and Mortality. Retrieved from IDF Diabetes Atlas website: http://www.diabetesatlas.org/content/diabetesmortality

Jakoby, M. G., Garey, A., Hall, M., Morris, L., Erikson, D., Wardwell, L., et al. (2008). Management of hospitalized diabetic patients by a hospital diabetes care team improves both inpatient and ambulatory glycemic control. Abstract. Carle Foundation Hospital. Urbana, IL.

Joint Commission (2011). Advanced Certification in Inpatient Diabetes Retrieved February 1,2011 , from http://www.jointcommission.org/certification/inpatient_diabetes.aspx

Kornum, J. B., Thomsen, R. W., Riis, A., Lervang, H. H., Schonheyder, H. C., \& Sorensen, H. T. (2007). Type 2 diabetes and pneumonia outcomes: a population-based cohort study. Diabetes Care, 30(9), 2251-2257. doi: 10.2337/dc06-2417.

Krinsley, J. S. (2003). Association between hyperglycemia and Increased hospital mortality in a heterogeneous population of critically ill patients. Mayo Clinic Proceedings, 78, 1471-1478.

Krinsley, J. S. (2004). Effect of an intensive glucose management protocol on the mortality of critically ill adult patients. Mayo Clinic Proceedings, 79(8), 992-1000.

Krinsley, J. S. (2008). Glycemic variability: a strong independent predictor of mortality in critically ill patients. Critical Care Medicine, 36(11), 3008-3013. doi:

10.1097/CCM.0b013e31818b38d2 
Krinsley, J. S., \& Grissler, B. (2005). Intensive glycemic management in critically ill patients. Joint Commission Journal on Quality and Patient Safety, 31(6), 308-312.

Krinsley, J. S., \& Grover, A. (2007). Severe hypoglycemia in critically ill patients: risk factors and outcomes. Critical Care Medicine, 35(10), 2262-2267. doi:

10.1097/01.CCM.0000282073.98414.4B

Krinsley, J. S., \& Preiser, J. C. (2008). Moving beyond tight glucose control to safe effective glucose control. Critical Care, 12(3), 149. doi: 10.1186/cc6889

MEDMARX Data Report: A report on the relationship of drug names and medication errors in response to the institute of medicine's call for action. (2008). In R. W. Hicks, Becker, S. C., and Cousins, D. D. (Ed.), (pp. 1-406). Rockville, MD: Center for the Advancement of Patient Safety, US Pharmacopeia.

Mertler, C. A., and Vannatta, R. A. (2010). Advanced and multivariate statistical methods (4th Ed.). Glendale, CA: Pyrczak Publishing.

Moghissi, E. (2004). Hospital management of diabetes: Beyond the sliding scale. Cleveland Clinical Journal of Medicine, 71(10), 801-808.

Moghissi, E. S., Korytkoski, M. T., DiNardo, M., et al. (2009). American Association of Clinical Endocrinologists and American Diabetes Association consensus statement on inpatient glycemic control. Endocrine Practice, 15(4), 1-17.

Mullen, B., \& Kelley, P. A. W. (2006). Diabetes nurse case management: An effective tool. Journal of the American Academy of Nurse Practitioners, 18, 22-30. 
Mundinger, M. O., Kane, R. L., Lenz, E. R., Totten, A. M., Tsai, W.-Y., Cleary, P. D., et al. (2000). Primary care outcomes in patients treated by nurse practitioners or physicians. Journal of the American Medical Association, 283(1), 59-68.

Munro, B. H. (2005). Statistical methods for health care research (5th ed.). Philadelphia: Lippincott Williams \& Wilkins.

Nathan, D. M., Kuenen, J., Borg, R., Zheng, H., Schoenfeld, D., Heine, R. (2008). Translating the A1C assay into estimated average glucose values. Diabetes Care, 31(8), 14731478. doi: $10.2337 / \mathrm{dc0}-0545$

Ofman, J. J., Badamgarav, E., Henning, J. M., Knight, K., Gano, A. D., Jr., Levan, R. K., et al. (2004). Does disease management improve clinical and economic outcomes in patients with chronic diseases? A systematic review. American Journal of Medicine, $117(3), 182-192$.

Pioro, M. H., Landefeld, C. S., Brennan, P. F., Daly, B., Fortinsky, R. H., Kim, U., et al. (2001). Outcomes-based trial of an inpatient nurse practitioner service for general medical patients. Journal of Evaluation in Clinical Practice, 7(1), 21-33. doi: jep276 [pii]

Smith, W. D., Winterstein, A. G., Johns, T., Rosenberg, E. and Sauer, B. C. (2005). Causes of hyperglycemia and hypoglycemia in adult inpatients. American Journal of HealthSystem Pharmacy, 62, 714-719.

The International Expert Committee (2009). International Expert Committee report on the role of the A1C assay in the diagnosis of diabetes. Diabetes Care, 32(7), 1-8. doi: $10.2337 / \mathrm{dc} 09-9033$ 
Turchin, A., Matheny, M. E., Shubina, M., Scanlon, J. V., Greenwood, B., \& Pendergrass, M. L. (2009). Hypoglycemia and clinical outcomes in patients with diabetes hospitalized in the general ward. Diabetes Care, 32(7), 1153-1157. doi: 32/7/1153 [pii] $10.2337 / \mathrm{dc08}-2127$

Umpierrez, G. E., Isaacs, S. D, Bazargan, N., You, X., Thaler, L. M., Kitabchi, A. E. (2002). Hyperglycemia: an independent marker of in-hospital mortality in patients with undiagnosed diabetes. The Journal of Clinical Endocrinology \& Metabolism, 87(3), 978-982.

Umpierrez, G. E., Smiley, D., Jacobs, S., Peng, L., Temponi, A., Mulligan, P., et al. (2011). Randomized study of basal-bolus insulin therapy in the inpatient management of patients with type 2 diabetes undergoing general surgery (RABBIT 2 Surgery). Diabetes Care, 34(2), 256-261. doi: 10.2337/dc10-1407

Van den Berghe, G., Wouters, P., Weekers, F., Verweast, C., et al. (2001). Intensive insulin therapy in critically ill patients. New England Journal of Medicine, 345(19), 13591369.

Vriesendorp, T. M., DeVries, J. H., van Santen, S., Moeniralam, H. S., de Jonge, E., Roos, Y. B., et al. (2006). Evaluation of short-term consequences of hypoglycemia in an intensive care unit. Critical Care Medicine, 34(11), 2714-2718. doi:

10.1097/01.CCM.0000241155.36689.91

Wexler, D. J., Nathan, D. M., Grant, R. W., Regan, S., Leuvan, A. L. V., \& Cagliero, E. (2008). Prevalence of elevated hemoglobin $\mathrm{A} 1 \mathrm{c}$ among patients admitted to the hospital 
without a diagnosis of diabetes. Journal of Clinical Endocrinology and Metabolism, 93(11), 4238-4244.

Wheeler, K., Crawford, R., McAdams, D., Benel, S., Dunbar, V. G., Caudle, J. M., et al. (2004). Inpatient to Outpatient Transfer of Care in Urban Patients With Diabetes. Archive of Internal Medicine, 164, 447-453.

Wong, F. K., Mok, M. P., Chan, T., \& Tsang, M. W. (2005). Nurse follow-up of patients with diabetes: randomized controlled trial. Journal of Advanced Nursing, 50(4), 391-402. doi: [AN3404 [pii] 10.1111/j.1365-2648.2005.03404.x 
Tables

Table 1. Exclusion \& Inclusion Criteria

\section{Inclusion}

\section{Exclusion}

- Diagnosis of Diabetes with ICD-9 codes 250.00-250.09 and 250.30-250.99

- Hyperglycemia with ICD-9 codes 249.00 249.09, 249.30-249.99, and 790.29

- Patients with complete baseline data and characteristics

- Average of 3 or more days of hospital stay

- Age 18 years \& older

- Patients with 2 or more BG values in 24 hour period 
Table 2. Measures

\begin{tabular}{|c|c|c|}
\hline Dimension & Variable & Data Source \\
\hline $\begin{array}{l}\text { Characteristics/ } \\
\text { Baseline data }\end{array}$ & $\begin{array}{l}\text { - Age } \\
\text { - } \text { Gender } \\
\text { - } \text { Athnicity } \\
\text { - Admission Diagnosis } \\
\text { - } \mathrm{A}_{1} \mathrm{C} \\
\text { - } \text { PMI } \\
\text { Practitioner managing blood glucose }\end{array}$ & $\begin{array}{l}\text { EMR } \\
\text { EMR } \\
\text { EMR } \\
\text { EMR } \\
\text { EMR } \\
\text { EMR } \\
\text { PCR } \\
\text { PCR }\end{array}$ \\
\hline $\begin{array}{l}\text { Clinical } \\
\text { Outcomes }\end{array}$ & 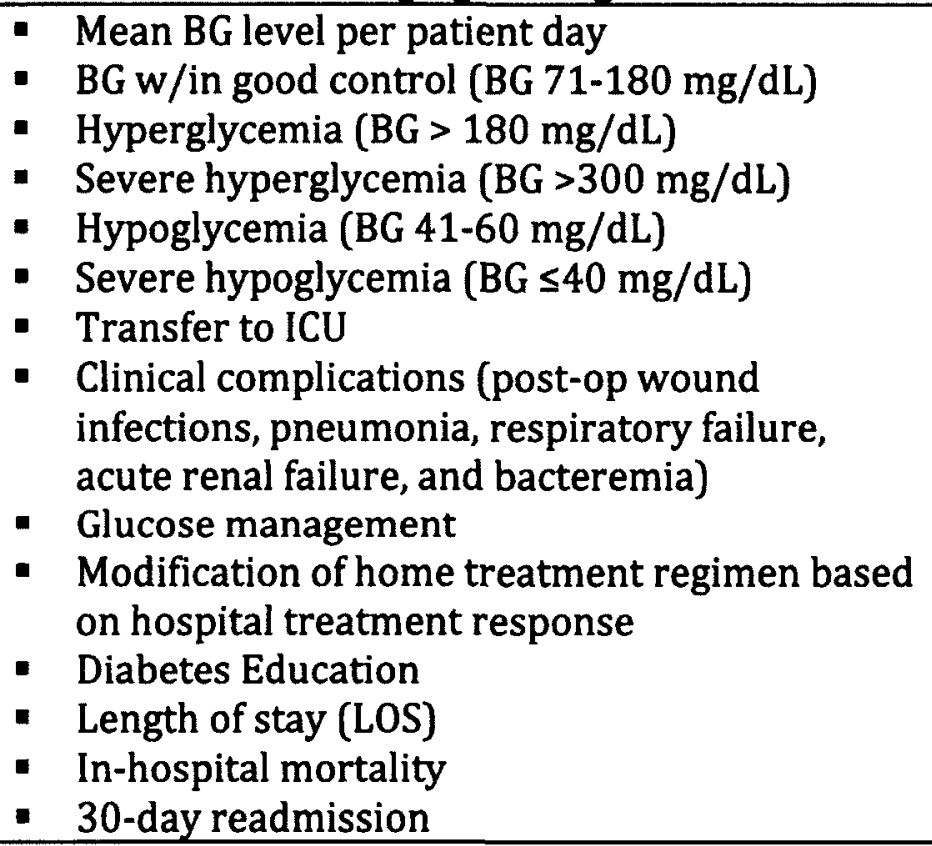 & $\begin{array}{c}\text { EMR } \\
\text { EMR } \\
\text { EMR } \\
\text { EMR } \\
\text { EMR } \\
\text { EMR } \\
\text { EMR } \\
\text { EMR/PCR } \\
\\
\text { EMR/PCR } \\
\text { PCR } \\
\text { PCR } \\
\text { EMR } \\
\text { EMR } \\
\text { EMR }\end{array}$ \\
\hline Economic Costs & $\begin{array}{l}\text { Overall hospital costs } \\
\text { - Direct costs (nursing, laboratory, \& pharmacy) }\end{array}$ & $\begin{array}{l}\text { EFR } \\
\text { EFR }\end{array}$ \\
\hline
\end{tabular}


Table 3. Research Study Members

\begin{tabular}{|c|c|c|}
\hline Study Role & Name & Title \\
\hline Primary Investigator & $\begin{array}{l}\text { Crisamar Anunciado, MSN, RN, } \\
\text { FNP-BC }\end{array}$ & $\begin{array}{l}\text { Inpatient Diabetes Nurse } \\
\text { Practitioner; PhD } \\
\text { candidate, University of } \\
\text { San Diego }\end{array}$ \\
\hline $\begin{array}{l}\text { Director of Nursing } \\
\text { Research \& Faculty, } \\
\text { University of San Diego } \\
\text { (USD) }\end{array}$ & $\begin{array}{l}\text { Cynthia D. Connelly, PhD, RN, } \\
\text { FAAN }\end{array}$ & $\begin{array}{l}\text { Dissertation Committee, } \\
\text { Chair }\end{array}$ \\
\hline $\begin{array}{l}\text { Associate Professor, } \\
\text { University of San Diego } \\
\text { (USD) }\end{array}$ & Kathy Shadle James, DNSc, APRN & $\begin{array}{l}\text { Dissertation Committee, } \\
\text { Member }\end{array}$ \\
\hline $\begin{array}{l}\text { Medical Director, Diabetes } \\
\text { Program }\end{array}$ & Georges M. Argoud, MD, FACE & Adviser/Consultant \\
\hline Chief Executive Office & Pablo Velez, PhD, RN & $\begin{array}{l}\text { Dissertation Committee, } \\
\text { Member } \\
\text { Adviser/Consultant }\end{array}$ \\
\hline $\begin{array}{l}\text { Director of Research and } \\
\text { Education }\end{array}$ & Karen Wikoff, PhD, RN & Adviser/Consultant \\
\hline Accountant & Mark Reyes & Finance Consultant \\
\hline Decision Support & $\begin{array}{l}\text { Brett MacLaren, MBA } \\
\text { Josh Fluty }\end{array}$ & $\begin{array}{l}\text { Manager, Decision } \\
\text { Support } \\
\text { Decision Support Staff }\end{array}$ \\
\hline Statistician & Dale Glaser, PhD & Statistician/Consultant \\
\hline $\begin{array}{l}\text { Director, Diabetes } \\
\text { Program for Sharp } \\
\text { Healthcare }\end{array}$ & Jacqui Thompson, RN, MS & Adviser/Consultant \\
\hline
\end{tabular}


Table 4. Statistics and Definitions

\begin{tabular}{|c|c|c|}
\hline Term & $\begin{array}{l}\text { Variable Type } \\
\text { \& Statistics }\end{array}$ & Definition \\
\hline $\begin{array}{l}\text { 30-day } \\
\text { readmission rate }\end{array}$ & $\begin{array}{l}\text { Continuous } \\
\text { ANOVA }\end{array}$ & Rate of 30 -day readmission \\
\hline $\mathbf{A}_{1} \mathbf{C}$ & $\begin{array}{l}\text { Continuous } \\
\text { ANOVA }\end{array}$ & $\begin{array}{l}\text { A glycosylated hemoglobin } A_{1} C \text { level is an average } B G \text { level over } 3 \\
\text { months. This laboratory test is obtained once on admission to the } \\
\text { hospital. It is a useful diagnostic test in managing the patient as an } \\
\text { inpatient and when deciding what diabetes regimen to send the } \\
\text { patient home with upon discharge }\end{array}$ \\
\hline Admission BG & $\begin{array}{l}\text { Continuous } \\
\text { ANOVA }\end{array}$ & $\begin{array}{l}\text { The first BG, serum glucose or POC fingerstick, obtained upon } \\
\text { admission to the hospital }\end{array}$ \\
\hline $\begin{array}{l}\text { Admission } \\
\text { Dlagnosis }\end{array}$ & $\begin{array}{l}\text { Categorical } \\
\text { ANOVA }\end{array}$ & $\begin{array}{l}\text { Admission diagnosis is the primary diagnosis listed for the } \\
\text { patient's hospital stay }\end{array}$ \\
\hline Age & $\begin{array}{l}\text { Continuous } \\
\text { ANOVA }\end{array}$ & Age during the hospital stay \\
\hline BMI & $\begin{array}{l}\text { Continuous } \\
\text { ANOVA }\end{array}$ & $\begin{array}{l}\text { Body mass index (BMI) is a measure of the patient's weight in } \\
\text { relation to his/her height. This measurement is taken once for each } \\
\text { hospital admission }\end{array}$ \\
\hline $\begin{array}{l}\text { Clinical } \\
\text { Complications }\end{array}$ & $\begin{array}{l}\text { Categorical } \\
\text { ANOVA }\end{array}$ & $\begin{array}{l}\text { Complications are limited the ICD-9 Codes below. For the purpose } \\
\text { of this study, this variable will be identified to describe the sample } \\
\text { population. } \\
\text { Postoperative wound infection - ICD-9 codes: } \\
\text { - } 998.59 \text { - other post operative infection } \\
\text { Pneumonia - ICD-9 codes: } \\
\text { - } 480 .^{*} \text { - Viral pneumonia } \\
\text { - } 481 .^{*} \text { - Pneumococcal pneumonia [streptococcus } \\
\text { pneumoniae pneumonia] } \\
\text { - } 482 .^{*} \text { - Other bacterial pneumonia } \\
\text { - } 483 .^{*} \text { - Pneumonia due to other specified organism } \\
\text { - } 484 .^{*} \text { - Pneumonia in infectious disease classified elsewhere } \\
\text { - } 485 .^{*} \text { - Bronchopneumonia organism unspecified } \\
\text { - } 486 .^{*} \text { - Pneumonia organism unspecified } \\
\text { Respiratory failure - ICD-9 codes: } \\
\text { - } 518.5 \text { - Pulmonary insufficiency following trauma and } \\
\text { surgery } \\
\text { - } 518.81 \text { - Acute respiratory failure } \\
\text { Acute renal failure - ICD-9 codes: } \\
\text { - } 584 .^{*} \text { - Acute kidney failure } \\
\text { - } 586 \text { - Renal failure unspecified } \\
\text { Bacteremia - ICD-9 codes: } \\
\text { - } 790.7 \text { - Bacteremia AND one of the following } 3: \\
\text { - } 038.0 /{ }^{*} \text {-038.9 - Septicemia } \\
\text { - } 599.0 \text { - Urinary tract infection site not specified } \\
\text { - } 999.3^{*} \text { - Other infection due to medical care not elsewhere } \\
\text { classified }\end{array}$ \\
\hline
\end{tabular}




\begin{tabular}{|c|c|c|}
\hline Term & $\begin{array}{l}\text { Variable Type } \\
\text { \& Statistics }\end{array}$ & Definition \\
\hline $\begin{array}{l}\text { Comorbid } \\
\text { Conditions }\end{array}$ & $\begin{array}{c}\text { Categorical } \\
\text { ANOVA }\end{array}$ & $\begin{array}{l}\text { Comorbid conditions are all other diagnoses listed after the } \\
\text { primary admission diagnosis specifically, end-stage renal disease } \\
\text { or chronic renal failure, congestive heart failure, depression, } \\
\text { hypertension, and hyperlipidemia. These will be identified to help } \\
\text { describe the study population }\end{array}$ \\
\hline $\begin{array}{l}\text { Diabetes } \\
\text { Education }\end{array}$ & $\begin{array}{c}\text { Categorical } \\
\text { ANOVA }\end{array}$ & $\begin{array}{l}\text { This data will be collected and documented on the spreadsheet as a } \\
\text { (0) yes or (1) no. The diabetes nurse educator who is a member of } \\
\text { the GMT usually provides diabetes education. }\end{array}$ \\
\hline Direct Costs & $\begin{array}{c}\text { Continuous } \\
\text { ANOVA }\end{array}$ & $\begin{array}{l}\text { As estimated direct cost of care will be labeled on the spreadsheet } \\
\text { as: } \\
\text { (0) Total direct cost } \\
\text { (1) Laboratory POC BG } \\
\text { (2) Nursing } \\
\text { (3) Pharmacy }\end{array}$ \\
\hline Ethnicity & $\begin{array}{l}\text { Categorical } \\
\text { Chi Square }\end{array}$ & $\begin{array}{l}\text { Ethnicity will be describe based on what is entered on the } \\
\text { electronic file upon admission }\end{array}$ \\
\hline Gender & $\begin{array}{l}\text { Categorical } \\
\text { Chi Square }\end{array}$ & $\begin{array}{l}\text { Gender will be described as: } \\
\text { (0) Male } \\
\text { (1) Female }\end{array}$ \\
\hline Glucose Control & $\begin{array}{l}\text { Categorical } \\
\text { Poisson } \\
\text { Regression } \\
\text { Modeling }\end{array}$ & $\begin{array}{l}\text { It has several categories as listed: } \\
\text { (0) } \mathrm{BG}<40 \mathrm{mg} / \mathrm{dl} \\
\text { (1) } \mathrm{BG} 41-60 \mathrm{mg} / \mathrm{dl} \\
\text { (2) } \mathrm{BG} 71-180 \mathrm{mg} / \mathrm{dl} \\
\text { (3) } \mathrm{BG} 180-299 \mathrm{mg} / \mathrm{dl} \\
\text { (4) } \mathrm{BG} \geq 300 \mathrm{mg} / \mathrm{dl} \\
\text { (5) Mean } \mathrm{BG}\end{array}$ \\
\hline $\begin{array}{l}\text { Glucose } \\
\text { Management }\end{array}$ & $\begin{array}{c}\text { Categorical } \\
\text { ANOVA }\end{array}$ & $\begin{array}{l}\text { Type of treatment used: } \\
\text { (0) Subcutaneous prandial only } \\
\text { (1) Basal-bolus } \\
\text { (2) Insulin infusion } \\
\text { (3) Oral antidiabetes drugs (OADs) only } \\
\text { (4) Combination of insulin and OADs } \\
\text { (5) None }\end{array}$ \\
\hline Good BG Control & $\begin{array}{l}\text { Categorical } \\
\text { Poisson } \\
\text { Regression } \\
\text { Modeling }\end{array}$ & $\begin{array}{l}\text { This is a category of the "Glucose Control" variable. BGs } 71-180 \text { are } \\
\text { considered within good control will be measured per patient per } \\
\text { patient day }\end{array}$ \\
\hline $\begin{array}{l}\text { Home treatment } \\
\text { modification }\end{array}$ & $\begin{array}{l}\text { Categorical } \\
\text { Chi Square }\end{array}$ & $\begin{array}{l}\text { This data will be collected and documented on the spreadsheet as a } \\
(0) \text { Yes or (1) No. Modification to home treatment regimen will be } \\
\text { collected and analyzed to observe if there is a relationship between } \\
\text { home treatment regimen modification and } A_{1} C \text { level }\end{array}$ \\
\hline
\end{tabular}




\begin{tabular}{|c|c|c|}
\hline Term & $\begin{array}{l}\text { Vuriuble Type } \\
\text { \& Statistics }\end{array}$ & Definition \\
\hline $\begin{array}{l}\text { Hyperglycemia } \\
\text { (mild to } \\
\text { moderate) }\end{array}$ & $\begin{array}{l}\text { Categorical } \\
\text { Poisson } \\
\text { Regression } \\
\text { Modeling }\end{array}$ & $\begin{array}{l}\text { This is a category of the "Glucose Control" variable. BG > } 180 \text { to } 299 \\
\text { mg/dl are considered mild to moderate hyperglycemia and will be } \\
\text { measured per patient per patient day }\end{array}$ \\
\hline $\begin{array}{l}\text { Hypoglycemia } \\
\text { (mild to } \\
\text { moderate) }\end{array}$ & $\begin{array}{l}\text { Categorical } \\
\text { Poisson } \\
\text { Regression } \\
\text { Modeling }\end{array}$ & $\begin{array}{l}\text { This is a category of the "Glucose Control" variable. This is a } \\
\text { category of the "Glucose Control" variable. BG range of } 41 \text { to } 60 \\
\mathrm{mg} / \mathrm{dl} \text { are considered mild to moderate hypoglycemia and will be } \\
\text { measured per patient per patient day }\end{array}$ \\
\hline LOS & $\begin{array}{l}\text { Continuous } \\
\text { ANOVA }\end{array}$ & Length of stay from 3 days onward \\
\hline Mean BG level & $\begin{array}{l}\text { Categorical } \\
\text { Chi Square }\end{array}$ & $\begin{array}{l}\text { This is a category of the "Glucose Control" variable. Mean BG level } \\
\text { will be obtained from all BGs within a } 24 \text {-hour period, per patient, } \\
\text { per patient day }\end{array}$ \\
\hline Mortality rate & $\begin{array}{l}\text { Continuous } \\
\text { ANOVA }\end{array}$ & Rate of in-hospital mortality \\
\hline Overall Costs & $\begin{array}{l}\text { Continuous } \\
\text { ANOVA }\end{array}$ & $\begin{array}{l}\text { An estimated overall hospital cost analyses for each patient } \\
\text { hospital stay }\end{array}$ \\
\hline $\begin{array}{l}\text { Practitioner } \\
\text { managing } \\
\text { glucose }\end{array}$ & $\begin{array}{l}\text { Categorical } \\
\text { Chi Square }\end{array}$ & $\begin{array}{l}\text { Practitioner managing the blood glucose could be a physician with } \\
\text { any type of specialty (which will be identified) or the diabetes } \\
\text { nurse practitioner (DM NP) who has been consulted by the } \\
\text { attending physician to assist in the management of the patient's } \\
\text { BGs during patients' hospital stay. This will be labeled on the } \\
\text { spreadsheet as: } \\
\text { (0) DM NP } \\
\text { (1) Physician (include specialty) }\end{array}$ \\
\hline $\begin{array}{l}\text { Severe } \\
\text { Hyperglycemia }\end{array}$ & $\begin{array}{l}\text { Categorical } \\
\text { Polychotomous } \\
\text { Logistic } \\
\text { Regression } \\
\text { Modeling } \\
\end{array}$ & $\begin{array}{l}\text { This is a category of the "Glucose Control" variable. BGs }>300 \text { are } \\
\text { considered severe hyperglycemia and will be measured per patient } \\
\text { per patient day }\end{array}$ \\
\hline $\begin{array}{l}\text { Severe } \\
\text { Hypoglycemia }\end{array}$ & $\begin{array}{l}\text { Categorical } \\
\text { Polychotomous } \\
\text { Logistic } \\
\text { Regression } \\
\text { Modeling }\end{array}$ & $\begin{array}{l}\text { This is a category of the "Glucose Control" variable. BGs }<40 \mathrm{mg} / \mathrm{dl} \\
\text { are considered severe hypoglycemia and will be measured per } \\
\text { patient per patient day }\end{array}$ \\
\hline Transfer to ICU & $\begin{array}{l}\text { Categorical } \\
\text { Chi Square }\end{array}$ & $\begin{array}{l}\text { A patient admitted to the general ward transferred to the ICU at } \\
\text { anytime time during the hospital stay. This will be collected and } \\
\text { entered on the spreadsheet as: } \\
\text { (0) Yes } \\
\text { (1) No }\end{array}$ \\
\hline
\end{tabular}


Table 5. Descriptive Statistics

The following table for the one-way ANOVA includes the descriptive statistics (i.e., mean, SD) for each group as well as the significance test result $\left(F, p\right.$-value), effect size $\left(\eta^{2}\right)$ and confidence interval around the mean difference for each of the variables.

\begin{tabular}{|l|l|l|l|l|l|l|}
\hline & GMT (IV) & $\begin{array}{c}\text { Physician } \\
\text { (IV) }\end{array}$ & F & p-value & $\eta^{2}$ & $\mathbf{9 5 \%}$ Cl \\
\hline (DVs) & Mean (SD) & Mean (SD) & & & & \\
\hline Age & & & & & & \\
\hline Gender & & & & & & \\
\hline Ethnicity & & & & & & \\
\hline Admission diagnosis & & & & & & \\
\hline Admission BG & & & & & & \\
\hline A1C & & & & & & \\
\hline BMI & & & & & & \\
\hline Practitioner managing BG & & & & & & \\
\hline Glucose management & & & & & & \\
\hline Mean BG level/patient day & & & & & & \\
\hline BG 71 - 180 mg/dL & & & & & & \\
\hline BG $180-299$ mg/dL & & & & & & \\
\hline BG $\geq 300 \mathrm{mg} / \mathrm{dL}$ & & & & & & \\
\hline BG 41 - <60 mg/dL & & & & & & \\
\hline BG $\leq 40 \mathrm{mg} / \mathrm{dL}$ & & & & & & \\
\hline Comorbid conditions & & & & & & \\
\hline Complications & & & & & & \\
\hline Transfer to ICU & & & & & & \\
\hline LOS & & & & & & \\
\hline Mortality & & & & & & \\
\hline 30-day readmission rate & & & & & & \\
\hline Overall costs & & & & & & \\
\hline Direct costs & & & & & \\
\hline Diabetes education & & & & & \\
\hline $\begin{array}{l}\text { Home treatment } \\
\text { modification }\end{array}$ & & & & & & \\
\hline
\end{tabular}


Table 6. Research Aims, Questions, \& Statistics

\section{Aims}

Characterize the study population (i.e., age, gender, ethnicity, admission diagnosis, admission BG, A1C level, BMI, co-morbid conditions) by type of care delivery.

Examine the differences in glycemic control: mean BG, good glucose control (BG $71-180 \mathrm{mg} / \mathrm{dl}$ ), incidences of mild to moderate hyperglycemia (BG 181-299 $\mathrm{mg} / \mathrm{dl}$ ), severe hyperglycemia $B G \geq 300 \mathrm{mg} / \mathrm{dl}$ ), mild to moderate hypoglycemia (BG $41-<60 \mathrm{mg} / \mathrm{dl}$ ), and severe hypoglycemia $(\leqslant 40 \mathrm{mg} / \mathrm{dl})$, by type if care delivery.

Examine which glycemic control variables predict rates of clinical outcomes (hospital complications, LOS, inpatient mortality, and 30-day readmission).

Assess the relationship of glycemic control variables with economic costs (overall hospital costs and direct costs).

Examine the differences in inpatient diabetes services provided by type of care delivery
1. Is there a difference in patient characteristics between provider groups (GMT versus physician)?

2. Is there a difference in the range of glucose control between the two provider groups?

3. Does the level of glucose control predict the rates hospital complications, LOS, inpatient mortality, and 30-day readmission?

4. Which predictors account for the variance cost of hospitalization?

5. Is there a difference in inpatient diabetes services provided (glucose management, diabetes education and changes in diabetes regimen upon discharge) by type of care delivery?
Between group differences*

One-way ANOVA

Chi-square

Between group

differences*

Mann-Whitney

Group membership *

Logistic Regression,

i.e., Poisson regression modeling

Degree of relationship*

Multiple Regression

Between group

differences*

Logistic regression

*Mertler \& Vannatta, 2010; Munro, 2005 


\section{Chapter 4: MANUSCRIPTS}

MANUSCRIPT 1

\section{UNIVERSITY OF SAN DIEGO}

Hahn School of Nursing and Health Sciences

Inpatient Glycemic Management: Relationship Among Glucose Control, Clinical Outcomes and Costs

Crisamar Javellana-Anunciado, PhD, RN, FNP-BC 


\begin{abstract}
TITLE: Inpatient Glycemic Management: Relationship Among Glucose Control, Clinical Outcomes and Costs
\end{abstract}

AUTHORS: Crisamar I. Anunciado, PhD, RN, FNP-BC

OBJECTIVE: The aim of this study is to examine the relationship between glycemic control (GC), hospital acquired complications (HAC), Charlson Comorbidity Index (CCI), ICU stay, length of stay (LOS), 30-day readmission (30DRA), care provider, and total estimated costs (TEC).

RESEARCH DESIGN AND METHODS: A retrospective cohort study of 800 patients ( $n=$ $400 \mathrm{GMT}$ and $n=400 \mathrm{MD}$ ) with diabetes or hyperglycemia admitted to a large urban community medical center located in Southern California was conducted. Descriptive statistics was used for demographic and baseline data. Mann-Whitney was used to examine the differences in Sharp BG measures by type of care delivery. Logistic regression was used to estimate the likelihood of 30DRA with covariates $\mathrm{CCI}, \mathrm{GC}, \mathrm{ICU}$ stay, HAC, and LOS. Multiple regression analysis was used to determine the accuracy of the independent variables LOS, provider group, $\mathrm{CCI}$, HAC, and GC in predicting TEC.

RESULTS: GMT patients had significant higher mean BG $190 \mathrm{mg} / \mathrm{dL}(\mathrm{SD}=41) F(1,799)$ $=4.8, p=.03, \eta^{2}=.006 ;$ and BG count $3.9(\mathrm{SD}=.44) F(1,799)=108, p=.001, \eta^{2}=.12$, than MD patients with $183 \mathrm{mg} / \mathrm{dL}(\mathrm{SD}=43) ; 3.5(\mathrm{SD}=.44)$. GMT patients had higher $\mathrm{A} 1 \mathrm{C}: 8.2,(\mathrm{SD}=2) F(1,799)=3.62, p=.057, \eta^{2}=.005$ and longer $\operatorname{LOS} 5.8$ days $(\mathrm{SD}=2.5)$ $F(1,799)=3.8, p=.053, \eta^{2}=.005$ than MD patients with $7.9 \mathrm{SD}=2.1,5.5$ days $(\mathrm{SD}=$ 
2.4). MD patients had a statistically significant higher $\mathrm{CCI}, 1.52(\mathrm{SD}=1.3)$ compared to GMT patients with $1.35(\mathrm{SD}=1.2), \mathrm{F}(1,799)=3.9, p=.048, \eta^{2}=.005$. GMT patients had statistically significant higher mean days with BGs $180-299 \mathrm{mg} / \mathrm{dL}$ (4.8 vs. 4.2 days, $p$ $=.001)$ and $B G s \geq 300 \mathrm{mg} / \mathrm{dL}(1.5$ vs. 1.1 days, $\mathrm{p}=.000$ ). Comparison of $\mathrm{BG}$ trending per day over 14 days was comparable between groups except for days 1-4 when GMT started with higher mean BGs and days 13 and 14 of hospitalization where MD group trended up and GMT continued to trend down. The likelihood of 30DRA with covariates: CCI, GC, ICU stay, HAC, and LOS did not show significant results. Increase in LOS, GMT services and having 1 or more HAC were related to increase in TEC whereas increase in $\mathrm{GC}(\geq 180 \mathrm{mg} / \mathrm{dL})$ was related to decrease in TEC.

CONCLUSIONS: GMT patients were younger; slightly more male, had higher A1C levels, higher mean BGs, lower CCI, higher LOS, higher TEC, and more BG count or BG checks. Sharp BG Measures: good glucose control (BG $70-180 \mathrm{mg} / \mathrm{dl}$ ), hypoglycemia (BG 41$<60 \mathrm{mg} / \mathrm{dl}$ ), and severe hypoglycemia $(\leq 40 \mathrm{mg} / \mathrm{dl}$ ) were comparable between groups except for hyperglycemia (BG 181-299 mg/dl) and severe hyperglycemia $B G \geq 300$ $\mathrm{mg} / \mathrm{dl}$ ), which were slightly higher for the GMT patients. Factors that might increase the likelihood of 30DRA such as higher CCI, GC, ICU stay, presence of HAC, and longer LOS were examined for association with 30DRA but showed no association. Higher TEC/costs were associated with longer LOS, GMT patients and presence of HAC. Higher in $\mathrm{GC}(\geq 180 \mathrm{mg} / \mathrm{dL})$ was related to decrease in costs. CCI had no significant association with TEC whereas LOS and HAC had significant impact on increasing TEC. Further studies should examine the factors e.g. inadequate discharge planning, poor patient compliance, lack of follow-up care, poor family/caregiver support, deterioration of 
patient condition and medical errors increasing the LOS, 30DRA rates, and costs for patients with diabetes. 


\section{Background}

Diabetes is one of the leading comorbid conditions for hospitalized patients. Notably, over the past two decades, hospital stays of patient with diabetes rose from 2.8 million in 1990 to 7.7 million in 2008 (Fraze, Jiang, \& Burgess 2010). One in every five hospital beds is occupied by a patient with diabetes (Cook et al. 2009). The estimated cost of care for these inpatients is $\$ 87$ billion, about half of the annual overall health care expenditure for diabetes (ADA 2008). Patients with diabetes, with or without diabetes-related comorbidity, have complex needs requiring extensive and costly healthcare resources (Struijs et al 2006).

Extant studies, both observational and randomized controlled trials, indicate inpatient hyperglycemia, with or without a history of diabetes, results in poor patient outcomes (ADA 2012). An estimated one-third of patients will experience significant hyperglycemia during hospitalization (Levetan et al 1998). Hyperglycemia in critical care increases morbidity, mortality, and length of stay (LOS) and was associated with increased mortality and complications in the general medical/surgical units (Kornum et al 2007; Krinsley 2004; Umpierrez et al 2002). Intensive glucose control in surgical care was related with decreased mortality, sepsis, low cardiac output syndrome, blood transfusion, pneumonia, stroke and LOS (Frisch et al 2010; Furnary et al 2003; Furnary \& Wu, 2006; Umpierrez et al., 2011) and decreased mortality, morbidity, sepsis, dialysis blood transfusion, polyneuropathy, LOS in the critical care (Krinsley 2004; Van den Berghe et al., 2001, 2006). 
On the opposite end of the spectrum, 34 per 1000 hospital admissions are related to hypoglycemia (Ginde et al 2008). Severe hypoglycemia of $B G<40 \mathrm{mg} / \mathrm{dL}$ is defined in many studies although this is lower than the threshold wherein cognitive impairment occurs in normal individuals at $\mathrm{BG}<50 \mathrm{mg} / \mathrm{dL}$ (ADA 2012; Schnipper et all 2008; Umpierrez et al 2012). Hypoglycemia resulting from illness, alterations in nutrition, medications, and aggressive glucose control (Brunkhorst et al 2008; Moghissi et al., 2009; Van den Berghe et al., 2001, 2006; Vriesendorp et al., 2006) increases the risk for deleterious effects (e.g. seizures, coma, increased LOS) and likelihood of death (Turchin et al., 2009).

Wide glucose variability (GV) including hyperglycemia and hypoglycemia are extremely unsafe for inpatients and are strong predictors of mortality (ADA, 2012; Krinsley, 2008; Moghissi et al 2009). Controlling GV can be challenging due to acute illness, inconsistent nutrition intake, medication changes, and timing of BG monitoring with insulin administration. It is important to avoid $\mathrm{GV}(\mathrm{BG}<70 \mathrm{mg} / \mathrm{dL}$ and $\mathrm{BG}>180$ $\mathrm{mg} / \mathrm{dL}$ ) by making inpatient glycemic management (IGM) an integral part of inpatient care (ADA 2012; Moghissi et al., 2009; Umpierrez et al., 2012).

In the last decade, various approaches to achieving inpatient glucose control (IGC) were implemented at several institutions in the U.S. and abroad. However, despite all these efforts, IGC remains suboptimal (Boord et al., 2009). One major reason deterring success of IGC is its' complexity - requiring considerable effort in training and coordination staff and hospital resources (ADA 2012; Umpierrez et al., 2012). Implementation of a coordinated team approach such as a glycemic management teams (GMT) showed improved IGC, decreased length of stay, and improved post discharge 
A1C levels (Flanagan et al., 2008; Jakoby et al., 2008). Agencies such as the American Diabetes Association (ADA), American Association of Clinical Endocrinologists (AACE), and the Society of Hospital Medicine (SHM) endorsed the use of team approach to IGM. While there is empirical support for the benefits of intensive IGM using a team approach, there is limited research on clinical outcomes comparing a team approach such as a GMT to current traditional management by physicians (MD) alone.

The aim of this study is to examine the relationship between glycemic control (GC), hospital acquired complications (HAC), Charlson Comorbidity Index (CCI), ICU stay, length of stay (LOS), 30-day readmission (30DRA), care provider, and total estimated costs (TEC).

Research Design and Methods

A retrospective cohort design was used for this study. Participants were selected from patients with diabetes or hyperglycemia $(\mathrm{N}=7914)$ receiving services from large urban community medical center located in Southern California and admitted between January 2008 and December 2009 to the acute and critical care settings; of these, 1000 were randomly selected per year. Eight hundred patients met inclusion criteria: diagnosis of diabetes with ICD-9 codes 250.00-250.09 and 250.30-250.99; hyperglycemia with ICD-9 codes 249.00-249.09, 249.30-249.99, and 790.29; average of 3 or more days of hospital stay; age 18 years \& older; patients with 2 or more BG values in 24 hour period, and identified care provider group. Exclusion criteria were: admission to sub-acute and long-term care facilities; diagnoses of diabetes ketoacidosis or hyperosmolar hyperglycemic syndrome; and LOS > 14 days. Data for the analyses 
were abstracted from electronic medical records and paper charts. Precautions were taken to protect patient privacy in accordance with the Health Insurance Portability and Accountability Act (HIPAA). All study procedures were reviewed and approved by appropriate institutional review boards and administrators. No actual patient contact involving any risk occurred since data was collected retrospectively.

Measures

The GMT and MD performed inpatient glucose management (IGM) using the intravenous insulin order set (IOS) in critical care (Figure 1) or the basal-bolus subcutaneous insulin order set (SIOS) in critical care and general medical/surgical units (Figure 2). Diabetes care was individualized based on the patient's unique needs (nutrition status, medications affecting glucose metabolism, corticosteroid use, and individual insulin requirements). The BG goal for SIOS was $<110 \mathrm{mg} / \mathrm{dL}$ to a maximum of $180 \mathrm{mg} / \mathrm{dL}$, whereas IOS goal was $80 \mathrm{mg} / \mathrm{dL}$ to $150 \mathrm{mg} / \mathrm{dL}$. For the purpose of this study, Sharp BG measures were defined as severe hypoglycemia $<40 \mathrm{mg} / \mathrm{dL}$, hypoglycemia $<60 \mathrm{mg} / \mathrm{dL}$, good control $71 \mathrm{mg} / \mathrm{dL}$ to $180 \mathrm{mg} / \mathrm{dL}$, hyperglycemia 180 $\mathrm{mg} / \mathrm{dL}$, and severe hyperglycemia $>300 \mathrm{mg} / \mathrm{dL}$. Glucose control (GC) was categorized into two levels: mean BG that achieved goal of $<180 \mathrm{mg} / \mathrm{dL}$ and those that did not achieve goal $\geq 180 \mathrm{mg} / \mathrm{dL}$ during the hospital stay. 
Figure 1. IOS

STARP Oubline

Intravenous Insulin Order Set (KOS)

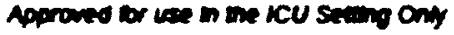

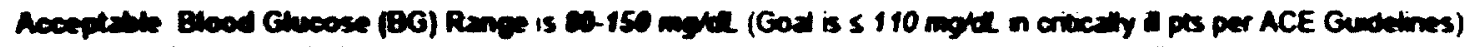

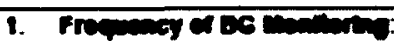

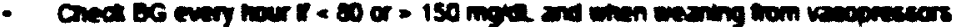

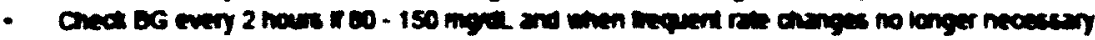

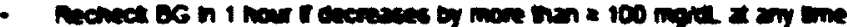

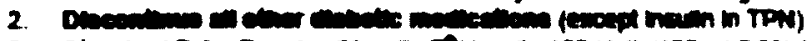

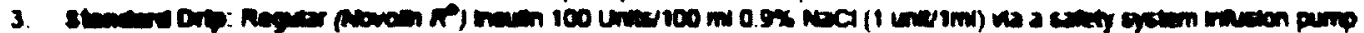

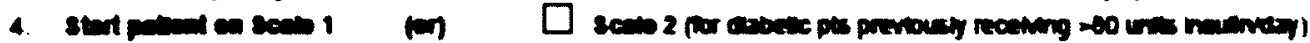

\begin{tabular}{|c|c|c|c|c|c|c|c|}
\hline \multicolumn{8}{|c|}{ 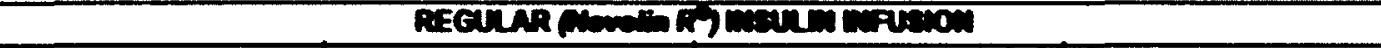 } \\
\hline \multicolumn{2}{|c|}{81} & \multicolumn{2}{|c|}{2} & \multicolumn{2}{|c|}{28} & \multicolumn{2}{|c|}{26} \\
\hline \multicolumn{8}{|c|}{ 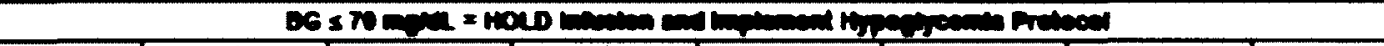 } \\
\hline 5 & 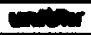 & $\infty$ & $\infty$ & $\infty$ & 0 & $\infty$ & 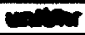 \\
\hline$n-\pi$ & O & $\pi-n$ & On & $71-7$ & On & $72-7$ & an \\
\hline 010 & On & $0-\infty$ & C & $2 \sqrt{0}$ & 0.5 & $\theta-n$ & 0.5 \\
\hline 10-1n & O & 1014 & 0.5 & $110-10$ & 1 & $110-110$ & 1 \\
\hline $120-10$ & 0.5 & $12-10$ & 1 & $18-10$ & 1.5 & then & 2 \\
\hline $15-17$ & 1 & $100-17$ & 1.5 & IS-In & 2 & EAth & 3 \\
\hline $10 x$ & 1.5 & 100 & 2 & rosen & 3 & 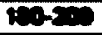 & 4 \\
\hline 2002 & 1.5 & $2+20$ & 25 & 21025 & 4 & 21025 & 6 \\
\hline 202 & $\overline{2}$ & 2020 & 3 & 2028 & 6 & $20-20$ & 8 \\
\hline 27029 & 2 & $2 \pi-20$ & 4 & $2 \pi-20$ & 8 & $2 n-20$ & 10 \\
\hline 300 & 25 & 305 & 5 & 300 & 10 & $3 \operatorname{sen}$ & 14 \\
\hline $350-30$ & 3 & 35050 & 6 & $36-30$ & 12 & 3025 & 16 \\
\hline-5 & 3.5 & -30 & 7 & 25 & 14 & 3 & 18 \\
\hline
\end{tabular}

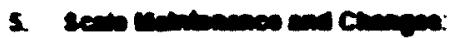

\begin{tabular}{|c|c|c|c|c|c|}
\hline & & & שصחת & תח & \\
\hline 4 & 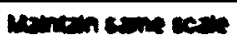 & 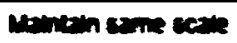 & Nowe conn one case & Nove ann ore ceore & $<$ \\
\hline $6-10$ & 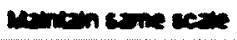 & 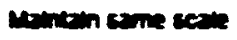 & Minth some ceols & Move comn one were & 5.10 \\
\hline$=10$ & Nove ap one bets & Nove up one cerse & 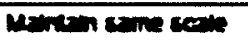 & 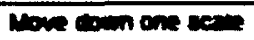 & -10 \\
\hline
\end{tabular}

c. matrot.
- $86 \leq 70 \operatorname{mog}$ or $=360 \mathrm{mga}$

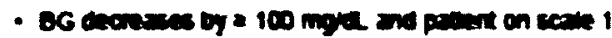

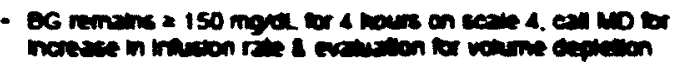

7. $800 \times r \min$

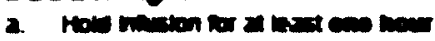

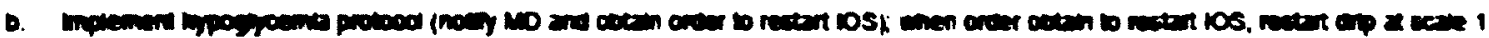

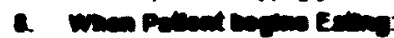

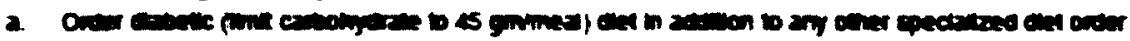

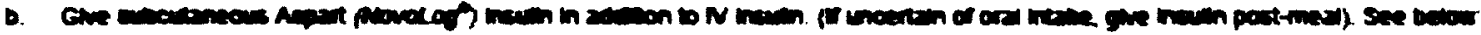

\begin{tabular}{|c|c|c|}
\hline 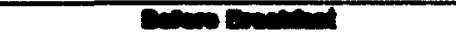 & Dem In & 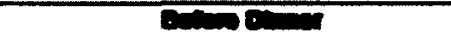 \\
\hline 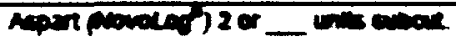 & 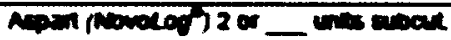 & 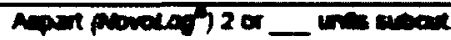 \\
\hline
\end{tabular}

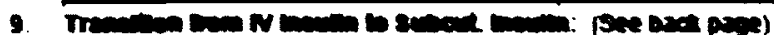

N

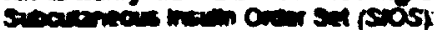

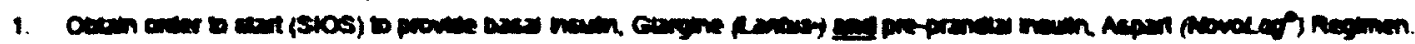

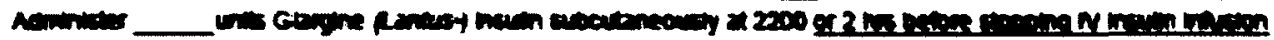

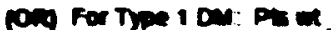
9x02 uns -

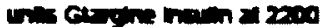

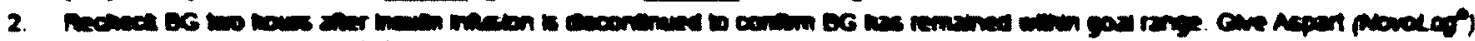

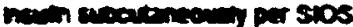


Figure 2. SIOS

QTAPT Chula Vure Medical Cenuer

Subcuteneous Masulin Orders (SHOS)

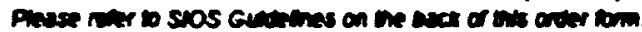

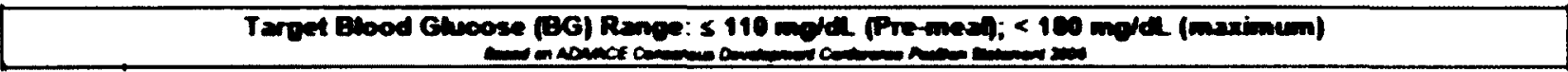

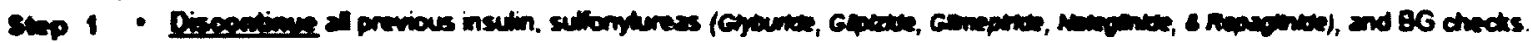

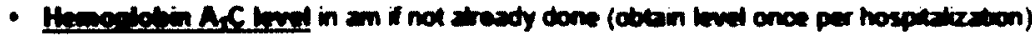

$\operatorname{map}_{2}$ Chost PG upon adrisaion and

\begin{tabular}{|c|c|c|}
\hline 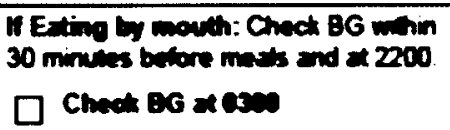 & 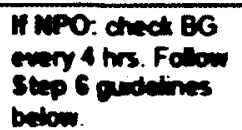 & 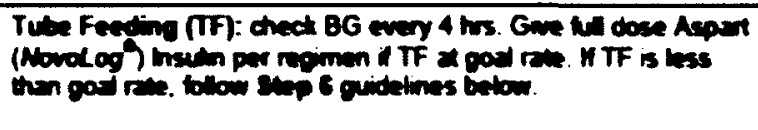 \\
\hline$\square \quad$ a & & 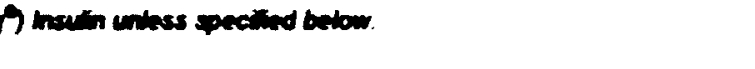 \\
\hline
\end{tabular}

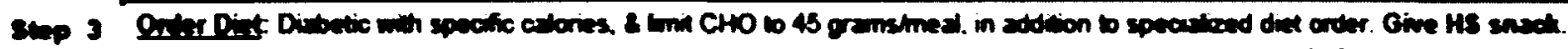

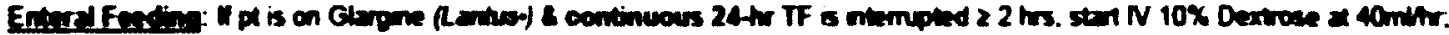

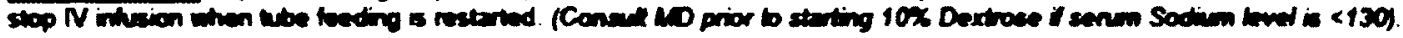

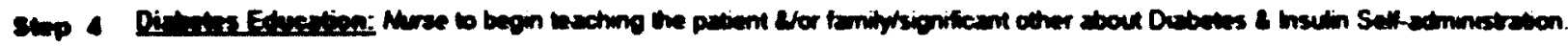

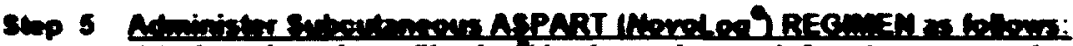

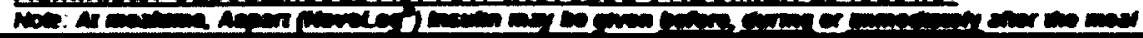

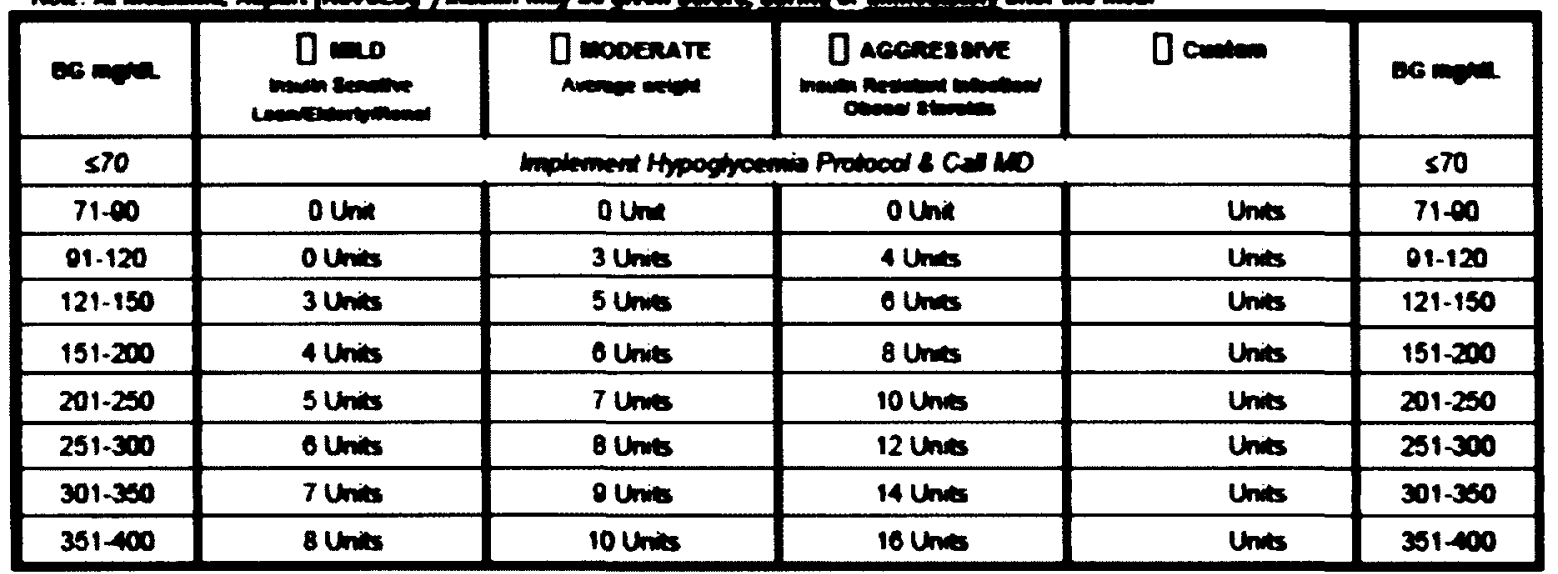

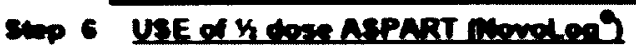

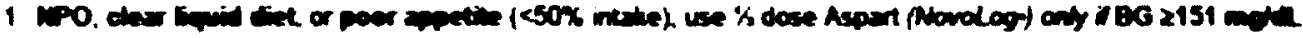

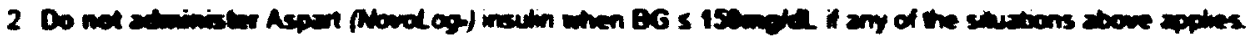

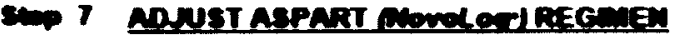

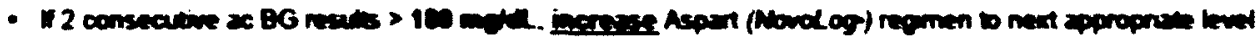

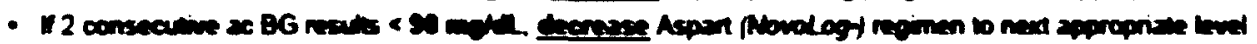

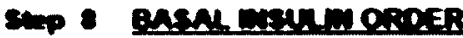

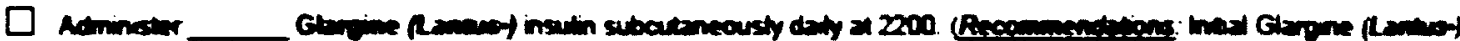

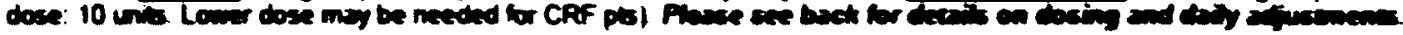

$\operatorname{stap} 9$ motrey

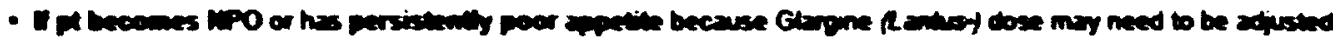

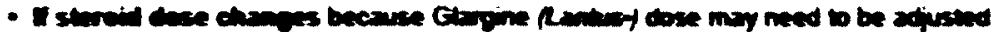

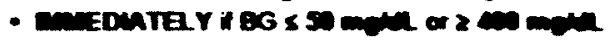

- in All or next MD Rounds i BG s 70 mera or or 2391 merce or

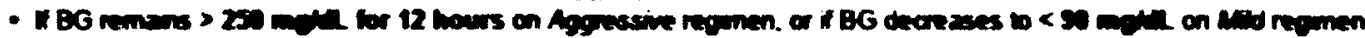


The MDs represented a variety of specialties: internists $(55 \%, n=220)$, hospitalists $(15 \%, n=60)$, pulmonologists $(11.5 \%, n=46)$, nephrologists $(10 \%, n=40)$, cardiologists $(4 \%, n=15)$, endocrinologists $(1.5 \%, n=6)$, and other $(3 \%, n=13)$. Although the attending MDs retained responsibility for BG management for most patients with hyperglycemia, they referred patients with complex insulin needs and difficult to control BGs to GMT for IGC.

GMT was comprised of nurse practitioners (NP) and diabetes nurse educators under the supervision of the diabetes medical director and with the collaboration of attending physicians. Once the attending physician referred a patient to the GMT, the NPs assume 24-hour responsibility for IGM, which entails not only IGC but also assessing the need for inpatient diabetes education, reconciling diabetes medication list to ensure accuracy, referring to outpatient diabetes education or endocrinology followup, and providing clear written instructions on diabetes treatment regimen modifications as needed. The diabetes nurse educator provides patients with diabetes survival skills, basic education, supplies (i.e. log books, handouts, glucose meter), resources (i.e., outpatient free clinics, support groups, classes), and referral to outpatient diabetes education/case management. Other measures are defined in Table 1. 
Table 1. Measures with Definition

\begin{tabular}{|c|c|}
\hline $\mathrm{A} 1 \mathrm{C}$ & $\begin{array}{l}\text { Glycosylated hemoglobin is a form of hemoglobin that is measured to identify the average plasma } \\
\text { glucose concentration over } 120 \text { days. Normal A1C is } 4-6 \% \text {. A1C of } 5.7-6.4 \% \text { is prediabetes. An A1C of } \\
>6.5 \% \text { is diabetes (Nathan et al 2008; ADA, 2012). }\end{array}$ \\
\hline $\begin{array}{l}\text { Charlson } \\
\text { Comorbidity } \\
\text { Index }\end{array}$ & $\begin{array}{l}\text { Abbreviated as CCI. This was originally developed in } 1984 \text {. It contained } 17 \text { categories of comorbidity, } \\
\text { originally based on ICD-9-CM diagnoses and procedure codes, and their associated weights that } \\
\text { provide an overall comorbidity score to reflect the cumulative increased likelihood of one-year } \\
\text { mortality. The score ranges from } 1-5 \text { with increase risk of death with increase in score. The index has } \\
\text { been updated in } 2011 \text { for use with ICD-10 coding. The updated weight for certain diagnoses and the } \\
\text { categories narrowed down to } 12 \text { comorbidities (Quan, et al., 2011). }\end{array}$ \\
\hline $\begin{array}{l}\text { Hospital- } \\
\text { acquired } \\
\text { Complications }\end{array}$ & $\begin{array}{l}\text { Abbreviated as } \mathrm{HAC} \text {. This includes postoperative wound infection, pneumonia, respiratory failure, } \\
\text { acute renal failure and bacteremia. }\end{array}$ \\
\hline $\begin{array}{l}\text { Patient } \\
\text { characteristics }\end{array}$ & $\begin{array}{l}\text { Includes age, gender, race/ethnicity, admission BG, A1C, BMI, mean BG, BG count, admission diagnosis } \\
\text { by medical diagnosis category (MDC), discharge disposition, Charlson comorbidity index, length of stay } \\
\text { (LOS), and 30-day readmission rate. }\end{array}$ \\
\hline $\begin{array}{l}\text { Sharp BG } \\
\text { Measures }\end{array}$ & 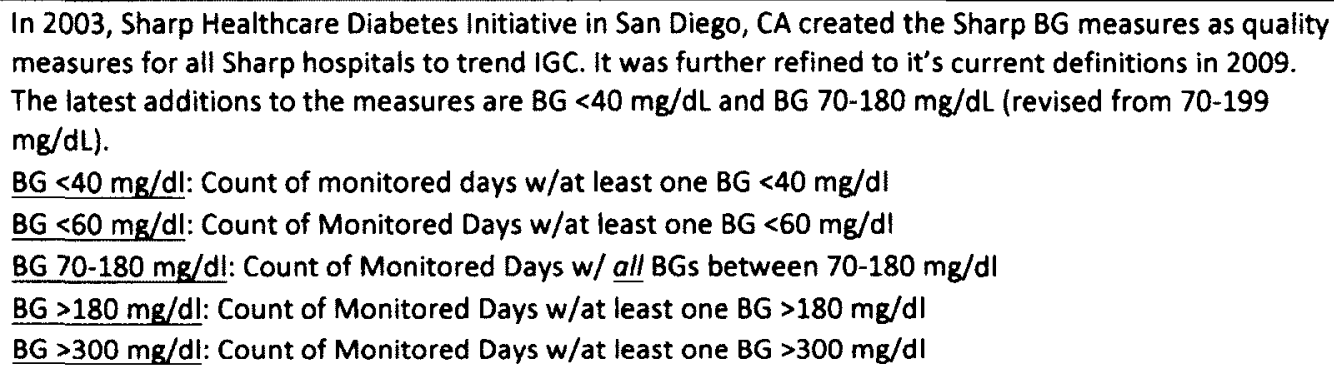 \\
\hline
\end{tabular}

\section{Statistical Analysis}

Sample size for the analyses is 800 , which is sufficient to detect a moderate standardized effect size $(d=0.32)$ using a two-tailed significance test with a power of .80, and a significance level of .05 (Cohen 1988). Data was analyzed using the SPSS 19 (IBM, 2010). Descriptive and multivariate statistics was used for data analysis. Descriptive statistics was used for demographic and baseline data. Mann-Whitney was used to examine the differences in Sharp BG measures by type of care delivery. Logistic regression was used to estimate the likelihood of 30DRA with covariates: CCI, GC, ICU stay, HAC, and LOS. Multiple regression analysis was used to determine the accuracy of the independent variables LOS, provider group, $\mathrm{CCI}, \mathrm{HAC}$, and $\mathrm{GC}$ in predicting TEC. A $p$ value of $<0.05$ was considered significant. 


\section{Results}

The sample was fairly evenly distributed by gender with slightly more females $(53 \%, n=422)$ than males. The sample was diverse with almost half Latino $(48 \%, n=$ $382)$, White $(18 \%, n=146)$, Asian $(8 \%, n=64)$, Black $(6 \%, n=44)$, and other $(21 \%, n=$ 164), and is representative of the city's racial breakdown as reported in the 2010 census (US Census, 2010). Age ranged from 20 to $99(M=66, s d=14.8$; median $=69)$. Average body mass index $(\mathrm{BMI})$ was $30.6(\mathrm{sd}=8.2$; median $=29)$, with most patients either overweight or obese. The most frequent diagnoses for admission were circulatory $26 \%(n=209)$; respiratory system $11 \%(n=89)$, kidney/urinary tract system $10.4 \%(n=83)$, nervous system $8.5 \%(n=68)$, and musculoskeletal/connective tissue $7.8 \%(n=62)$. Patients were admitted with $B G$ ranged from $32 \mathrm{mg} / \mathrm{dL}$ to 789 $\mathrm{mg} / \mathrm{dL}(\mathrm{M}=221, \mathrm{sd}=111 ;$ median $=198)$. Service providers were equally distributed $(400=\mathrm{GMT}, 400=\mathrm{MD})$ See Table 2 for details. 
Table 2. Patient Profile

\begin{tabular}{|c|c|c|c|c|c|c|}
\hline & $\begin{array}{l}\text { Overall } \\
n=800\end{array}$ & $\begin{array}{c}\text { GMT } \\
n=400\end{array}$ & $\begin{array}{c}\text { MD } \\
n=400\end{array}$ & $F(d f)$ & $x^{2}(d f)$ & $p$ \\
\hline Age - Mean (SD) & $66(14.8)$ & $64.5(14.7)$ & $67.7(14.6)$ & $9.36(1,798)$ & & .002 \\
\hline Gender - Percent (Count) & & & & & & .01 \\
\hline Female & $53 \%(422)$ & $46 \%(194)$ & $53 \%(228)$ & & $5.79(1)$ & \\
\hline Male & $47 \%(388)$ & $54.5 \%(206)$ & $46 \%(172)$ & & & \\
\hline Ethnicity - Percent (Count) & & & & & $4.3(4)$ & .36 \\
\hline Asian & $8 \%(64)$ & $6 \%(26)$ & $9 \%(38)$ & & & \\
\hline Black & $6 \%(44)$ & $5 \%(19)$ & $6 \%(25)$ & & & \\
\hline Hispanic & $48 \%(382)$ & $48 \%(192)$ & $48 \%(190)$ & & & \\
\hline White & $18 \%(146)$ & $19 \%(74)$ & $18 \%(72)$ & & & \\
\hline Other & $20 \%(164)$ & $22 \%(89)$ & $19 \%(75)$ & & & \\
\hline$A_{1} C-\operatorname{Mean}(S D)$ & $8 \%(2.08)$ & $8.2 \%(2)$ & $7.9 \%(2.1)$ & $3.62(1,798)$ & & .057 \\
\hline BMI - Mean (SD) & $30.6(8.3)$ & $30.9(8.3)$ & $30.2(8.3)$ & $1.46(1,798)$ & & .228 \\
\hline Admission BG - Mean (SD) & $221(110.8)$ & $226(118.4)$ & $216(102.5)$ & 1.77 & & .184 \\
\hline Mean BG level (mg/dL) - Mean (SD) & $186(42)$ & $190(41)$ & $183(43)$ & $4.8(1,798)$ & & .03 \\
\hline Last Day BG $(\mathrm{mg} / \mathrm{dL})$ - Mean (SD) & $164(48.6)$ & $164(46.8)$ & $164(50.4)$ & $.034(1,798)$ & & .854 \\
\hline BG Count (Lab/POC) & $3.7(.47)$ & $3.9(.44)$ & $3.5(.44)$ & $108.6(1,798)$ & & .000 \\
\hline $\begin{array}{l}\text { Medical Diagnostic Groups (MDC) - } \\
\text { Percent (Count) }\end{array}$ & & & & & 16.37 & .693 \\
\hline Circulatory System & $26.1 \%(209)$ & $28.8 \%(115)$ & $23.5 \%(94)$ & & & \\
\hline Respiratory System & $11.1 \%(89)$ & $11.5 \%(46)$ & $10.8 \%(43)$ & & & \\
\hline Kidney/Urinary tract & $10.4 \%(83)$ & $8.8 \%(35)$ & $12 \%(48)$ & & & \\
\hline Nervous System & $8.5 \%(68)$ & $9.3 \%(37)$ & $7.8 \%(31)$ & & & \\
\hline Musculoskeletal/ & $7.8 \%(62)$ & $7.5 \%(30)$ & $8 \%(32)$ & & & \\
\hline \multicolumn{7}{|l|}{ Connective Tissue } \\
\hline Digestive System & $6.9 \%(55)$ & $7 \%(28)$ & $6.8 \%(27)$ & & & \\
\hline Infectious and Parasitic & $6.1 \%(49)$ & $5 \%(20)$ & $7.3 \%(29)$ & & & \\
\hline \multicolumn{7}{|l|}{ Metabolic System } \\
\hline Hepatobiliary System \& Pancreas & $5.6 \%(45)$ & $6.5 \%(26)$ & $4.8 \%(19)$ & & & \\
\hline Skin, Subcutaneous Tissue \& & $5.3 \%(42)$ & $3.8 \%(15)$ & $6.8 \%(27)$ & & & \\
\hline \multicolumn{7}{|l|}{ Breast } \\
\hline Other & $6.3 \%(51)$ & $6.5 \%(26)$ & $6.25 \%(25)$ & & & \\
\hline
\end{tabular}

One-way ANOVA showed GMT providers provided care to patients with a statistically significant higher mean BG $190 \mathrm{mg} / \mathrm{dL}(\mathrm{SD}=41) F(1,799)=4.8, p=.03$, $\eta^{2}=.006 ;$ and BG count $3.9(\mathrm{SD}=.44) F(1,799)=108, p=.001, \eta^{2}=.12$, than patients followed by the MD $183 \mathrm{mg} / \mathrm{dL}(\mathrm{SD}=43) ; 3.5(\mathrm{SD}=.44)$, respectively. There was a trend for GMT patients to have higher admission $\mathrm{A} 1 \mathrm{C}: 8.2,(\mathrm{SD}=2) F(1,799)=3.62, p$ $=.057, \eta^{2}=.005$ and stay longer in the hospital at 5.8 days $(\mathrm{SD}=2.5) F(1,799)=3.8, p$ $=.053, \eta^{2}=.005$ than those followed by MDs with $7.9 \mathrm{SD}=2.1,5.5$ days $(\mathrm{SD}=2.4) . \mathrm{MD}$ 
patients had a statistically significant higher $\mathrm{CCl}, 1.52(\mathrm{SD}=1.3)$ compared to GMT patients with $1.35(\mathrm{SD}=1.2), \mathrm{F}(1,799)=3.9, p=.048, \eta^{2}=.005$.

The institution used Sharp BG Measures to report hospital-wide BG control (Refer to Table 1 for details). GMT patients had statistically significant higher mean days with BGs $180-299 \mathrm{mg} / \mathrm{dL}$ (4.8 vs. 4.2 days, $p=.001$ ) and BGs $\geq 300 \mathrm{mg} / \mathrm{dL}$ (1.5 vs. 1.1 days, $p=.000$ ). See Table 3 for comparison.

Table 3. Sharp BG Measures: Glucose Control By Count of Days

\begin{tabular}{|lcccccc|}
\hline Measure & Overall & GMT & MD & $F(d f)$ & $n^{2}$ & $p$ value \\
& $n=800$ & $n=400$ & $n=400$ & & & \\
Good Control $71-180 \mathrm{mg} / \mathrm{dL}$ (SD) & $1.5(2)$ & $1.4(2)$ & $1.6(2)$ & $1.4(1,798)$ & .002 & .237 \\
Hyperglycemia $180-299 \mathrm{mg} / \mathrm{dL}$ (SD) & $4.51(2.25)$ & $4.8(2.3)$ & $4.2(2.2)$ & $11.2(1,798)$ & .014 & .001 \\
Severe Hyperglycemia $\geq 300 \mathrm{mg} / \mathrm{dL}$ (SD) & $1.29(1.58)$ & $1.5(1.7)$ & $1.1(1.4)$ & $12.7(1,798)$ & .016 & .000 \\
Hypoglycemia 41-60 mg/dL (SD) & $.21(0.56)$ & $.23(0.56)$ & $.19(.55)$ & $1.03(1,798)$ & .001 & .310 \\
Severe Hypoglycemia $\leq 40 \mathrm{mg} / \mathrm{dL}$ (SD) & $.05(0.26)$ & $.06(0.31)$ & $.04(0.20)$ & $2.28(1,798)$ & .003 & .131 \\
\hline
\end{tabular}

Comparison of BG trending per day over 14 days was almost comparable between groups (Figure 3) except for days 1-4 where GMT patients started with higher mean BGs and days 13 and 14 of hospitalization where MD patients trended up and GMT continued to trend down.

Figure 3. 14-Day BG Graph Comparison

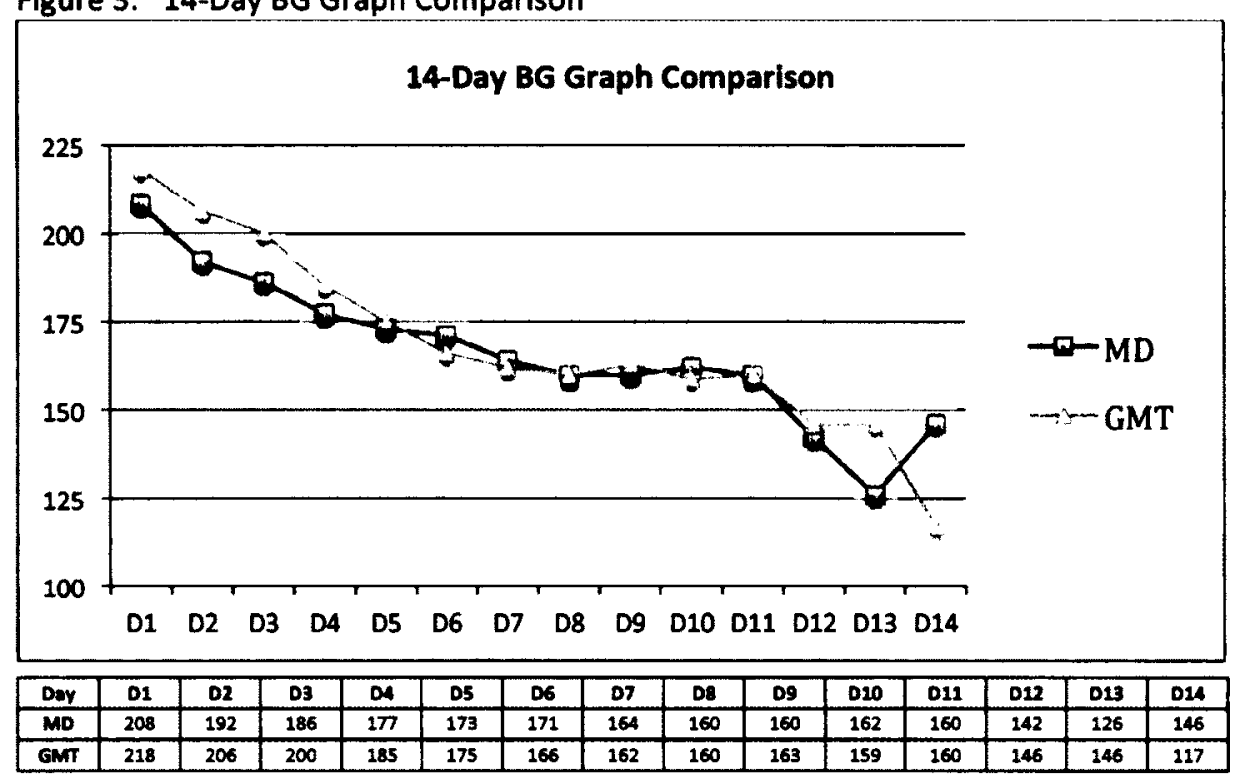


Chi-square analysis (Table 4) indicated associations of HAC, ICU stay, GC, and 30DRA. One-way ANOVA evaluated differences in LOS and CCI between provider groups. Significant findings showed GMT patients had more BGs $\geq 180 \mathrm{mg} / \mathrm{dL}$, longer LOS, higher estimated costs, and lower CCI than MD patients.

Table 4. Associations of HAC, ICU stay, GC, CCI, LOS, and 30DRA

\begin{tabular}{|c|c|c|c|c|c|}
\hline & $\begin{array}{l}\text { Overall } \\
n=800\end{array}$ & $\begin{array}{c}\text { GMT } \\
n=400\end{array}$ & $\begin{array}{c}\text { MD } \\
n=400\end{array}$ & $x^{2}(d f)$ & $\boldsymbol{p}$ \\
\hline $\begin{array}{l}\text { Hospital-acquired Complications (yes) } \\
\text { - Percent (Count) }\end{array}$ & $5 \%(40)$ & $5.5 \%(22)$ & $4.5 \%(18)$ & $.421(1)$ & .516 \\
\hline ICU Stay - Percent (Count) & & & & $2.55(2)$ & .280 \\
\hline No ICU Stay & $87 \%(699)$ & $87 \%(349)$ & $88 \%(350)$ & & \\
\hline$<4$ days ICU Stay & $11 \%(85)$ & $10 \%(40)$ & $11 \%(45)$ & & \\
\hline$\geq 4$ days ICU Stay & $2 \%(16)$ & $3 \%(11)$ & $1 \%(5)$ & & \\
\hline Glucose control (Count) & & & & $6.85(1)$ & .009 \\
\hline $\mathrm{BGs}<180 \mathrm{mg} / \mathrm{dL}$ & $49 \%(393)$ & $44 \%(178)$ & $54 \%(215)$ & & \\
\hline $\mathrm{BGs} \geq 180 \mathrm{mg} / \mathrm{dL}$ & $51 \%(407)$ & $56 \%(222)$ & $46 \%(185)$ & & \\
\hline 30-day Readmission (yes) - Percent (Count) & $16 \%(130)$ & $18 \%(73)$ & $14 \%(57)$ & $2.35(1)$ & .125 \\
\hline $\begin{array}{l}\text { Charlson Comorbidity Index (2011) } \\
\text { - Mean (SD) }\end{array}$ & $1.43(1.2)$ & $1.35(1.2)$ & $1.52(1.2)$ & & .048 \\
\hline LOS - Mean (SD) & $5.67(2.45)$ & $5.8(2.5)$ & $5.5(2.4)$ & & 0.53 \\
\hline Estimated Costs (\$) (SD) & $\begin{array}{c}8334.45 \\
(5393.86)\end{array}$ & $\begin{array}{c}8863.15 \\
(6021.35)\end{array}$ & $\begin{array}{l}7805.75 \\
(4630.68)\end{array}$ & & .005 \\
\hline
\end{tabular}

Logistic regression was used to estimate the likelihood of 30DRA with covariates: $\mathrm{CCI}, \mathrm{GC}, \mathrm{ICU}$ stay, $\mathrm{HAC}$, and LOS. As shown in Table 5 the overall predictive model for 30DRA was statistically significant (likelihood ratio chi-square $=12.343(5), p$ $=.030)$. Hosmer-Lemeshow test indicated the model was a good fit for the data $\chi^{2}=$ $9.68(8), .288$. The classification result indicated high success wherein it classified $84 \%$ of the cases. The overall effect size was small with Nagelkerke $R$ square of .026 . None of the predictor variables were significantly related to the likelihood of 30DRA. 
Table 5. Logistic Regression Results Predicting the Probability of 30-day Readmission ( $n=800$ )

\begin{tabular}{|c|c|c|c|c|c|c|c|}
\hline \multirow[t]{2}{*}{ Predictor } & \multirow[t]{2}{*}{$B$} & \multirow[t]{2}{*}{ Wald } & \multirow[t]{2}{*}{$d f$} & \multirow{2}{*}{$\begin{array}{l}\text { Odds } \\
\text { Ratio }\end{array}$} & \multicolumn{2}{|c|}{$95 \%$ Confidence Interval } & \multirow[t]{2}{*}{$\bar{p}$} \\
\hline & & & & & Lower & Upper & \\
\hline Charlson Comorbidity Index & .126 & 2.98 & 1 & 1.14 & .98 & 1.31 & .085 \\
\hline Glucose Control & .133 & .46 & 1 & 1.14 & .78 & 1.68 & .497 \\
\hline ICU Stay & .254 & 1.34 & 1 & 1.29 & .84 & 1.98 & .248 \\
\hline Hospital-acquired Complication & -.287 & .52 & 1 & .75 & .34 & 1.64 & .472 \\
\hline Length of Stay & .069 & 2.99 & 1 & 1.07 & .99 & 116 & 084 \\
\hline
\end{tabular}

Model (likelihood ratio) chi-square $=12.34(5), p=.030$

Percent correctly classified $=84 \%$

Nagelkerke $R^{2}=.026$

Simultaneous multiple regression was used to determine the accuracy of the independent variables LOS, provider group, $\mathrm{CCI}, \mathrm{HAC}$, and GC in predicting TEC. This standard multiple regression strategy was appropriate because all independent variables are viewed as having equal importance, there were no apriori hypotheses, and regression diagnostic procedures did not detect problems with multicollinearity among the predictor variables. All tolerance values were $<0.99$. Regression results indicate the overall model accounts for $53 \%$ of the variance and significantly predicts TEC: $\mathrm{R}^{2}=$ $.529, \mathrm{R}^{2}$ adj $=.527, \mathrm{~F}(5,794)=178.69, \mathrm{p}=.000$. A summary of the regression coefficients in Table 6 indicates four of the five variables significantly contributed to the model. Increase in LOS, GMT services and having 1 or more HAC were related to increase in TEC whereas increase in GC $(\geq 180 \mathrm{mg} / \mathrm{dL})$ was related to decrease in TEC.

Table 6. Results of LOS, Provider Group, CCI, HAC, GC, and 30DRA in Predicting TEC $(n=800)$

\begin{tabular}{|l|c|c|c|r|}
\hline \multicolumn{1}{|c|}{ Variable } & B & B & t & p-value \\
\hline LOS & .066 & .694 & 27.43 & .000 \\
\hline GC &. .024 & .053 & -2.14 & .032 \\
\hline CCI & .002 & .013 & .509 & .611 \\
\hline Provider Group & .024 & .052 & 2.11 & .035 \\
\hline HAC & .086 & .081 & 3.28 & .001 \\
\hline
\end{tabular}




\section{Discussion}

This study examined the relationship between GC, HAC, CCI, ICU stay, LOS, 30DRA, care provider, and TEC. The findings indicate that for this study population, the patients seen by GMT were younger; slightly more male, higher A1C levels, higher mean BGs, lower CCI, higher LOS, higher TEC, and more BG count or BG checks. Sharp BG Measures: good glucose control (BG $70-180 \mathrm{mg} / \mathrm{dl}$ ), hypoglycemia (BG $41-<60 \mathrm{mg} / \mathrm{dl}$ ), and severe hypoglycemia ( $\leq 40 \mathrm{mg} / \mathrm{dl}$ ) were comparable between groups except for hyperglycemia (BG 181-299 mg/dl) and severe hyperglycemia $B G \geq 300 \mathrm{mg} / \mathrm{dl}$ ), which were slightly higher for the GMT patients.

Patients referred to GMT services had slightly higher admission BGs and were considered to have more difficult to manage BGs; hence, there were increased BG checks for patients under the GMT services. BG improvement was noted on both provider groups over 14 days (Figure 3). GMT patients started with higher BGs on days 1-4 of admission, had similar BG improvement with MD patients on days 5-12, and better improvement on days 13 and 14 . The graph showed that longer LOS was associated with lower mean BG. Longer LOS allowed the providers time to adjust treatment to improve $B G s$ to goal. Interestingly, mean $B G$ goal of $<180 \mathrm{mg} / \mathrm{dL}$ was achieved in almost half of the overall sample. However, the graph showed this was achieved on day 4 by the MD group and day 5 by the GMT. By the last day of hospitalization, $B G$ average for both provider groups was the same ( $B G=164 \mathrm{mg} / \mathrm{dL}$ ). GMT services referral of more difficult to manage BGs for IGC showed improved overall BG control during the hospital stay as shown in this study and the study by Jakoby and 
associates (2008). GMT services also provided diabetes discharge planning, treatment modification, and education, which consequently allowed more time for MDs to focus their efforts in managing the patients overall care.

30DRA rates are particularly important to most hospital institutions due to Medicare/Medical reimbursement guidelines that limit payment to hospitals with higher 30DRA rates. In 2005 , it was estimated that $17.6 \%$ of hospital admissions resulted in a 30DRA. Older patients with chronic illnesses such as diabetes and heart disease tend to get readmitted to the hospital more often, however, much is still unknown about that factors that increase the probability of readmissions (Stone and Hoffman 2010). The overall 30DRA rate for this study was $16 \%$ with no significant difference between groups. Factors that may increase the likelihood of 30DRA such as higher CCI, GC, ICU stay, presence of HAC, and longer LOS were examined for association with 30DRA. Surprisingly, none of these variables were associated with 30DRA. Other risk factors not evaluated in this study may have increased the likelihood of hospital readmissions such as inadequate discharge planning, poor patient compliance, lack of follow-up care, poor family/caregiver support, deterioration of patient condition and medical errors as a few of the reasons for readmissions (Stone and Hoffman 2010).

Improved IGC was associated with decrease LOS, HAC, and costs (Frisch et al 2010; Furnary et al 2003; Furnary \& Wu, 2006; Umpierrez et al., 2011; Krinsley 2004; Van den Berghe et al., 2001, 2006). This study population had higher TEC/costs that were associated with longer LOS, GMT patients and presence of HAC; whereas higher in 
$\mathrm{GC}(\geq 180 \mathrm{mg} / \mathrm{dL})$ was related to decrease in costs. CCI had no significant association with TEC whereas LOS and HAC had significant impact on increasing TEC. Patients in this study with higher LOS were managed by the GMT. Analyses from this study did not show association of GC $(<180 \mathrm{mg} / \mathrm{dL})$ to shorter LOS and decrease costs.

What remains inadequately answered in this study was despite the GMT patients being younger and had lower $\mathrm{CCI}$ - both factors that were supposedly associated with shorter LOS, they were instead associated with longer LOS and increase TEC. However, we have to take this study in the context that it was a retrospective design; the effect sizes and correlations were small, population of patients were restricted in Southern California region with higher Hispanic population than national average, and many other factors not explored in this study. Decreasing LOS, 30DRA rates and costs are of particular importance in the care of diabetes patients. Further studies should examine the factors e.g. inadequate discharge planning, poor patient compliance, lack of followup care, poor family/caregiver support, deterioration of patient condition and medical errors increasing the LOS, 30DRA rates, and costs for patients with diabetes. 


\section{References}

American Diabetes Association (ADA) (2008). Economic Costs of Diabetes in the U.S. in 2007. Diabetes Care, 311(3), 596-615. doi: $10.2337 / \mathrm{dc} 08-9017$

American Diabetes Association (ADA) (2010). Position Statement: Standards of Medical Care in Diabetes - 2010. Diabetes Care, 33(S1), S11-S61. doi: 10.2337/dc10-S011

American Diabetes Association (2012). Standards of medical care in diabetes--2012. Diabetes Care, 35 Supplement 1, S11-63. doi: 10.2337/dc12-s011

Boord, J. B., Greevey, R.A., Braithwaite, S., Arnold, P.C., Selig, P.M., Brake, H., Cuny, J., \& Baldwin, D. (2009). Evaluation of Hospital Glycemic Control at US Academic Medical Centers. Society of Hospital Medicine, 4(1), 35-44. doi: 10.1002/jhm.390

Brunkhorst, F. M., Engel, C., Bloos, F., Meier-Hellmann, A., Ragaller, M., Weiler, N., et al. (2008). Intensive insulin therapy and pentastarch resuscitation in severe sepsis. New England Journal of Medicine, 358(2), 125-139. doi: 358/2/125 [pii] 10.1056/NEJMoa070716

Center for Disease Control and Prevention (CDC) (2011). National diabetes fact sheet: national estimates and general information on diabetes and prediabetes in the United States, 2011 (pp. 12). Atlanta, GA: Center for Disease Control and Prevention.

Cook, C. B., Seifert, K. M., Hull, B. P., Hovan, M. J., Charles, J. C., Miller-Cage, V., et al. (2009). Inpatient to outpatient transfer of diabetes care: Planning for an effective hospital discharge. Endocrine Practice, 15(3), 263-269. 
Custer, M. L. (2010). Outcomes of clinical nurse specialist-initiated system-level standardized glucose management. Clinical Nurse Specialist, 24(3), 132-139. doi: 10.1097/NUR.0b013e3181d82a31 00002800-201005000-00006 [pii]

Ehrlich, S. F., Quesenberry, C. P., Jr., Van Den Eeden, S. K., Shan, J., \& Ferrara, A. (2010). Patients diagnosed with diabetes are at increased risk for asthma, chronic obstructive pulmonary disease, pulmonary fibrosis, and pneumonia but not lung cancer. Diabetes Care, 33(1), 55-60. doi: 10.2337/dc09-0880

Flanagan, D., Moore, E., Baker, S., Wright, D., and Linch, P. (2008). Diabetes care in the hospital-the impact of a dedicated inpatient care team. Diabetic Medicine, 25, 147-151. doi:10.1111/j.1464-5491.2007.02326

Frisch, A., Chandra, P., Smiley, D., Peng, L., Rizzo, M., Gatcliffe, C., et al. (2010). Prevalence and clinical outcome of hyperglycemia in the perioperative period in noncardiac surgery. Diabetes Care, 33(8), 1783-1788. doi: dc10-0304 [pii] $10.2337 / \mathrm{dc} 10-0304$

Ginde, A. A., Espinola, J. A., \& Camargo, C. A., Jr. (2008). Trends and disparities in U.S. emergency department visits for hypoglycemia, 1993-2005. Diabetes Care, 31(3), 511-513. doi: dc07-1790 [pii] 10.2337/dc07-1790

International Business Machines, Inc. (IBM). (2010). IBM SPSS Statistics (Version 19). United States: International Business Machines, Inc.

Jakoby, M. G., Garey, A., Hall, M., Morris, L., Erikson, D., Wardwell, L., et al. (2008). Management of hospitalized diabetic patients by a hospital diabetes care team 
improves both inpatient and ambulatory glycemic control. Abstract. Carle Foundation Hospital. Urbana, IL.

Joint Commission (2011). Advanced Certification in Inpatient Diabetes Retrieved February 1, 2011, from http://www.jointcommission.org/certification/inpatient_diabetes.aspx

Kornum, J. B., Thomsen, R. W., Riis, A., Lervang, H. H., Schonheyder, H. C., \& Sorensen, H. T. (2007). Type 2 diabetes and pneumonia outcomes: a population-based cohort study. Diabetes Care, 30(9), 2251-2257. doi: 10.2337/dc06-2417.

Krinsley, J. S. (2003). Association between hyperglycemia and Increased hospital mortality in a heterogeneous population of critically ill patients. Mayo Clinic Proceedings, 78, 1471-1478.

Krinsley, J. S. (2004). Effect of an intensive glucose management protocol on the mortality of critically ill adult patients. Mayo Clinic Proceedings, 79(8), 992-1000.

Krinsley, J. S. (2008). Glycemic variability: a strong independent predictor of mortality in critically ill patients. Critical Care Medicine, 36(11), 3008-3013. doi: 10.1097/CCM.0b013e31818b38d2

Krinsley, J. S., \& Grissler, B. (2005). Intensive glycemic management in critically ill patients. Joint Commission Journal on Quality and Patient Safety, 31(6), 308-312.

Krinsley, J. S., \& Grover, A. (2007). Severe hypoglycemia in critically ill patients: risk factors and outcomes. Critical Care Medicine, 35(10), 2262-2267. doi: 10.1097/01.CCM.0000282073.98414.4B 
Krinsley, J. S., \& Preiser, J. C. (2008). Moving beyond tight glucose control to safe effective glucose control. Critical Care, 12(3), 149. Doi: 10.1186/cc6889

Lang, T. A., \& Secic, M. (2006). How to report statistics in medicine : annotated guidelines for authors, editors, and reviewers (2nd ed.). New York: American College of Physicians.

Levetan, C., Passaro, M., Jablonski, K., Kass, M., \& Ratner, R. (1998). Unrecognized diabetes among hospitalized patients. Diabetes Care, 21(2), 246-249.

MEDMARX Data Report: A report on the relationship of drug names and medication errors in response to the institute of medicine's call for action. (2008). In R. W. Hicks, Becker, S. C., and Cousins, D. D. (Ed.), (pp. 1-406). Rockville, MD: Center for the Advancement of Patient Safety, US Pharmacopeia.

Mertler, C. A., and Vannatta, R. A. (2010). Advanced and multivariate statistical methods (4th Ed.). Glendale, CA: Pyrczak Publishing.

Moghissi, E. (2004). Hospital management of diabetes: Beyond the sliding scale. Cleveland Clinical Journal of Medicine, 71(10), 801-808.

Moghissi, E. S., Korytkoski, M. T., DiNardo, M., et al. (2009). American Association of Clinical Endocrinologists and American Diabetes Association consensus statement on inpatient glycemic control. Endocrine Practice, 15(4), 1-17.

Mullen, B., \& Kelley, P. A. W. (2006). Diabetes nurse case management: An effective tool. Journal of the American Academy of Nurse Practitioners, 18, 22-30. 
Mundinger, M. O., Kane, R. L., Lenz, E. R., Totten, A. M., Tsai, W.-Y., Cleary, P. D., et al. (2000). Primary care outcomes in patients treated by nurse practitioners or physicians. Journal of the American Medical Association, 283(1), 59-68.

Munro, B. H. (2005). Statistical methods for health care research (5th ed.). Philadelphia: Lippincott Williams \& Wilkins.

Nathan, D. M., Kuenen, J., Borg, R., Zheng, H., Schoenfeld, D., Heine, R. (2008). Translating the $\mathrm{A} 1 \mathrm{C}$ assay into estimated average glucose values. Diabetes Care, 31(8), 1473 1478. doi: $10.2337 / \mathrm{dc} 08-0545$

Ofman, J. J., Badamgarav, E., Henning, J. M., Knight, K., Gano, A. D., Jr., Levan, R. K., et al. (2004). Does disease management improve clinical and economic outcomes in patients with chronic diseases? A systematic review. American Journal of Medicine, 117(3), 182-192.

Pioro, M. H., Landefeld, C. S., Brennan, P. F., Daly, B., Fortinsky, R. H., Kim, U., et al. (2001). Outcomes-based trial of an inpatient nurse practitioner service for general medical patients. Journal of Evaluation in Clinical Practice, 7(1), 21-33. doi: jep276 [pii]

Smith, W. D., Winterstein, A. G., Johns, T., Rosenberg, E. and Sauer, B. C. (2005). Causes of hyperglycemia and hypoglycemia in adult inpatients. American Journal of Health-System Pharmacy, 62, 714-719. 
Stone, J., \& Hoffman, G. J. (2010). Medicare Hospital Readmissions: Issues, Policy Options and PPACA. (R40972). Washington, D.C.: Congressional Research Service Retrieved from www.crs.gov.

Struijs, J. N., Baan, C. A., Schellevis, F. G., Westert, G. P., \& Van den Bos, G. A. (2006). Comorbidity in patients with diabetes mellitus: impact on medical health care utilization. BMC Health Services Research, 6, 84. doi: 10.1186/1472-6963-6-84

The International Expert Committee (2009). International Expert Committee report on the role of the $\mathrm{A} 1 \mathrm{C}$ assay in the diagnosis of diabetes. Diabetes Care, 32(7), 1-8. doi: $10.2337 / \mathrm{dc} 09-9033$

Turchin, A., Matheny, M. E., Shubina, M., Scanlon, J. V., Greenwood, B., \& Pendergrass, M. L. (2009). Hypoglycemia and clinical outcomes in patients with diabetes hospitalized in the general ward. Diabetes Care, 32(7), 1153-1157. doi: $32 / 7 / 1153$ [pii] 10.2337/dc08-2127

Umpierrez, G. E., Isaacs, S. D, Bazargan, N., You, X., Thaler, L. M., Kitabchi, A. E. (2002). Hyperglycemia: an independent marker of in-hospital mortality in patients with undiagnosed diabetes. The Journal of Clinical Endocrinology \& Metabolism, 87(3), 978-982.

Umpierrez, G. E., Smiley, D., Jacobs, S., Peng, L., Temponi, A., Mulligan, P., et al. (2011). Randomized study of basal-bolus insulin therapy in the inpatient management of patients with type 2 diabetes undergoing general surgery (RABBIT 2 Surgery). Diabetes Care, 34(2), 256-261. doi: 10.2337/dc10-1407 
Van den Berghe, G., Wouters, P., Weekers, F., Verweast, C., et al. (2001). Intensive insulin therapy in critically ill patients. New England Journal of Medicine, 345(19), 13591369.

Vriesendorp, T. M., DeVries, J. H., van Santen, S., Moeniralam, H. S., de Jonge, E., Roos, Y. B., et al. (2006). Evaluation of short-term consequences of hypoglycemia in an intensive care unit. Critical Care Medicine, 34(11), 2714-2718. doi: 10.1097/01.CCM.0000241155.36689.91

Wexler, D. J., Nathan, D. M., Grant, R. W., Regan, S., Leuvan, A. L. V., \& Cagliero, E. (2008). Prevalence of elevated hemoglobin A1c among patients admitted to the hospital without a diagnosis of diabetes. Journal of Clinical Endocrinology and Metabolism, 93(11), 4238-4244.

Wheeler, K., Crawford, R., McAdams, D., Benel, S., Dunbar, V. G., Caudle, J. M., et al. (2004). Inpatient to Outpatient Transfer of Care in Urban Patients With Diabetes. Archive of Internal Medicine, 164, 447-453. 


\section{Chapter 4: MANUSCRIPTS}

\section{MANUSCRIPT 2}

\section{UNIVERSITY OF SAN DIEGO}

Hahn School of Nursing and Health Sciences

Inpatient Glycemic Management: Team Approach in Diabetes Education and Discharge Planning

Crisamar Javellana-Anunciado, PhD, RN, FNP-BC 


\begin{abstract}
TITLE: Inpatient Glycemic Management: Team Approach in Diabetes Education and Discharge Planning
\end{abstract}

AUTHORS: Crisamar J. Anunciado, PhDc, FNP-BC

OBJECTIVE: The aim of this study was to assess the association between discharge planning (education, treatment modification) and care coordination by the glycemic management team (GMT) and physician (MD) for hospitalized diabetics.

RESEARCH DESIGN AND METHODS: A retrospective cohort study of 800 patients ( $n=$ $400 \mathrm{GMT}$ and $n=400 \mathrm{MD}$ ) with diabetes or hyperglycemia admitted to a large urban community medical center located in Southern California was conducted. Chi-square analyses (categorical variables) and ANOVA (continuous variables) were used to test for associations in patient characteristics, inpatient diabetic services (diabetes education and discharge treatment modification) and provider group. For the logistic regression analyses, models were fit to identify factors associated with the probability of receiving inpatient education, treatment modification, and having a 30-day readmission.

RESULTS: The sample was slightly more females $53 \%$ than males. Average age was $66 \pm 14.8$. The most frequent admission diagnoses were circulatory $26 \%$, respiratory system $11 \%$, kidney/urinary tract system $10.4 \%$, nervous system $8.5 \%$, and musculoskeletal/connective tissue $7.8 \%$. The sample was $48 \%$ Latino, $18 \%$ White, $8 \%$ Asian, $6 \%$ Black and $21 \%$ other. Patient education was given to $61.6 \%$ of GMT patients 
versus $38.4 \%$ MD patients. Diabetes treatment modification was made for $53.2 \%$ of GMT patients compared to $46.8 \%$ of MD patients. For patients admitted with $A_{1} C$ levels $\geq 8.1 \%, 54.9 \%$ of GMT patients received services compared to $45.1 \%$ MD patients. Patients who had a high admission $\mathrm{A} 1 \mathrm{C}$, treatment modification, and care coordinated by GMT were more likely to receive education. Patients who had a high admission A1C and received discharge education were more likely to have treatment modification. Patients who had a longer hospital stay were more likely to be readmitted in 30 days.

CONCLUSIONS: Diabetes care coordinated by GMT received more patient education and discharge treatment modification than their MD counterparts. The GMT also provided more services to patients with admission $\mathrm{A} 1 \mathrm{C} \geq 8.1 \%$. There was no difference in care coordination for patients who were readmitted in 30 days. Study findings provide additional data for health care and policy agencies considering the use of GMTs in the inpatient setting to improve overall discharge planning and care coordination for hospitalized patients. Further research is needed to explore definitive inpatient glucose control, economic costs, and post discharge outcome differences between the two service provider groups. 


\section{Background}

Diabetes is the most common co-morbid diagnosis for hospitalized patients. It accounts for increased emergency department visits, longer lengths of stay, and higher cost of care than patients without diabetes (ADA, 2008; Fraze, Jiang, \& Burgess, 2010). Notably, patients with diabetes occupy one in every five hospital beds at a staggering cost of $\$ 87$ billion annually (Cook, et al., 2009; Moghissi, 2004). Inpatient glycemic management (IGM), glucose control, and establishing an appropriate discharge plan, are widely recognized as integral parts of inpatient care; however, wide glucose variability, persistent hyperglycemia, and recurrent and severe hypoglycemia are noted in many inpatient settings (Krinsley, 2003, 2004, 2008; Krinsley \& Grover, 2007; Umpierrez et al., 2002).

IGM has traditionally been the responsibility of the patient's attending physician; however, changes in healthcare practices over the past decade have resulted in more complex inpatient management. Previous research identified barriers to effective care for patients with preexisting diabetes: (1) care focused primarily on acute illness that triggered hospital admission; (2) fear of hypoglycemia causing deleterious effects; (3) insulin administration initiated at blood glucose (BG) levels greater than $180 \mathrm{mg} / \mathrm{dL}$ to $200 \mathrm{mg} / \mathrm{dL}$; (4) inadequate adjustment of insulin in response to changes in nutrition status and medical illness; (5) unpredictability of hospital-related procedures; (6) medication affects on glucose metabolism; and (7) time constraints (Cook et al., 2009; Lansang \& Umpierrez, 2008). Successful implementation of IGM depends on effectively addressing these barriers. 
Healthcare administrators implemented programs targeting inpatient glycemic control based upon the American Diabetes Association (ADA) and the American College of Clinical Endocrinologists (AACE) recommended inpatient glycemic control targets: BG levels of $140-180 \mathrm{mg} / \mathrm{dL}$ in critical care and less than $140 \mathrm{mg} / \mathrm{dL}$ premeal with no random $\mathrm{BG}$ more than $180 \mathrm{mg} / \mathrm{dL}$ for acute care. Based upon the extant research on intensive glucose control ( $\mathrm{BG}<140 \mathrm{mg} / \mathrm{dL}$ ), risks for multi-organ failure, sepsis, morbidity, mortality, and length of stay are significantly reduced (Krinsley \& Grissler, 2005; Van den Berghe et al., 2001). These targets come with a caveat in achieving euglycemia - control hyperglycemia, but limit the possible deleterious consequences of severe hypoglycemia (ADA, 2010; Moghissi, et al., 2009).

In response, healthcare organizations were quick to adopt various forms of insulin protocols with mixed successes and failures. The increased use of insulin in the hospital setting brought new challenges for clinicians regarding patient safety issues. Indeed, insulin is the number one drug implicated in medication errors causing harm (Hicks et al., 2008). The AACE and ADA recognized a physician or nurse singularly might be inadequately equipped to handle the challenges of a comprehensive IGM. In fact, administrative support and inpatient glycemic expert providers are needed to successfully monitor patient safety and manage care (Moghissi, 2004; Moghissi et al., 2009).

IGM is further complicated by many factors affecting inpatient glycemic control (IGC) (Smith et al., 2005) requiring a multidisciplinary team to sufficiently tackle disease management in today's complex healthcare environment. Ofman et al (2004) 
seminal review identified disease management as a coordinated and comprehensive patient care service addressing care across the health care delivery continuum. Disease management is associated with improvement in patient satisfaction, patient adherence, disease control, patient knowledge and decreased morbidity and mortality. Many of these programs are staffed with advanced practice nurses (APNs) and other healthcare professionals with specialized training or expertise in their particular field of disease management (Custer, 2010; Wheeler et al., 2004; Wong et al., 2005). The specialized glycemic management team (GMT) is one team model developed to address IGM. GMTs are staffed with a team of healthcare professionals, which include any or all of these team members: physicians, APNs, diabetes nurse educators, pharmacists, and/or dietitians (Flanagan et al., 2008; Jakoby et al., 2008). The GMT can provide focused care on patients admitted with persistent hyperglycemia. These patients with high glycohemoglobin A1C are particularly at risk for poor short-term and long-term outcomes. Lack of coordinated patient care at the time of discharge to home or other facilities is associated with medical errors and readmission (ADA, 2012; Krinsley, 2003; Umpierrez et al., 2012).

Discharge planning is designated by National Patient Safety Goals and the Centers for Medicare and Medicaid Services as a national patient safety priority (Cook et al., 2009) resulting in Joint Commission guidelines with an option for healthcare agencies to become certified in inpatient diabetes (Joint Commission, 2011). Effective diabetes discharge is one where the patient receives necessary skill training while in the hospital, and is provided clear and understandable post-discharge plan (Cook et al., 2009). Previous research has found a diabetes team approach to IGM including 
transition to ambulatory care to be effective in controlling inpatient blood glucose, improving post discharge A1C levels, and decreasing length of stay (Flanagan et al., 2008; Jakoby et al., 2008).

Although the need for IGC is well established, it is important to assess whether GMT's improve IGC outcomes. The aim of this study was to assess the association between discharge planning (education and treatment modification) and care coordination (GMT or MD) for hospitalized diabetics.

\section{Research Design and Methods}

A retrospective cohort study of patients with diabetes or hyperglycemia admitted to a large urban community medical center located in Southern California was conducted. Participants were selected from all patients with diabetes and hyperglycemia ( $=7914$ ) admitted from January 1, 2008 through December 30, 2009; of these 1000, were randomly selected per year. Eight hundred (400 GMT; $400 \mathrm{MD}$ ) met inclusion criteria (Table 1). Data for the analyses reported here were abstracted from electronic medical records and paper charts. All study procedures were reviewed and approved by appropriate institutional review boards and administrators. Since the data were collected retrospectively, there was no actual patient contact that involved any risk. Precautions were taken to protect patient privacy in accordance with the Health Insurance Portability and Accountability Act (HIPAA); data were de-identified prior to transferring the information to the statistician for analysis. 
Table 1. Exclusion \& Inclusion Criteria

$\begin{array}{ll}\text { Inclusion } & \text { Exclusion } \\ \text { - Diagnosis of Diabetes with ICD-9 codes } & \text { - Patients admitted to sub-acute and long-term } \\ 250.00-250.09 \text { and } 250.30-250.99 & \text { care facilities } \\ \text { - Hyperglycemia with ICD-9 codes } 249.00- & \text { - Patients admitted for diabetes ketoacidosis or } \\ 249.09,249.30-249.99, \text { and } 790.29 & \text { hyperosmolar hyperglycemic syndrome } \\ \text { - Patients with complete baseline data and } & \text { - LOS }>14 \text { days } \\ \text { characteristics } & \\ \text { - Average of } 3 \text { or more days of hospital stay } & \\ \text { - Age } 18 \text { years \& older } & \\ \text { - Patients with } 2 \text { or more BG values in } 24 \text { hour } & \\ \text { period }\end{array}$

\section{Measures}

Care coordination was measured by whether attending physician (MD) or GMT coordinated diabetes care management. The MDs represented a variety of specialties: internists ( $55 \%, n=220)$, hospitalists $(15 \%, n=60)$, pulmonologists $(11.5 \%, n=46)$, nephrologists $(10 \%, n=40)$, cardiologists $(4 \%, n=15)$, endocrinologists $(1.5 \%, n=6)$, and other $(3 \%, n=13)$. GMT was comprised of nurse practitioners (NP), diabetic nurse educator, diabetes medical director, and attending physician. Once the attending physician referred a patient to the GMT, the NPs assume 24-hour responsibility for IGM that entails not only IGC, but also assessing the need for inpatient diabetes education, reconciling diabetes medication list to ensure accuracy, referring to outpatient diabetes education or endocrinology follow-up, and providing clear written instructions on diabetes treatment regimen modifications as needed. The diabetes nurse educator provides patients with diabetes survival skills, basic education, supplies (i.e. log books, handouts, glucose meter), resources (i.e., outpatient free clinics, support groups, classes), and referral to outpatient diabetes education/case management. For definitions of other measures, see Table 2. 
Table 2. Measures with Definition

\begin{tabular}{|c|c|}
\hline $\mathrm{A} 1 \mathrm{C}$ & $\begin{array}{l}\text { Glycosylated hemoglobin is a form of hemoglobin that is measured to } \\
\text { identify the average plasma glucose concentration over } \sim 120 \text { days. Normal } \\
\text { A1C is } 4-6 \% \text {. However, an A1C of } 5.7-6.4 \% \text { is a diagnosis of prediabetes. } \\
\text { An A1C of }>6.5 \% \text { is a diagnosis of diabetes (ADA, 2012). }\end{array}$ \\
\hline TX Modification & $\begin{array}{l}\text { Performed by GMT or MD based on the patient's A1C level and changing } \\
\text { needs (patient's time and skill level in diabetes self-management, home } \\
\text { tapering of glucocorticoids, new kidney failure, pot-operative cardiac surgery, } \\
\text { and availability of environmental/support services). }\end{array}$ \\
\hline Education & $\begin{array}{l}\text { Performed by the certified diabetes educator who is a member of the GMT. } \\
\text { Diabetes education includes providing the patient diabetes survival skills, } \\
\text { basic education, supplies, outpatient resources, and referral to outpatient } \\
\text { diabetes education/case management. }\end{array}$ \\
\hline $\begin{array}{l}\text { Charlson Comorbidity } \\
\text { Index }\end{array}$ & $\begin{array}{l}\text { This was originally developed in } 1984 \text {. It contained } 17 \text { categories of } \\
\text { comorbidity, originally based on ICD-9-CM diagnoses and procedure codes, } \\
\text { and their associated weights that provide an overall comorbidity score to } \\
\text { reflect the cumulative increased likelihood of one-year mortality. The score } \\
\text { ranges from } 1-5 \text { with increase risk of death with increase in score. The index } \\
\text { has been updated in } 2011 \text { for use with ICD-10 coding. The updated weight } \\
\text { for certain diagnoses and the categories narrowed down to } 12 \text { comorbidities } \\
\text { (Quan, et al., 2011). }\end{array}$ \\
\hline LOS & Length of Stay \\
\hline 30-day readmission & Yes/No variable \\
\hline Patient characteristics & $\begin{array}{l}\text { Includes age, gender, race/ethnicity, admission BG, A1C, BMI, mean BG, } \\
\text { BG count, admission diagnosis by medical diagnosis category, discharge } \\
\text { disposition, Charlson comorbidity index, and length of stay. }\end{array}$ \\
\hline
\end{tabular}

Statistical Analysis

Sample size for the analyses is 800 , which is sufficient to detect a moderate standardized effect size $(d=0.32)$ using a two-tail significance test with a power of .80 , and a significance level of .05 (Cohen, 1988). Descriptive and multivariate statistics were used for analyses. Chi-square analyses (categorical variables) and ANOVA (continuous variables) were used to test for associations in patient characteristics, inpatient diabetic services (diabetes education and changes in diabetes regimen upon discharge) and provider group (GMT versus MD). For the logistic regression analyses, models were fit to identify factors associated with the probability of receiving inpatient 
education, treatment modification, and having a 30-day readmission. Statistical analyses were performed using SPSS 19 (IBM, 2010).

\section{Results}

The sample was fairly evenly distributed by gender with slightly more females $(53 \%, n=422)$ than males. Age ranged from 20 to $99(M=66, S D=14.8$; median $=69)$. Patients were admitted for a variety of reasons. The most frequent medical diagnoses were circulatory $26 \%(n=209)$, respiratory system $11 \%(n=89)$, kidney/urinary tract system $10.4 \%(n=83)$, nervous system $8.5 \%(n=68)$, and musculoskeletal/connective tissue $7.8 \%(n=62)$. The sample was diverse with almost half Latino $(48 \%, n=382)$, White $(18 \%, n=146)$, Asian $(8 \%, n=64)$, Black $(6 \%, n=44)$, and other $(21 \%, n=164)$, and is representative of the city's racial breakdown as reported in the 2010 census (US Census, 2010). See Table 3 for details. 
Table 3. Patient Profile

\begin{tabular}{|c|c|c|c|c|c|c|}
\hline & $\begin{array}{l}\text { Overall } \\
n=800\end{array}$ & $\begin{array}{c}\text { GMT } \\
n=400\end{array}$ & $\begin{array}{c}M D \\
n=400\end{array}$ & $F(d)$ & $X^{2}(d)$ & $p$ \\
\hline Age - Mean (SD) & $66(14.8)$ & $64.5(14.7)$ & $67.7(14.6)$ & $9.36(1,798)$ & & .002 \\
\hline Gender - Percent (Count) & & & & & & .01 \\
\hline Female & $53 \%(422)$ & $46 \%(194)$ & $53 \%(228)$ & & $5.79(1)$ & \\
\hline Male & $47 \%(388)$ & $54.5 \%(206)$ & $46 \%(172)$ & & & \\
\hline Ethnicity - Percent (Count) & & & & & $4.3(4)$ & .36 \\
\hline Asian & $8 \%(64)$ & $6 \%(26)$ & $9 \%(38)$ & & & \\
\hline Black & $6 \%(44)$ & $5 \%(19)$ & $6 \%(25)$ & & & \\
\hline Hispanic & $48 \%(382)$ & $48 \%(192)$ & $48 \%(190)$ & & & \\
\hline White & $18 \%(146)$ & $19 \%(74)$ & $18 \%(72)$ & & & \\
\hline Other & $20 \%(164)$ & $22 \%(89)$ & $19 \%(75)$ & & & \\
\hline$A_{1} C-$ Mean $(S D)$ & $8 \%(2.08)$ & $8.2 \%(2)$ & $7.9 \%(2.1)$ & $3.62(1,798)$ & & .057 \\
\hline BMI - Mean (SD) & $30.6(8.3)$ & $30.9(8.3)$ & $30.2(8.3)$ & $1.46(1,798)$ & & .228 \\
\hline Admission BG - Mean (SD) & $221(110.8)$ & $226(118.4)$ & $216(102.5)$ & 1.77 & & .184 \\
\hline $\begin{array}{l}\text { Mean BG level }(\mathrm{mg} / \mathrm{dL}) \text { - Mean } \\
\text { (SD) }\end{array}$ & $186(42)$ & $190(41)$ & $183(43)$ & $4.8(1,798)$ & & .03 \\
\hline $\begin{array}{l}\text { Last Day BG }(\mathrm{mg} / \mathrm{dL}) \text { - Mean } \\
\text { (SD) }\end{array}$ & $164(48.6)$ & $164(46.8)$ & $164(50.4)$ & $.034(1,798)$ & & .854 \\
\hline BG Count (Lab/POC) & $3.7(.47)$ & $3.9(.44)$ & $3.5(.44)$ & $108.6(1,798)$ & & .000 \\
\hline $\begin{array}{l}\text { Medical Diagnostic Groups (MDC) } \\
\text { Percent (Count) }\end{array}$ & & & & & 16.37 & .693 \\
\hline Circulatory System & $26.1 \%(209)$ & $28.8 \%(115)$ & $23.5 \%(94)$ & & & \\
\hline Respiratory System & $11.1 \%(89)$ & $11.5 \%(46)$ & $10.8 \%(43)$ & & & \\
\hline Kidney/Urinary tract & $10.4 \%(83)$ & $8.8 \%(35)$ & $12 \%(48)$ & & & \\
\hline Nervous System & $8.5 \%(68)$ & $9.3 \%(37)$ & $7.8 \%(31)$ & & & \\
\hline $\begin{array}{l}\text { Musculoskeletal/ } \\
\text { Connective Tissue }\end{array}$ & $7.8 \%(62)$ & $7.5 \%(30)$ & $8 \%(32)$ & & & \\
\hline Digestive System & $6.9 \%(55)$ & $7 \%(28)$ & $6.8 \%(27)$ & & & \\
\hline Infectious and Parasitic & $6.1 \%(49)$ & $5 \%(20)$ & $7.3 \%(29)$ & & & \\
\hline $\begin{array}{l}\text { Endocrine, Nutritional, \& } \\
\text { Metabolic System }\end{array}$ & $5.9 \%(47)$ & $5.5 \%(22)$ & $6.3 \%(25)$ & & & \\
\hline $\begin{array}{l}\text { Hepatobiliary System \& } \\
\text { Pancreas }\end{array}$ & $5.6 \%(45)$ & $6.5 \%(26)$ & $4.8 \%(19)$ & & & \\
\hline $\begin{array}{l}\text { Skin, Subcutaneous Tissue \& } \\
\text { Breast }\end{array}$ & $5.3 \%(42)$ & $3.8 \%(15)$ & $6.8 \%(27)$ & & & \\
\hline Other & $6.3 \%(51)$ & $6.5 \%(26)$ & $6.25 \%(25)$ & & & \\
\hline $\begin{array}{l}\text { Charlson Comorbidity Index } \\
\text { (2011) - Mean (SD) }\end{array}$ & $1.43(1.2)$ & $1.35(1.2)$ & $1.52(1.2)$ & $3.92(1,798)$ & & .048 \\
\hline LOS - Mean (SD) & $5.67(2.45)$ & $5.8(2.5)$ & $5.5(2.4)$ & 3.76 & & .53 \\
\hline
\end{tabular}

Chi-square analysis (Table 4) indicated associations between care coordinator and provision of education wherein $61.6 \%(n=237)$ of GMT patients received patient education compared to $38.4 \%(n=148)$ of MD patients, $\chi^{2}(1)=38.7 p=.000$. Diabetes treatment modification was made for slightly more than half of the total patient population $(51.9 \%, n=425)$. Of those, $53.2 \%(n=226)$ of GMT patients received treatment modification compared to $46.8 \%(n=199)$ of MD patients, $\chi^{2}(1)=3.7 p$ 
$=.056$. For patients admitted with $\mathrm{A}_{1} \mathrm{C}$ levels $\geq 8.1 \%$, slightly more than half $(54.9 \%, \mathrm{n}=$ 174) received GMT services, and $45.1 \%(n=143)$ received MD services, $\chi^{2}(1)=5.02 p$ $=.025$. Of the 130 patients readmitted within 30 days, slightly more than half, $56.2 \%(\mathrm{n}$ $=73)$ received GMT services, $43.8 \%(n=53)$ received MD services, $\chi^{2}(1)=2.35 p=.125$.

Table 4. Patient Education, Treatment Modification, Discharge Disposition, 30-day Readmission and Inpatient Care Coordination

\begin{tabular}{|lccccc|}
\hline & Overall & GMT & MD & $X^{2}$ (df) & $p$ \\
& $N=800$ & $n=400$ & $n=400$ & & \\
Treatment Modification (yes) & $53 \%(424)$ & $53 \%(225)$ & $47 \%(199)$ & $3.39(1)$ & .006 \\
Education (yes) & $48 \%(384)$ & $61.5 \%(236)$ & $38.5 \%(142)$ & $38.78(1)$ & .000 \\
Discharge Disposition & & & & $4.2(4)$ & .377 \\
Percent (Count) & & & & \\
$\quad$ Mortality & $1 \%(8)$ & $.7 \%(3)$ & $1.2 \%(5)$ & & \\
$\quad$ Home & $75.8 \%(606)$ & $77.5 \%(310)$ & $74 \%(296)$ & & \\
$\quad$ Nursing home & $19.8 \%(158)$ & $17.5 \%(70)$ & $22 \%(88)$ & & \\
$\quad$ Rehab facility & $1.4 \%(11)$ & $1.75 \%(7)$ & $1 \%(4)$ & & \\
Other & $2 \%(17)$ & $2.5 \%(10)$ & $1.75 \%(7)$ & & \\
30 day Readmission (yes) & $16 \%(130)$ & $18 \%(73)$ & $14 \%(57)$ & $2.35(1)$ & .125 \\
\hline
\end{tabular}

Logistic regression was used to estimate the probability of having had discharge education, treatment modification, and a 30-day readmission. Predictor variables: LOS, care coordination, $\mathrm{A} 1 \mathrm{C}$, treatment modification, and education were used in the analysis with simultaneous entry of predictors.

As shown in Table 5, the overall predictive model for discharge education was statistically significant with a likelihood ratio chi-square $=66.15(5), p=.000$. HosmerLemeshow test indicated the model was a good fit to the data $\chi^{2}=9.07(8), .33$. Although the overall model and 5 predictors were statistically significant, the classification result indicated moderate success as it only classified $62.1 \%$ of the cases. 
The overall effect size was also modest with Nagelkerke R square.103. Three predictor variables were significantly related to the likelihood of receiving discharge education. Wald statistics indicated admission A1C, treatment modification, and care coordination was significant in predicting the likelihood of discharge education. Patients who had a high admission A1C, treatment modification, and care coordinated by GMT were more likely to receive education.

Table 5. Logistic Regression Results Predicting the probability of Receiving Education ( $N=800$ )

\begin{tabular}{|c|c|c|c|c|c|c|c|}
\hline \multirow[t]{2}{*}{ Predictor } & \multirow[t]{2}{*}{$B$} & \multirow[t]{2}{*}{ Wald } & \multirow[t]{2}{*}{ df } & \multirow{2}{*}{$\begin{array}{l}\text { Odds } \\
\text { Ratio }\end{array}$} & \multicolumn{2}{|c|}{$95 \%$ Confidence Interval } & \multirow[t]{2}{*}{$p$} \\
\hline & & & & & Lower & Upper & \\
\hline Length of Stay & .018 & .355 & 1 & 1.01 & .959 & 1.08 & .551 \\
\hline Charlson-2011 & .020 & .108 & 1 & 1.02 & .907 & 1.14 & .743 \\
\hline A1C-admission & .132 & 12.48 & 1 & 1.14 & 1.06 & 1.22 & .000 \\
\hline Provider $0=$ MD; $1=$ GMT) & .856 & 33.31 & 1 & 2.35 & 1.76 & 3.14 & .000 \\
\hline Treatment Modification ( $1=$ yes) & .475 & 10.15 & 1 & 1.60 & 1.20 & 2.15 & .001 \\
\hline
\end{tabular}

Model (likelihood ratio) chi-square $=66.15(5), p=.000$

Percent correctly classified $=62.1 \%$

Nagelkerke $R^{2}=.106$

The overall predictive model for treatment modification (Table 6) was statistically significant with a likelihood ratio chi-square $=32.93(5), p=.000$. HosmerLemeshow test indicated the model was a good fit to the data $\chi^{2}=10.15(8), .25$. Although the overall model and 5 predictors were statistically significant, the classification result indicated moderate success as it only classified $59.3 \%$ of the cases. The overall effect size was also modest with Nagelkerke R square .05 . Two predictor variables were significantly related to the likelihood of treatment modification. Wald statistics indicated admission A1C and discharge education were significant in predicting the likelihood of treatment modification. Patients who had a high admission $\mathrm{A} 1 \mathrm{C}$ and received discharge education were more likely to have treatment modification. 
Table 6. Logistic Regression Results Predicting the probability of Treatment Modification $(N=800)$

\begin{tabular}{|c|c|c|c|c|c|c|c|}
\hline \multirow[t]{2}{*}{ Predictor } & \multirow[t]{2}{*}{$B$} & \multirow[t]{2}{*}{ Wald } & \multirow[t]{2}{*}{$d f$} & \multirow{2}{*}{$\begin{array}{l}\text { Odds } \\
\text { Ratio }\end{array}$} & \multicolumn{2}{|c|}{$95 \%$ Confidence Interval } & \multirow[t]{2}{*}{$\boldsymbol{p}$} \\
\hline & & & & & Lower & Upper & \\
\hline Length of Stay & -.025 & 716 & 1 & .97 & .91 & 1.03 & .398 \\
\hline Charlson-2011 & .033 & .320 & 1 & 1.03 & 92 & 1.16 & .572 \\
\hline A1C - admission & 139 & 13.77 & 1 & 1.15 & 1.06 & 1.23 & .000 \\
\hline Provider $0=$ MD; $1=$ GMT) & 138 & .862 & 1 & 1.14 & 858 & 1.53 & .353 \\
\hline Education (1= yes) & 476 & 10.19 & 1 & 1.61 & 1.20 & 2.15 & 001 \\
\hline
\end{tabular}

Model (likelihood ratio) chi-square $=33.93(5), p=.000$

Percent correctly classified $=59.3 \%$

Nagelkerke $R^{2}=.055$

The overall predictive model for 30 -day readmission (Table 7) was statistically significant with a likelihood ratio chi-square $=13.98(6), p=.03$. Hosmer-Lemeshow test indicated the model was a good fit to the data $\chi^{2}=7.11(8), .52$. The classification result classified $83.8 \%$ of the cases correctly. The overall effect size was modest with Nagelkerke R square .03 . One predictor variable was significantly related to the likelihood of 30-day readmission. Wald statistics indicated length of hospitalization significantly in predicted the likelihood of 30-day readmission. Patients who had a longer hospital stay were more likely to be readmitted in 30 days.

Table 7. Logistic Regression Results Predicting the probability of 30-day Readmission ( $N=800$ )

\begin{tabular}{|l|c|c|c|c|c|c|c|}
\hline Predictor & $\boldsymbol{B}$ & Wald & $\boldsymbol{d f}$ & $\begin{array}{l}\text { Odds } \\
\text { Ratio }\end{array}$ & \multicolumn{2}{|c|}{$\mathbf{9 5 \% \text { Confidence Interval }}$} & $\boldsymbol{P}$ \\
\cline { 1 - 5 } & & & & Lower & Upper & \\
\hline Length of Stay & .08 & 4.60 & 1 & 1.08 & 1.00 & 1.16 & .03 \\
\hline Charlson-2011 & .12 & 2.79 & 1 & 1.13 & .979 & 1.30 & .09 \\
\hline A1C - admission & -.05 & 1.09 & 1 & .948 & 0.85 & 1.04 & .29 \\
\hline Provider 0 = MD; 1 = GMT) & .31 & 2.44 & 1 & 1.36 & .92 & 2.03 & .11 \\
\hline Education (1=yes) & .006 & .001 & 1 & 1.00 & .679 & 1.49 & .98 \\
\hline Treatment Modification & -.155 & .617 & 1 & .85 & .58 & 1.26 & .43 \\
\hline
\end{tabular}

Model (likelihood ratio) chi-square $=13.98(6), p=.03$

Percent correctly classified $=83.8 \%$

Nagelkerke $R^{2}=.03$

\section{Discussion}

The findings indicate that for the overall sample population, diabetes care coordinated by GMT received more patient education and only slight more discharge treatment modification than their MD counterparts. GMT provided more services to 
patients with admission $\mathrm{A} 1 \mathrm{C} \geq 8.1 \%$. However, there was no difference in care coordination for patients who were readmitted within 30 days. Characteristics of patients referred for GMT services are: higher A1C, history of poor compliance with diabetes regimen, complex diabetes regimen (multi-dose insulin injections, insulin pumps, pregnant diabetics, steroid taper, major life changes due to acute illness), and have complex social and environmental issues (lack of family support, placement issues, homelessness).

The GMT coordinates the complex care needs of these patients by working closely with the diabetes educator in providing specific/advanced education. They also collaborate with patient/family and other healthcare professionals (i.e., attending MD, primary care MD, diabetologists, case management, pharmacy, nutrition, social, and other services) in providing safe and effective discharge plan and treatment modification. Care coordination takes time and effort so when the patient is readmitted within 30 days, it is evident further targeted interventions are needed. Behavior change is difficult in learning new habits and thus discharge follow-up using telemedicine in concert with home visitation may be indicated.

Significant findings were noted on the increased probability of having discharge education, treatment modification, and a 30-day readmission. There was an increased likelihood of patients receiving diabetes education when they had high $\mathrm{A} 1 \mathrm{C}$, treatment modification, and care coordinated by GMT. Interestingly, the likelihood of patients receiving treatment modification was higher when they had high $\mathrm{A} 1 \mathrm{C}$ and received diabetes education regardless of care coordination. These findings may be related to 
GMT daily routine and responsibilities. Everyday, the GMT (NPs and diabetes educators) reviews the list of all inpatients with glycemic issues (hyperglycemia or hypoglycemia) and high $\mathrm{A} 1 \mathrm{C}$ results, and briefly meets to address needs of patients with complex needs. Previous studies found improvement in A1C and discharge planning process that indicated similar roles for the NPs and diabetes educators (Jakoby et al., 2008; Mullen \& Kelly, 2006).

Although diabetes education is not exclusive to the patients under the care of the NPs, they have easy access to diabetes educators (housed in the same office) when the need arise. Otherwise, MDs and nurses access diabetes educators by telephone. Unlike NPs, diabetes educator intervention does not require MD orders, hence, any patient with high $\mathrm{A} 1 \mathrm{C}$ or is being discharged will be prioritized for education intervention. Diabetes educators may trigger a call to the MD if they judge the patient needs care coordination by the NPs for IGC or discharge treatment modification.

Lastly, findings indicate that there is increased likelihood of readmission within 30-days when the patient had longer LOS. This may be associated with several factors, i.e., more comorbid conditions, higher Charlson scores, compliance issues, living situations, and other social/environmental factors.

These findings must be interpreted in the light there are several limitations to this study: the retrospective design, largely Hispanic population (not representative of the national ethnicity population distribution), and lack of outcomes post discharge. Regardless, taken in this context, study findings are encouraging and provide additional data for health care and policy agencies considering the use of GMTs in the inpatient 
setting to improve overall discharge planning and care coordination for hospitalized patients. Further research is needed to explore definitive IGC, economic costs, and post discharge outcome differences between the two service provider groups. 


\section{References}

American Diabetes Association (ADA) (2008). Economic Costs of Diabetes in the U.S. in 2007. Diabetes Care, 311(3), 596-615. Doi: 10.2337/dc08-9017

American Diabetes Association (ADA) (2010). Position Statement: Standards of Medical Care in Diabetes - 2010. Diabetes Care, 33(S1), S11-S61. Doi: 10.2337/dc10-S011

American Diabetes Association (ADA) (2012). Standards of medical care in diabetes-2012. Diabetes Care, 35 Supplement 1, S11-63. doi: 10.2337/dc12-s011

Cohen, J. (1988). Statistical power analysis for the behavioral sciences (2nd ed.). Hillsdale, N.J.: L. Erlbaum Associates.

Cook, C. B., Seifert, K. M., Hull, B. P., Hovan, M. J., Charles, J. C., Miller-Cage, V., et al. (2009). Inpatient to outpatient transfer of diabetes care: Planning for an effective hospital discharge. Endocrine Practice, 15(3), 263-269.

Custer, M. L. (2010). Outcomes of clinical nurse specialist-initiated system-level standardized glucose management. Clinical Nurse Specialist, 24(3), 132-139. doi: 10.1097/NUR.0b013e3181d82a31 00002800-201005000-00006 [pii]

Flanagan, D., Moore, E., Baker, S., Wright, D., and Linch, P. (2008). Diabetes care in the hospital-the impact of a dedicated inpatient care team. Diabetic Medicine, 25, 147-151. Doi: $10.1111 /$ j.1464-5491.2007.02326

Fraze, T., Jiang, J., and Burgess, J. "Hospital Stays for Patients with Diabetes, 2008." 1-11: Agency for Healthcare Research and Quality, 2010.

Hicks, R. W., Sikirica, V., Nelson, W., Schein, J. R., \& Cousins, D. D. (2008). Medication 
errors involving patient-controlled analgesia. [Research Support, Non-U.S. Gov't]. American Journal of Health-System Pharmacy, 65(5), 429-440. doi: 10.2146/ajhp070194

International Business Machines, Inc. (IBM). (2010). IBM SPSS Statistics (Version 19). United States: International Business Machines, Inc.

Jakoby, M. G., Garey, A., Hall, M., Morris, L., Erikson, D., Wardwell, L., et al. (2008). Management of hospitalized diabetic patients by a hospital diabetes care team improves both inpatient and ambulatory glycemic control. Abstract. Carle Foundation Hospital. Urbana, IL.

Joint Commission (2011). Advanced Certification in Inpatient Diabetes. Retrieved February 1,2011, from http://www.jointcommission.org/certification/inpatient_diabetes.aspx

Krinsley, J. S. (2003). Association between hyperglycemia and Increased hospital mortality in a heterogeneous population of critically ill patients. Mayo Clinic Proceedings, 78, 1471-1478.

Krinsley, J. S. (2004). Effect of an intensive glucose management protocol on the mortality of critically ill adult patients. Mayo Clinic Proceedings, 79(8), 992-1000.

Krinsley, J. S. (2008). Glycemic variability: a strong independent predictor of mortality in critically ill patients. Critical Care Medicine, 36(11), 3008-3013. Doi: 10.1097/CCM.0b013e31818b38d2

Krinsley, J. S., \& Grissler, B. (2005). Intensive glycemic management in critically ill patients. Joint Commission Journal on Quality and Patient Safety, 31(6), 308-312. 
Krinsley, J. S., \& Grover, A. (2007). Severe hypoglycemia in critically ill patients: risk factors and outcomes. Critical Care Medicine, 35(10), 2262-2267. Doi: 10.1097/01.CCM.0000282073.98414.4B

Lansang, M. C., and Umpierrez, G. E. "Management of Inpatient Hyperglycemia in Noncritically Ill Patients." Diabetes Spectrum 21, no. 4 (2008): 248-55.

Moghissi, E. (2004). Hospital management of diabetes: Beyond the sliding scale. Cleveland Clinical Journal of Medicine, 71(10), 801-808.

Moghissi, E. S., Korytkoski, M. T., DiNardo, M., et al. (2009). American Association of Clinical Endocrinologists and American Diabetes Association consensus statement on inpatient glycemic control. Endocrine Practice, 15(4), 1-17.

Mullen, B., \& Kelley, P. A. W. (2006). Diabetes nurse case management: An effective tool. Journal of the American Academy of Nurse Practitioners, 18, 22-30.

Ofman, J. J., Badamgarav, E., Henning, J. M., Knight, K., Gano, A. D., Jr., Levan, R. K., et al. (2004). Does disease management improve clinical and economic outcomes in patients with chronic diseases? A systematic review. American Journal of Medicine, 117(3), 182-192.

Quan, H., B. Li, C. M. Couris, K. Fushimi, P. Graham, P. Hider, J. M. Januel, and V. Sundararajan. "Updating and Validating the Charlson Comorbidity Index and Score for Risk Adjustment in Hospital Discharge Abstracts Using Data from 6 Countries." [In English]. American Journal of Epidemiology 173, no. 6 (Mar 15 2011): 676-82. 
Smith, W. D., Winterstein, A. G., Johns, T., Rosenberg, E. and Sauer, B. C. (2005). Causes of hyperglycemia and hypoglycemia in adult inpatients. American Journal of Health-System Pharmacy, 62, 714-719.

Umpierrez, G. E., Hellman, R., Korytkowski, M. T., Kosiborod, M., Maynard, G. A., Montori, V. M., et al. (2012). Management of hyperglycemia in hospitalized patients in non-critical care setting: an endocrine society clinical practice guideline. [Practice Guideline]. Journal of Clinical Endocrinology and Metabolism, 97(1), 1638. doi: 10.1210/jc.2011-2098

Umpierrez, G. E., Isaacs, S. D, Bazargan, N., You, X., Thaler, L. M., Kitabchi, A. E. (2002). Hyperglycemia: an independent marker of in-hospital mortality in patients with undiagnosed diabetes. The Journal of Clinical Endocrinology \& Metabolism, 87(3), 978-982.

US Census Bureau (2010). "State and County Quick Facts: Chula Vista, California." http://quickfacts.census.gov/qfd/states/06/0613392.html

Van den Berghe, G., Wouters, P., Weekers, F., Verweast, C., et al. (2001). Intensive insulin therapy in critically ill patients. New England Journal of Medicine, 345(19), 13591369.

Wheeler, K., Crawford, R., McAdams, D., Benel, S., Dunbar, V. G., Caudle, J. M., et al. (2004). Inpatient to Outpatient Transfer of Care in Urban Patients With Diabetes. Archive of Internal Medicine, 164, 447-453. 
Wong, F. K., M. P. Mok, T. Chan, and M. W. Tsang. "Nurse Follow-up of Patients with Diabetes: Randomized Controlled Trial." [In eng]. Journal of Advanced Nursing 50, no. 4 (May 2005): 391-402. 


\section{Chapter 4: MANUSCRIPTS}

\section{Grant Proposal}

\section{UNIVERSITY OF SAN DIEGO}

Hahn School of Nursing and Health Sciences

Inpatient Glycemic Management:

Clinical and economic impact of changing from sliding scale insulin to basal-bolus

Crisamar Javellana-Anunciado, PhD, RN, FNP-BC 
Glycemic control is recognized as an important part of inpatient care due to the common, serious, and costly complications of poor glycemic control. Hyperglycemia, severe hyperglycemia, mild hypoglycemia, severe hypoglycemia, and wide glucose variability are implicated in poor outcomes (Krinsley 2003, 2008; Krinsley \& Grover 2007). As the incidence of diabetes continuous to become more prevalent nationwide, the number of hospital discharges with diabetes also increased. Hospital care costs for patients with diabetes are staggering - accounting for approximately $\$ 87$ billion annually (American Diabetes Association 2008). Evidence suggests that hyperglycemia during acute medical or surgical illness is a marker of poor clinical outcomes with increased morbidity, mortality, and length of stay (Krinsley 2004; Umpierrez 2002). When blood glucose is intensively controlled to near normal levels, it reduces the risks of multi-organ failure, sepsis, morbidity, mortality, and length of stay (Krinsley \& Grissler 2005; Van den Berghe 2001). Optimum glycemic control reduces hospital costs and is important to patients with acute and critical illness. Despite controversy over specific glycemic targets, an understanding of glycemic control is widely understood to be at least under a blood glucose level of $180 \mathrm{mg} / \mathrm{dl}$ (American Diabetes Association 2010; Moghissi 2009; NICE-SUGAR 2009). Over the last decade, various approaches to achieving glycemic control have been implemented at several institutions nationwide but glycemic control remains suboptimal (Boord, 2009). There is still a considerable gap in research on the relationship between clinical outcomes and economic costs of good glycemic control. 


\section{Research Aims}

This retrospective research study is designed to evaluate the clinical outcomes and economic costs of implementing an inpatient glycemic management program intended to eliminate the use of the traditional sliding scale insulin (SSI) therapy in favor of the use of a more physiologic approach to hyperglycemia using basal-bolus insulin (BBI) therapy. This study will evaluate the clinical outcomes and economic costs of SSI vs. BBI therapy.

The primary outcomes are to evaluate the differences in glycemic control i.e., mean blood glucose (BG) control, incidences of hyperglycemia ( $B G>180 \mathrm{mg} / \mathrm{dL}$ ), severe hyperglycemia ( $B G>300 \mathrm{mg} / \mathrm{dL}$ ), hypoglycemia $(\mathrm{BG}<60 \mathrm{mg} / \mathrm{dL}$ ), and severe hypoglycemia ( $\mathrm{BG}<40 \mathrm{mg} / \mathrm{dL}$ ) between treatment groups (SSI vs. BBI therapy). Secondary outcomes include differences between treatment groups in length of stay, inpatient mortality, 30-day readmission rates, and economic costs, i.e., inpatient diabetes-related pharmacy and medical costs.

\section{Research Questions}

1. What are the clinical outcome differences (i.e. mean blood control, incidence of hyperglycemia and hypoglycemia, length of stay, inpatient mortality, and 30-day readmission rates) in converting from SSI therapy to BBI therapy?

2. What are the economic cost differences (i.e. inpatient diabetes-related pharmacy and medical costs) in converting from SSI therapy to BBI therapy? 
This is a retrospective quasi-experimental quantitative research study done at Sharp Chula Vista Medical Center (SCVMC), a 343-bed nonprofit community hospital in Southern California. A sample size of 5,000 patient cases will be reviewed retrospectively. This study includes historical evaluation of 1,000 patient cases per 12month period from March 2003 to February 2007, and another 1,000 patient cases for more current data comparison from the period of March 2009 to February 2010 (see Table 1 for details).

Table 1. Sampling

\begin{tabular}{|r|l|}
\hline Time Frame & Sample Size \\
\hline SSI = March 2003 to February 2005 & 2,000 \\
BBI = March 2005 to February 2007 & 2,000 \\
March 2009 to February 2010 & 1,000 \\
\hline
\end{tabular}

The patient cases will be obtained through convenience sampling with the use of the hospital admission database for the period described in Table 1. Patient cases will be selected based on this study's inclusion criteria, i.e., a diagnosis of either diabetes or hyperglycemia ( $\mathrm{BG}>180 \mathrm{mg} / \mathrm{dL}$ during the hospital stay), 18 years of age or older, available demographic \& baseline data (see Table 3), recorded BG values of two or more in a 24-hour period, and was on either SSI or BBI therapy. Patient cases that do not meet all the inclusion criteria or was admitted in diabetes crises will be eliminated from the study (see Table 2).

Descriptive statistics will be used describe the characteristics of the sample. One-way ANOVA will be applied to statistically examine this quasi-experimental 
research study for ( $g=2$ groups) between-group comparisons on key outcomes (e.g., LOS, Mean BG, etc.). If the outcomes are logically/statistically clustered, multivariate approaches, such as MANOVA, will be performed. Moreover, given a host of demographic/baseline data and clinically relevant drivers, a predictive approach will also be employed. A multiple regression approach will also be utilized to ascertain which variables are the strongest predictors of key outcomes.

Table 2. Exclusion \& Inclusion Criteria

\begin{tabular}{|ll|}
\hline \multicolumn{1}{|c|}{ Inclusion } & \multicolumn{1}{c|}{ lixclusion } \\
\hline Diagnosis of Diabetes or hyperglycemia & $\begin{array}{l}\text { Patients on sulfonylureas with insulin and/or } \\
\text { oral antidiabetic medications only }\end{array}$ \\
\hline Age 18 years \& older & $<18$ year old \\
\hline Average of 3 or more days of hospital stay & $<3$ day hospital stay \\
\hline $\begin{array}{l}\text { Patients with all required demographic \& } \\
\text { baseline data }\end{array}$ & $\begin{array}{l}\text { Patient with incomplete } \\
\text { demographic/baseline data }\end{array}$ \\
\hline $\begin{array}{l}\text { Patients with } 2 \text { or more BG values in 24 hour } \\
\text { period }\end{array}$ & Patients with < 2 BG values in 24 hour period \\
\hline Patients on subcutaneous insulin SSI or BBI & $\begin{array}{l}\text { Treatment of basal insulin without short- } \\
\text { acting insulin }\end{array}$ \\
\hline & Patients admitted for DKA or HHS \\
\hline Legend: DKA = diabetes ketoacidosis; HHS $=$ hyperosmolar hyperglycemic syndrome \\
\hline
\end{tabular}

Data will be obtained through electronic medical records (EMR) and electronic financial records (EFR). Hospital data from consecutive months of March 2003 to February 2007 will provide two years of sufficient data for SSI therapy and two years of BBI therapy. Additionally, hospital data from consecutive months of March 2009 to February 2010 will provide outcomes of the most recent year post-BBI implementation.

Table 3 lists the three categories of measures, which were collected for statistical analyses: (a) demographic or baseline data (i.e., age, gender, ethnicity, admission diagnosis, and admission BG); (b) clinical outcome measures (i.e., mean BG level per 
patient day, BG in good control, mild hyperglycemia, severe hyperglycemia, mild hypoglycemia, severe hypoglycemia, discharge diagnosis, transfer to ICU, length of stay, and 30-day readmission rate; and, (c) economic costs (i.e., overall hospital costs, inpatient pharmacy costs, and medical costs).

Table 3. Measures

\begin{tabular}{|c|c|c|}
\hline Dimension & Variable & Data Source \\
\hline $\begin{array}{l}\text { Demographics/ } \\
\text { Baseline data }\end{array}$ & $\begin{array}{ll}\text { Age } \\
\text { Gender } \\
\text { Ethnicity } \\
\text { Admission Diagnosis } \\
\text { Admission BG } \\
\end{array}$ & $\begin{array}{l}\text { EMR } \\
\text { EMR } \\
\text { EMR } \\
\text { EMR } \\
\text { EMR }\end{array}$ \\
\hline $\begin{array}{l}\text { Clinical } \\
\text { Outcomes for } \\
\text { SSI versus BBI }\end{array}$ & $\begin{array}{ll}\text { Mean BG level per patient day } \\
\text { BG w/in good control }(\mathrm{BG} 71-180 \mathrm{mg} / \mathrm{dL}) \\
\text { Hyperglycemia }(\mathrm{BG}>180 \mathrm{mg} / \mathrm{dL}) \\
\text { Severe hyperglycemia }(\mathrm{BG}>300 \mathrm{mg} / \mathrm{dL}) \\
\text { Hypoglycemia }(\mathrm{BG}<60 \mathrm{mg} / \mathrm{dL}) \\
\text { Severe hypoglycemia }(\mathrm{BG}<40 \mathrm{mg} / \mathrm{dL}) \\
\text { Hospital Discharge diagnosis } \\
\text { Transfer to ICU } \\
\text { Length of stay } \\
\text { In-hospital mortality } \\
\text { 30-day readmission }\end{array}$ & $\begin{array}{l}\text { EMR } \\
\text { EMR } \\
\text { EMR } \\
\text { EMR } \\
\text { EMR } \\
\text { EMR } \\
\text { EMR } \\
\text { EMR } \\
\text { EMR } \\
\text { EMR } \\
\text { EMR }\end{array}$ \\
\hline $\begin{array}{l}\text { Economic Costs } \\
\text { for SSI versus } \\
\mathrm{BBI}\end{array}$ & $\begin{array}{l}\text { Overall hospital costs } \\
\quad \text { Inpatient pharmacy costs } \\
\quad \text { Medical costs }\end{array}$ & $\begin{array}{l}\text { EFR } \\
\text { EFR } \\
\text { EFR }\end{array}$ \\
\hline
\end{tabular}

In 2002, Sharp Healthcare system started collecting all BG results from both laboratory and point-of-care fingerstick BGs using the Roche Inform $\otimes$ meter from all five Sharp Healthcare facilities. SCVMC has more than 250 diabetes patient cases and more than $10,000 \mathrm{BG}$ results monthly, which is the highest among the five hospitals. All $B G$ results are uploaded into the system database. Upon initial review of the BG data, we discovered that the data became more consistent at the end of the first quarter of 2003. The basal-bolus protocol, called Subcutaneous Insulin Order Set (SIOS) (shown in 
Figure 1) as well as a glycemic management team (GMT), was implemented on February 14, 2005. The use of SIOS increased beginning March 2005, and reached more than $80 \%$ use by June 2005 . For the purpose of this study, hospital BG data for the consecutive months of March 2003 to February 2005 provides two years of data for SSI therapy, and the consecutive months from March 2005 to February 2007 provides the initial two years of BBI therapy. Hospital data for the consecutive months of March 2009 to February 2010 provides outcomes for the most recent year post-BBI implementation.

\section{Limitations}

It is important to note that the GMT was implemented at the same time the use of the SIOS was implemented. The GMT is a group of nurse practitioners and diabetes educators under the general supervision of the diabetes medical director. When the patient's attending physician refers a patient to the GMT, the GMT takes over the diabetes care of the patient during the hospital stay. The GMT makes daily insulin adjustments, provides diabetes education, refers the patient to outpatient diabetes education program, and makes changes on diabetes regimen for home based on each individual patient's needs. The 3,000 patient cases on BBI therapy in this study were managed either by the physician alone or with the assistance of the GMT. The full impact of the GMT intervention will not be addressed in this study. 
Figure 1. Subcutaneous Insulin Order Set (SIOS)

Putudind 7.05 en, $11 / 108$ PRINT

ब.JADD Chula van

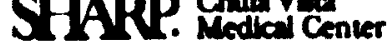

\section{RESET}

Subcutanoous Insulin Orders (SIOS)

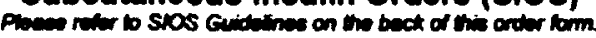

Taret Blood Cucose (BG) Ranos: $\leq 110 \mathrm{modil}$ (Pro-mad); < $120 \mathrm{moldl}$ (maximum)

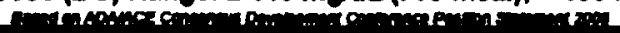

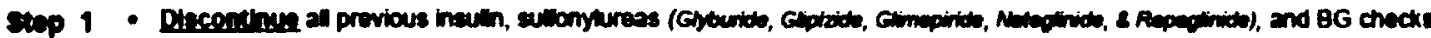

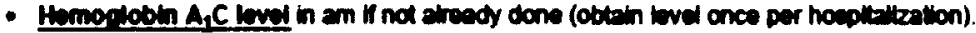

step 2 Chact Bg upon admisaion and

\begin{tabular}{|c|c|c|}
\hline 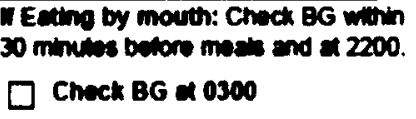 & $\begin{array}{l}\text { I mo: check BG } \\
\text { mery } 4 \text { min. Follow } \\
\text { step } 6 \text { guideines } \\
\text { below. }\end{array}$ & 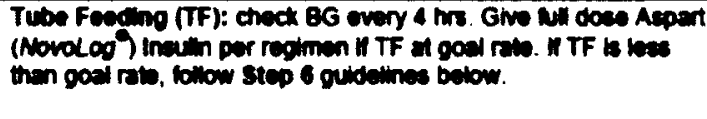 \\
\hline
\end{tabular}

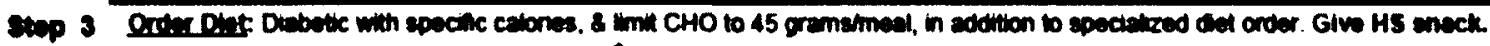

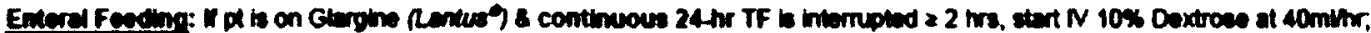

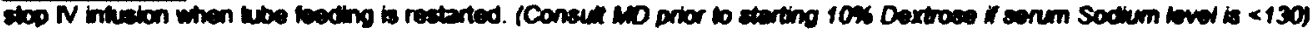

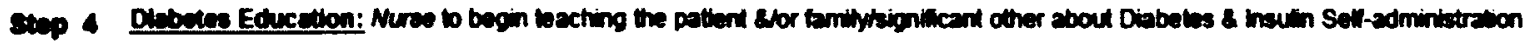

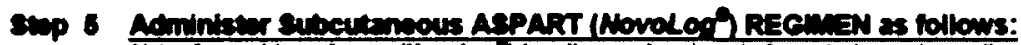

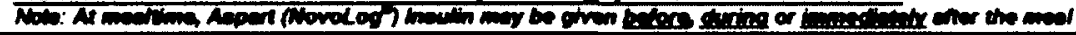

\begin{tabular}{|c|c|c|c|c|c|}
\hline EG made & 0 D & D wOOERATE & D AGGRESSIVE & Dcention & Bg mole \\
\hline$\leq 70$ & \multicolumn{4}{|c|}{ Implament Hypoctycomis Protocol \& Cal MO } & $\leq 70$ \\
\hline $71-90$ & o Unil & ounit & o Unil & Units & $71-90$ \\
\hline $91-120$ & o Unins & 3 Unis & 4 Units & Units & $91-120$ \\
\hline $121-150$ & 3 Unis: & 5 Units & 6 Units & Units & $121-150$ \\
\hline $151-200$ & 4 Units & 6 Unims & 8 Units & Units & $151-200$ \\
\hline $201-250$ & 5 Unis & 7 Units & 10 Units & Units & $201-250$ \\
\hline $251-300$ & 6 Units & 8 Unims & 12 Units & Units & $251-300$ \\
\hline $301-350$ & 7 Units & 9 Units & 14 Units & Units & $301-350$ \\
\hline $351-400$ & 8 Uning & 10 Unis & 16 Unins & Units & $351-400$ \\
\hline
\end{tabular}

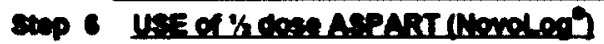

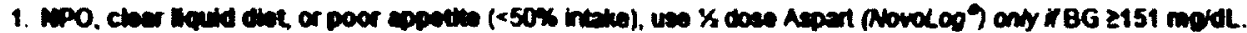

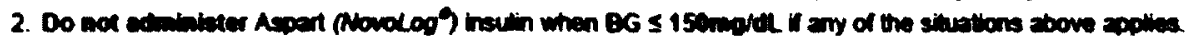

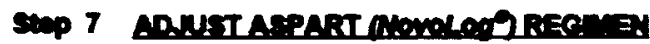

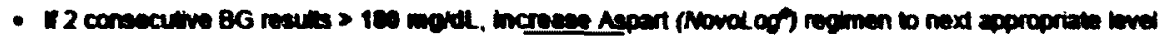

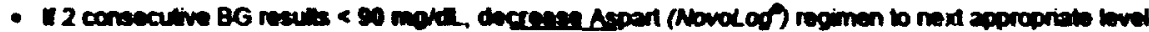

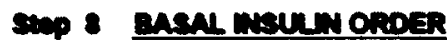

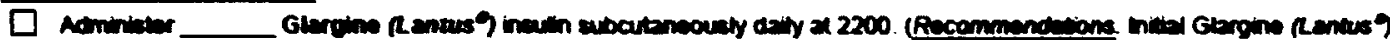

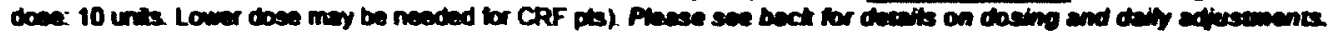

sup 5 HבY?

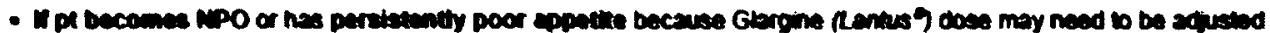

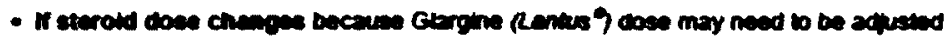

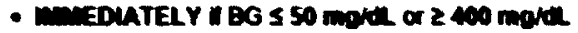

- In AM or nexa uD Rounds if BG $\leq 70$ mordL o or $\geq 301$ movel or

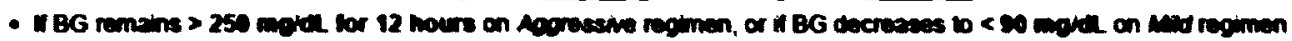

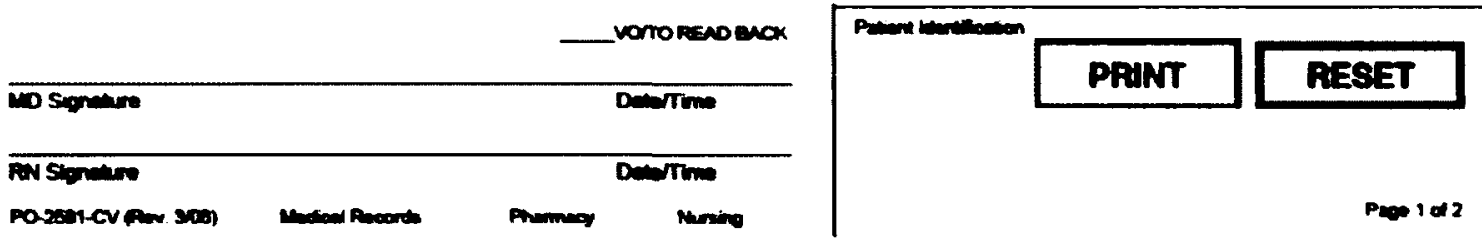


SUBCUTANEOUS INSULN ORDER SET (SHOS) CUIDEUNES

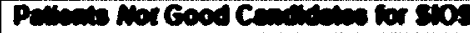

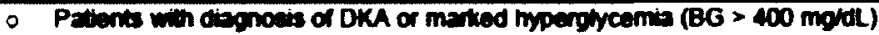

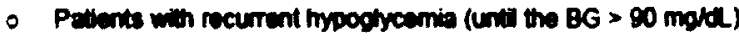

- Patents receiving nutrition excluaively by TPN

- Patients ntro are pregnent

L. Ses merrictions

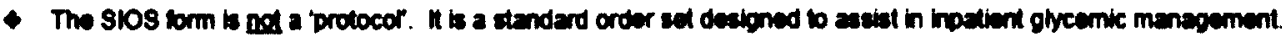

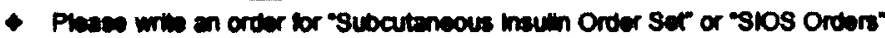

- mitution or Sros Order.

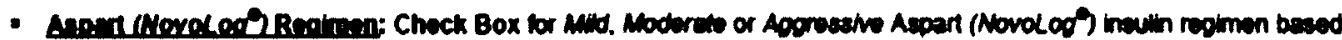
on petient condition and other contributing bectors.

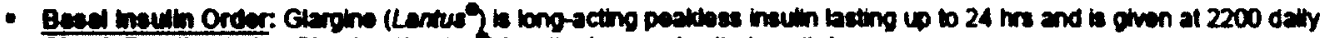
Choct Box I ordering Gergine (Lentus S inauin dose and wite in unit dose.

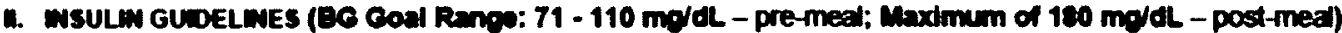

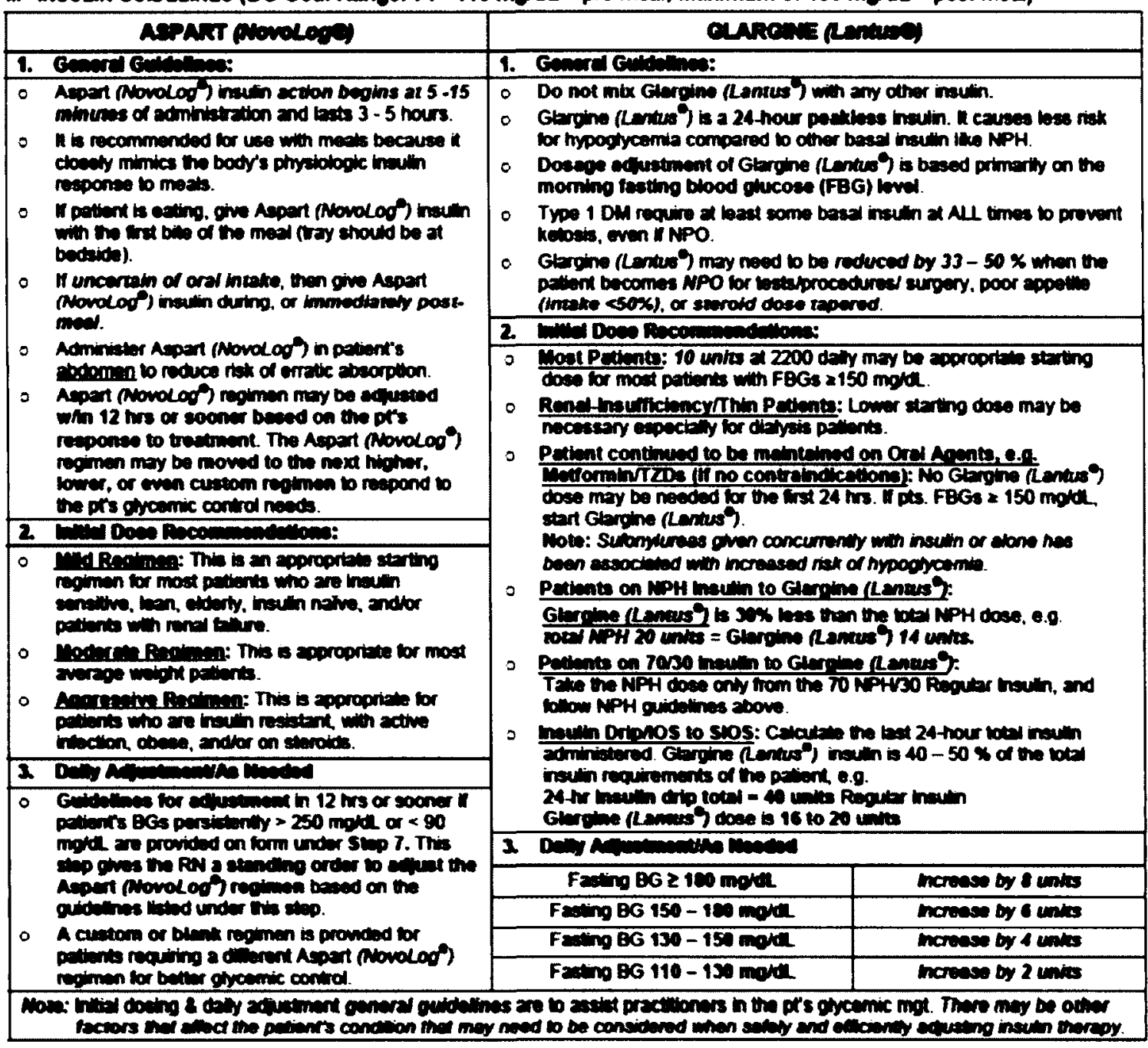

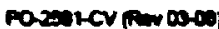




\section{Risks to Patients}

There are no direct patient risks involved. All data are collected retrospectively; hence, there will be no actual patient contact. Precautions to protect patient privacy in accordance to HIPAA regulations will be taken. Access to patient information will be limited to data collectors (i.e., primary investigator, data analysts, accounting department personnel, and research assistants). Data will be de-identified prior to transferring the information to the statistician and the study's funding agency.

\section{Deliverables}

Statistical analysis plan (SAP): Data collected will be entered in an excel spreadsheet to include all variables listed on Table 3. Data will be transferred to SPSS PASW version 17.0 for analysis or other statistical software preferred.

Feasibility of study: The members of this study as listed on Table 5, discussed the feasibility of this study. The principal investigator of this study will be primarily responsible for ensuring the timeliness, integrity, accuracy all data collection, analysis, and final report. Other members will either assist in some capacity with the data collection or as consultants for the study. Table 4 outlines the milestones and timelines for study completion. 
Table 4. Milestones and Timelines

\section{Milestones}

Complete data collection and statistical analysis (EMR and EFR data) for: SSI (March 2003 to February 2005) and BBI = March 2005 to February 2007, and March 2009 to February 2010

Executive Summary

Final Report

*Note: study days begin post contract consummation

\section{Timeline*}

90 days

120 days

150 days

Capability \& Competency Description

Sharp Chula Vista Medical Center (SCVMC) has been collecting and analyzing data on blood glucose measures since 2002 . We have dedicated resources to our Diabetes Program to improve the care of our patients with diabetes. In 2005, SCVMC instituted a glycemic management team exclusively dedicated in managing inpatient hyperglycemia and subsequently setting up patients' discharge plans. Table 5 lists the people involved in various capacities in this research project.

Table 5. Research Study Members

\begin{tabular}{|l|l|l|}
\hline Studly Role & Name \\
\hline Primary Investigator & $\begin{array}{l}\text { Crisamar Anunciado, MSN, RN, FNP- } \\
\text { BC }\end{array}$ & $\begin{array}{l}\text { Inpatient Diabetes Nurse } \\
\text { Practitioner }\end{array}$ \\
\hline $\begin{array}{l}\text { Medical Director, Diabetes } \\
\text { Program }\end{array}$ & Georges M. Argoud, MD, FACE & Adviser/Consultant \\
\hline Chief Executive Office & Pablo Velez, RN, PhD & Adviser/Consultant \\
\hline $\begin{array}{l}\text { Director of Research and } \\
\text { Education }\end{array}$ & Karen Wikoff, RN, PhD & Adviser/Consultant \\
\hline Accountant & Mark Reyes & Finance Consultant \\
\hline Decision Support & Brett MacLaren, MBA & $\begin{array}{l}\text { Manager } \\
\text { Staff }\end{array}$ \\
\hline Statistician & Dash Fluty & Statistician/Consultant \\
\hline $\begin{array}{l}\text { Director, Diabetes Program } \\
\text { for Sharp Healthcare }\end{array}$ & Jacqui Thompson, RN, MS & Adviser/Consultant \\
\hline
\end{tabular}




\section{Proposed Budget}

The proposed budget for this study is $\$ 105,000$. Refer to Table 6 for itemized description of the budget.

Table 6. Financial Proposal

\begin{tabular}{|c|c|c|c|c|}
\hline Harm & Qu:mlity & cost & Sublotal & Total \\
\hline $\begin{array}{l}\text { IRB Fee (expedited } \\
\text { review) }\end{array}$ & Once & $\$ 500$ & $\$ 500$ & $\$ 500$ \\
\hline Research Assistant & 250 hours & $\$ 40.00 /$ hour & $\$ 10,000$ & $\$ 10,000$ \\
\hline $\begin{array}{l}\text { Principal } \\
\text { Investigator }\end{array}$ & 480 hours & $\$ 100.00 /$ hour & $\$ 48,000$ & $\$ 48,000$ \\
\hline Consultants & 35 hours & $\$ 200.00 /$ hour & $\$ 7,000$ & $\$ 7,000$ \\
\hline $\begin{array}{l}\text { Decision } \\
\text { Support/Analyst }\end{array}$ & 160 hours & $\$ 50.00 /$ hour & $\$ 8,000$ & $\$ 8,000$ \\
\hline Finance Consultant & 80 hours & $\$ 100.00 /$ hour & $\$ 8,000$ & $\$ 8,000$ \\
\hline $\begin{array}{l}\text { Finance Assistant } \\
\text { (pulls pharmacy- } \\
\text { related costs) }\end{array}$ & 80 hours & $\$ 50.00 /$ hour & $\$ 4,000$ & $\$ 4,000$ \\
\hline Statistician & 120 hours & $\$ 150.00 /$ hour & $\$ 18,000$ & $\$ 18,000$ \\
\hline $\begin{array}{l}\text { Miscellaneous Office } \\
\text { supplies }\end{array}$ & Paper/ink/poster/other & $\$ 700$ & $\$ 700$ & $\$ 700$ \\
\hline $\begin{array}{l}\text { Conference Costs for } \\
\text { attendance; } \\
\text { presentation of } \\
\text { executive summary }\end{array}$ & $\begin{array}{l}\text { Conference } \\
\text { - Hotel } \\
\text { Meals }\end{array}$ & $\begin{array}{l}\$ 450 \\
\$ 250 \\
\$ 100\end{array}$ & $\begin{array}{l}\$ 450 \\
\$ 250 \\
\$ 100\end{array}$ & $\begin{array}{l}\$ 450 \\
\$ 250 \\
\$ 100\end{array}$ \\
\hline Total & & & & $\$ 105,00$ \\
\hline
\end{tabular}


Payment Schedule

The study will be completed within 150 days from the consummation of the contract with funding agency. Refer to Table 7 for details on proposed payment schedule.

Table 7. Milestones and Payment Schedule

\begin{tabular}{|c|c|c|c|}
\hline Milestones & $\begin{array}{l}\text { Payment } \\
\text { Percent }\end{array}$ & $\begin{array}{l}\text { Payment } \\
\text { Amount }\end{array}$ & Terms of Payment \\
\hline Contract execution & $10 \%$ & $\$ 10,500$ & $\begin{array}{l}\text { Need check cut within net } 5 \\
\text { days from date of invoice }\end{array}$ \\
\hline $\begin{array}{l}\text { Completion of data collection and } \\
\text { statistical analysis (raw data) }\end{array}$ & $40 \%$ & $\$ 42,000$ & Standard Payment Schedule \\
\hline Executive Summary & $40 \%$ & $\$ 42,000$ & Standard Payment Schedule \\
\hline Final Report & $10 \%$ & $\$ 10,500$ & Standard Payment Schedule \\
\hline Totill & $100 \%$ & $\$ 105,000$ & \\
\hline
\end{tabular}




\section{References}

American Diabetes Association (2008). Economic Costs of Diabetes in the U.S. in 2007. Diabetes Care, 311(3), 596-615. doi: DOI: $10.2337 / \mathrm{dc08}-9017$

American Diabetes Association (2010). Position Statement: Standards of Medical Care in Diabetes - 2010. Diabetes Care, 33(Supllement 1), S11-S61. doi: 10.2337/dc10S011

Boord, J. B., Greevey, R.A., Braithwaite, S., Arnold, P.C., Selig, P.M., Brake, H., Cuny, J., \& Baldwin, D. (2009). Evaluation of Hospital Glycemic Control at US Academic Medical Centers. Society of Hospital Medicine, 4(1), 35-44. doi: D0I $10.1002 / \mathrm{jhm} .390$

Krinsley, J. S. (2003). Association between hyperglycemia and Increased hospital mortality in a heterogeneous population of critically ill patients. Mayo Clinic Proceedinngs, 78, 1471-1478.

Krinsley, J. S. (2004). Effect of an intensive glucose management protocol on the mortality of critically ill adult patients. Mayo Clinic Proceedings, 79(8), 992-1000.

Krinsley, J. S. (2008). Glycemic variability: a strong independent predictor of mortality in critically ill patients. Critical Care Medecine, 36(11), 3008-3013. doi: 10.1097/CCM.0b013e31818b38d2

Krinsley, J. S., \& Grissler, B. (2005). Intensive glycemic management in critically ill patients. Joint Commission Journal on Quality and Patient Safety, 31(6), 308-312. 
Krinsley, J. S., \& Grover, A. (2007). Severe hypoglycemia in critically ill patients: risk factors and outcomes. Critical Care Medecine, 35(10), 2262-2267. doi: 10.1097/01.CCM.0000282073.98414.4B

Moghissi, E. S., Korytkoski, M. T., DiNardo, M., et al. (2009). American Association of Clinical Endocrinologists and American Diabetes Association consensus statement on inpatient glycemic control. Endocrine Practice, 15(4), 1-17.

NICE-SUGAR. (2009). Intensive versus conventional glucose control in critically ill patients. The New England Journal of Medicine, 360(13), 1283-1297.

Umpierrez, G. E., Isaacs, S. D, Bazargan, N., You, X., Thaler, L. M., Kitabchi, A. E. (2002). Hyperglycemia: an independent marker of in-hospital mortality in patients with undiagnosed diabetes. The Journal of Clinical Endocrinology \& Metabolism, 87(3), 978-982.

Van den Berghe, G., Wouters, P., Weekers, F., Verweast, C., et al. (2001). Intensive insulin therapy in critically ill patients. New England Journal of Medicine, 345(19), 13591369. 
Figure 2. Email Notification of Award of Mission

- Reply of Reply to All oforward | Close

\section{Award of Mission \\ Maria Kiwalle [maria.kiwalle-mcbride@sanofi-aventis.com] \\ You replied on 10/19/2010 1:47 PM.}

Sent: Tuesday, October 19, 2010 9:22 AM

To: Ciisama: Anunciado

Good day Crisamar

In reference to the below mission, we are pleased to advise you have been selected as our suppler:

Code société / Company code : sharpchula

Code utillsateur / User code :canunciado

Mot de passe / Password : You must use the personal password entered during your last connection

Basal Bolus

We will be contacting you shortly with all of the necessary documentations for proceeding forward.

If you have any questions, please do not hesitate to contact me.

Have a good day.

Regards,

Marla Kwalle, CPSM, C.P.M.

Mission Leader 
Appendices 
October 29, 2010

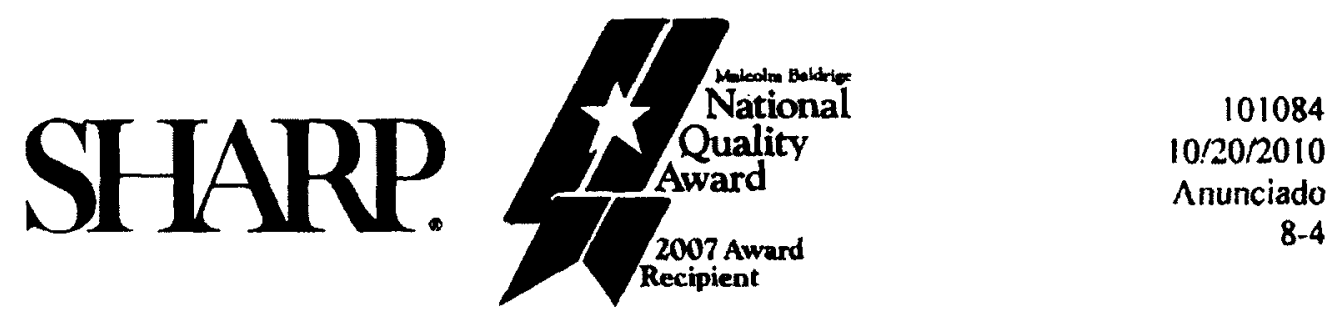

Crisamar Anunciado, RN, MSN, FNP-BC

Sharp Chula Vista Medical Center

751 Medical Center Court

Chula Vista, CA 91950

RE: IRB \#101084 / Sanofi-Aventis

Inpatient Glycemic Management: Clinical and Economic Impact of Changing from Sliding Scale Insulin to Basal-Bolus

Dear Mr. Anunciado:

The Sharp llealthCare Institutional Review Board (IRB00000920; FWA00000084) has reviewed and cxpeditiously approved your application for the above-rcferenced research activity in accordance with $45 \mathrm{CFR} 46.110(\mathrm{~b})(1)$, Calcgory 5. Waiver of authorization is allowed in accordance with 45 CFR $164.512(1)(2)$. Waiver of informed consent is allowed in accordance with 45 CFR 46.116(d)(1-4) and 21 CFR 56.109(c)(1). This approval includes:

- Protocol (15Sep2010)

This action will be repurted to all committee members at the October 20, 2010 mecting.

The following site and investigator(s) are approved:

Site: Chula Vista

Principal Investigator: Crisamar Anunciado, RN, MSN, FNP-BC

Study Coordinator: None

Sub-investigator and Other Study Personnel: Dale Glaser, PhD

The IRB approval reference number is 101084 . Please include this reference number in all future correspondence relative to this rescarch activity.

As a reminder, it is the responsibility of the Principal Investigator to submit periodic stutus reports to the IRB. Periodic review of this research activity may be conducted via an expedited process and is scheduled for inclusion on the September 21, 2011 IRB meeting agenda. Approval for this research activity will expire if periodic review is not conducted on or before October 5, 2011. Please provide a completed research status report to the IRB Omice no later than September 6, 2011 to assure timely review and continuation of this research activity.

Changes or amendments to the reseanch activity protocol, informed consent documents, and to other research activity-related documents, as well as new documents, tools or advertisements to be utilized as part of this rescarch activity, must be reviewed and approved by the IRB before changes are implemented.

It is the policy of Sharp HealthCare IRB that the Principal Investigator(s) submit a copy of their reports, findings, or manuscripts to the IRB prior to publication. Sharp HealthCare would expect that if the results of the research project came to publication, their role would be properly recognized in the research.

\section{SHARP ORGANIZATIONS}

Sharp llealuhCare Sharp Menorial Hospital Grossmnnt Hospital Corporation Sharp Chula Vista Mcdical Center Sharp Corunado Hospilal and Healiheare Center Sharp Mesa Vista Hospital Sharp Mary Birch Hospital For Women Sharp Visıa lacifica llospital Sharp Mission Park Medical Centers Sharp Rees-Stealy Medical Centers Sharp Healuh Han Sharp HcalthCarc Foundation . Grossmont Hospital Foundation 
Thank you and please feel free to contact Caryn Burgess, IRB Administrator, at (858) 499-4836 if you have any questions.

Sincerely,

David Bodkin, M.D.

Chair, Institutional Revicw Board

Sharp HealthCare

$/ \mathrm{clb}$

Enc. 